Florida International University FIU Digital Commons

$11-5-2012$

\title{
Comparison and Validation of Tropical Rainfall Measuring Mission (TRMM) Rainfall Algorithms in Tropical Cyclones
}

Joseph P. Zagrodnik

Florida International University, jzagr001@fiu.edu

DOI: $10.25148 /$ etd.FI13080517

Follow this and additional works at: https:// digitalcommons.fiu.edu/etd

Part of the Atmospheric Sciences Commons, Hydrology Commons, and the Meteorology Commons

\section{Recommended Citation}

Zagrodnik, Joseph P., "Comparison and Validation of Tropical Rainfall Measuring Mission (TRMM) Rainfall Algorithms in Tropical Cyclones" (2012). FIU Electronic Theses and Dissertations. 903.

https://digitalcommons.fiu.edu/etd/903 


\title{
FLORIDA INTERNATIONAL UNIVERSITY
}

Miami, Florida

\section{COMPARISON AND VALIDATION OF TROPICAL RAINFALL MEASURING MISSION (TRMM) RAINFALL ALGORITHMS IN TROPICAL CYCLONES}

\author{
A thesis submitted in partial fulfillment of \\ the requirements for the degree of \\ MASTER OF SCIENCE \\ in \\ GEOSCIENCES \\ by
}

Joseph P. Zagrodnik 
To: Dean Kenneth G. Furton

College of Arts and Sciences

This thesis, written by Joseph P. Zagrodnik, and entitled Comparison and Validation of Tropical Rainfall Measuring Mission (TRMM) Rainfall Algorithms in Tropical Cyclones, having been approved in respect to style and intellectual content, is referred to you for judgment.

We have read this thesis and recommend that it be approved.

Hugh Willoughby

Haiyan Jiang, Major Professor

Date of Defense: November 5, 2012

The thesis of Joseph P. Zagrodnik is approved.

$\begin{array}{r}\begin{array}{r}\text { Dean Kenneth G. Furton } \\ \text { College of Arts and Sciences }\end{array} \\ \hline \begin{array}{c}\text { Dean Lakshmi N. Reddi } \\ \text { University Graduate School }\end{array}\end{array}$

Florida International University, 2013 


\section{ACKNOWLEDGMENTS}

I would like to thank Dr. Haiyan Jiang for her constant support over the past 2+ years, her knowledge and leadership enabled me to succeed at FIU. Most of my accomplishments would not have been possible without her. I also express sincere gratitude to my committee members Dr. Hugh Willoughby and Dr. Ping Zhu for their assistance in completing this manuscript. Many of my fellow graduate students provided various advice on this project, programming, and graduate coursework including Cheng Tao, Margie Kieper, Jonathan Furst, Corey Walton, Amaryllis Cotto, and Cen Gao. My communications with Dr. Chuntao Liu, Dr. Daniel Cecil, and Dr. Christian Kummerow also provided useful feedback. Dr. Elizabeth Ebert and two anonymous reviewers contributed greatly to improving chapter 2. My wife Becca has sacrificed much to support me during my time in grad school and I am deeply thankful for her love and support. My mother and father have encouraged me to become a scientist since I was very young and have been with me every step of the way.

This work is supported financially by the NASA Earth and Space Science Fellowship (NESSF) award (\#NNX11AP84H). Additional support for this study is also provided by the NASA Precipitation Measurement Mission (PMM) grant NNX10AE28G, and NASA Hurricane Science Research Program (HSRP) grant NNX10AG34G. Specifically, I thank Drs. Ramesh Kakar and Ming-Ying Wei (NASA headquarters) for their continued support of TRMM and hurricane sciences. I also would like to acknowledge Sundog Publications for providing copyright permissions for two figures in chapter 1 . 


\begin{abstract}
OF THE THESIS
COMPARISON AND VALIDATION OF TROPICAL RAINFALL MEASURING

MISSION (TRMM) RAINFALL ALGORITHMS IN TROPICAL CYCLONES
\end{abstract}

by

Joseph P. Zagrodnik

Florida International University, 2012

Miami, Florida

Professor Haiyan Jiang, Major Professor

Tropical Rainfall Measuring Mission (TRMM) rainfall retrieval algorithms are evaluated in tropical cyclones (TCs). Differences between the Precipitation Radar (PR) and TRMM Microwave Imager (TMI) retrievals are found to be related to the storm region (inner core vs. rainbands) and the convective nature of the precipitation as measured by radar reflectivity and ice scattering signature. In landfalling TCs, the algorithms perform differently depending on whether the rainfall is located over ocean, land, or coastal surfaces. Various statistical techniques are applied to quantify these differences and identify the discrepancies in rainfall detection and intensity. Ground validation is accomplished by comparing the landfalling storms over the Southeast US to the NEXRAD Multisensor Precipitation Estimates (MPE) Stage-IV product. Numerous recommendations are given to algorithm users and developers for applying and interpreting these algorithms in areas of heavy and widespread tropical rainfall such as tropical cyclones. 


\section{TABLE OF CONTENTS}

CHAPTER $\quad$ PAGE

1. INTRODUCTION AND BACKGROUND ………

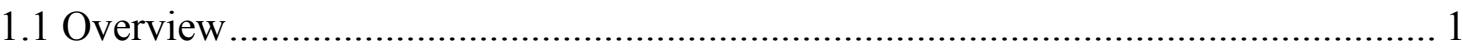

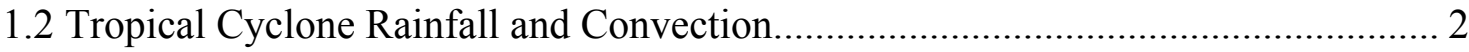

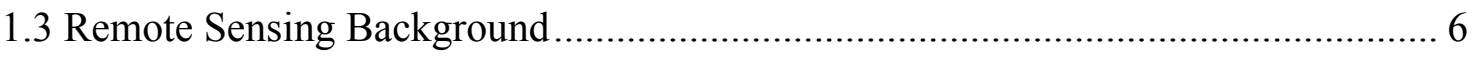

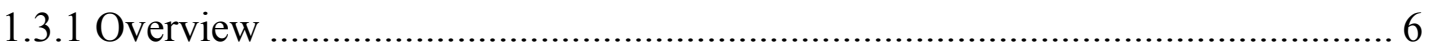

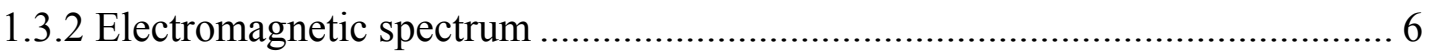

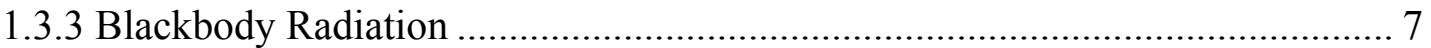

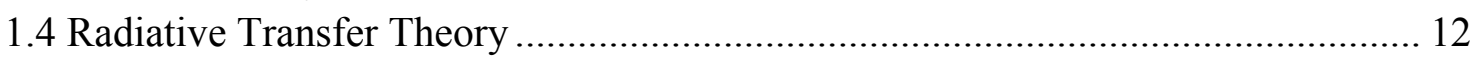

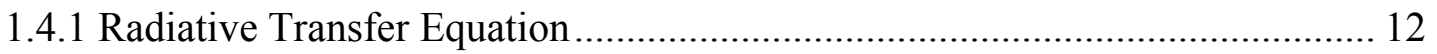

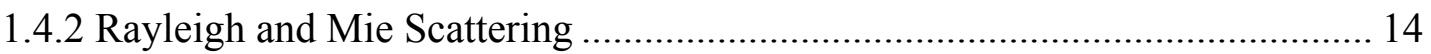

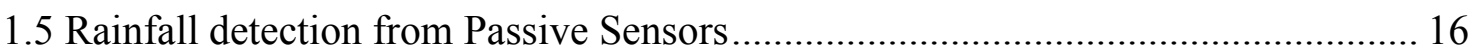

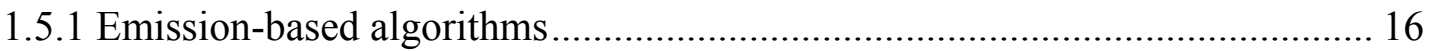

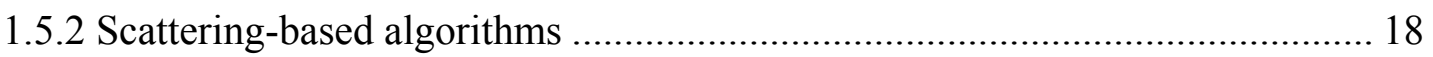

1.5.3 Polarization-Corrected brightness Temperature .............................................. 20

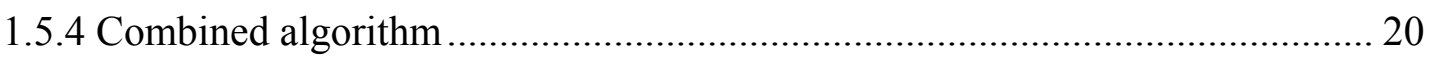

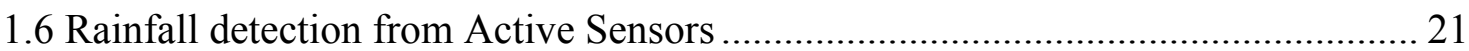

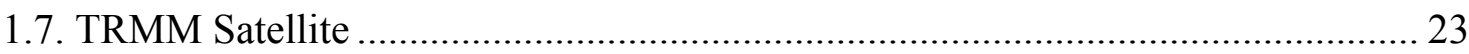

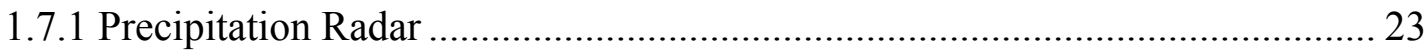

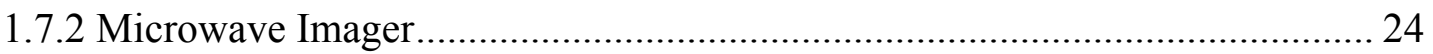

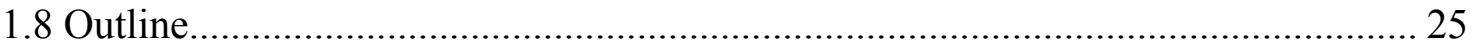

2. COMPARISON OF TRMM PR AND TMI VERSION 6 RAINFALL RETRIEVALS IN TROPICAL CYCLONE INNER CORES AND RAINBANDS .... 26

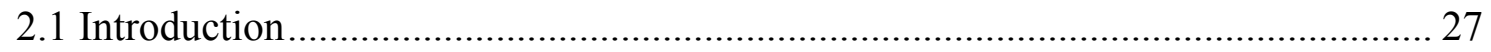

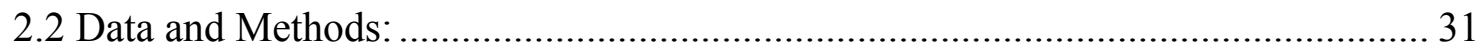

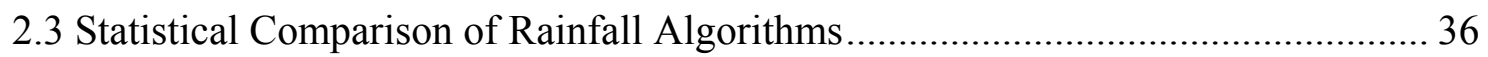

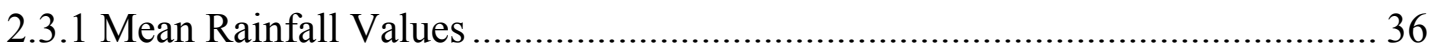

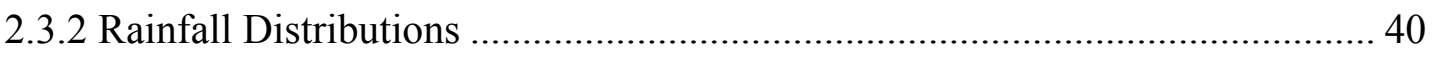

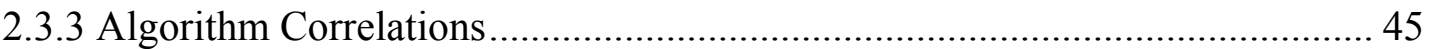

2.4. Rain rate in relation to convective parameters................................................... 48

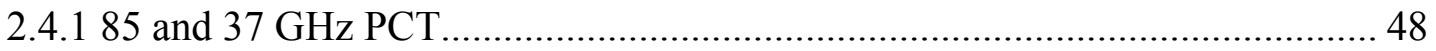

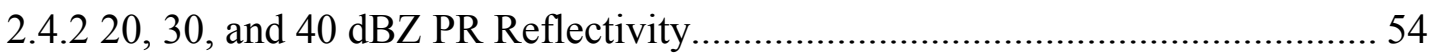

2.4.3. Relating convective parameters to algorithm differences ................................ 55

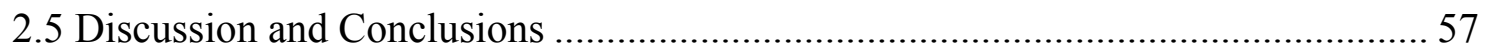


3. INVESTIGATION OF PR AND TMI VERSION 6 AND VERSION 7 RAINFALL ALGORITHMS IN LANDFALLING TROPICAL CYCLONES RELATIVE TO THE NEXRAD STAGE-IV MULTI-SENSOR PRECIPITATION ESTIMATE DATASET

61

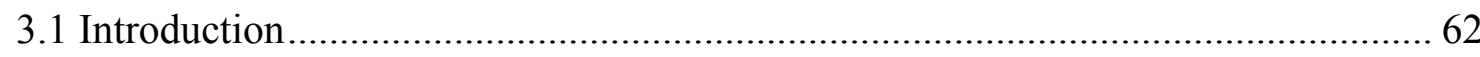

3.2 Data

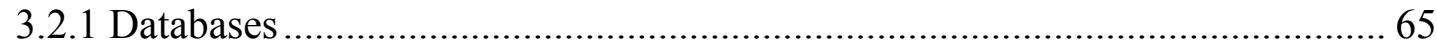

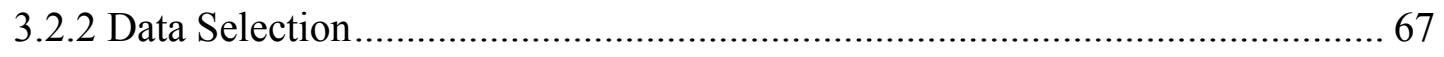

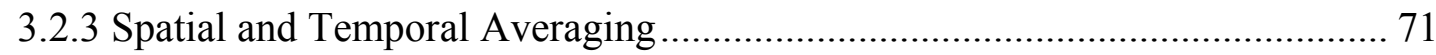

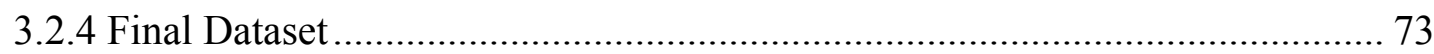

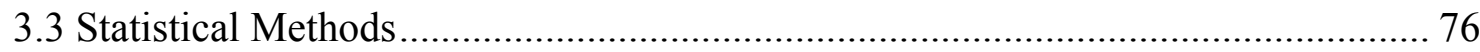

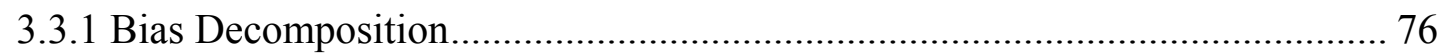

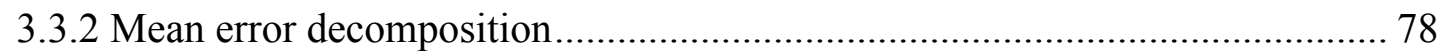

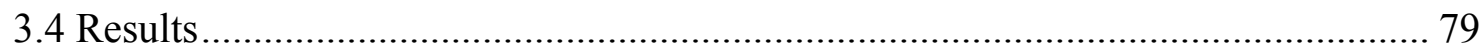

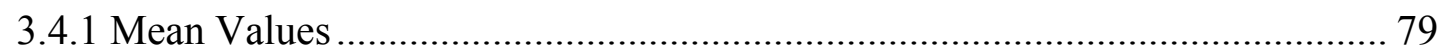

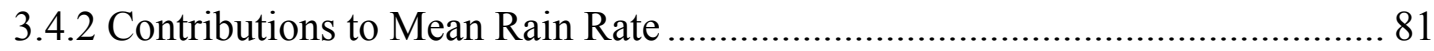

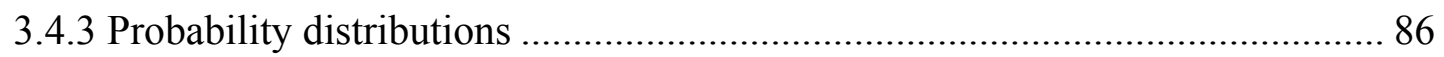

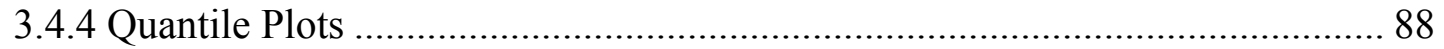

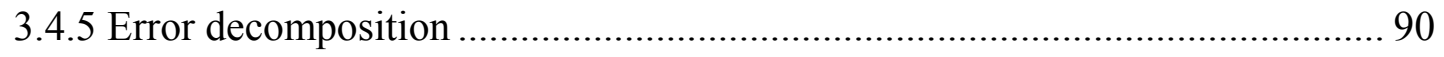

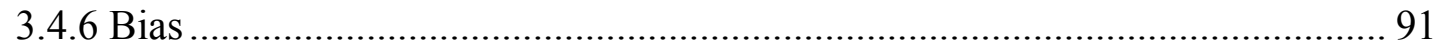

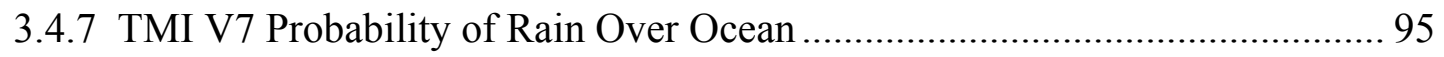

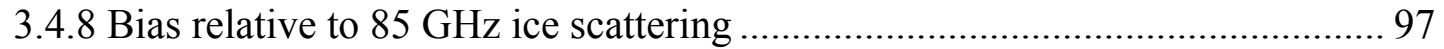

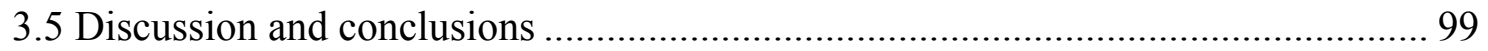




\section{LIST OF TABLES}

TABLE

PAGE

Table 2.1: Mean, minimum, maximum, and standard deviation of the outer edge of

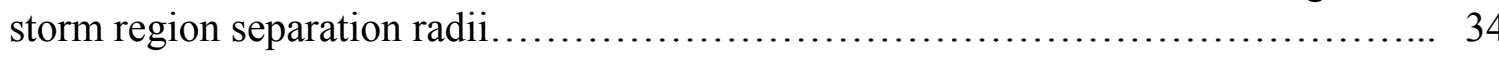

Table 2.2: Percentage of raining pixels meeting various convective thresholds. For 85 and $37 \mathrm{GHz}$ PCT criteria, the percent is calculated relative to TPF raining pixels. For PR reflectivity criteria, the percent is calculated relative to RPF raining pixels. All values are sorted by storm region and intensity.................................

Table 3.1: Sample size of all grid boxes including zero rain rates, unconditional mean rain rate (including all grid boxes) and conditional mean rain rate (including only grid boxes with nonzero rain rates)

Table 3.2: Percentage of all grid boxes with rain rates greater than $0,1,5$, and 10 , divided by algorithm and surface flag.

Table 3.3: Mean square error (MSE) and the percent of the MSE that can be attributed to systematic biases

Table 3.4: Sample size of grid boxes where each individual TRMM algorithm or the MPE-IV reference is nonzero and the percentage of those grid boxes that are designated as hits, misses, or false rain. 


\section{LIST OF FIGURES}

FIGURE

PAGE

Figure 1.1: Overview of the relationship between solar and terrestrial emission spectrums. Panel (a) represents the normalized blackbody curves corresponding to the approximate blackbody temperature of the sun and earth. Panel (b) depicts the absorption spectrum of the cloud-free atmosphere. Modified and awaiting permissions from A First Course in Atmospheric Radiation, Second Edition, G. W. Petty, p. 65

Figure 1.2: Relationship between particle size, radiation wavelength, and the size parameter for atmospheric constituents. Awaiting permissions from A First Course in

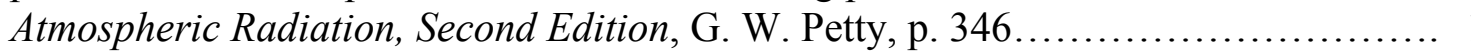

Figure 1.3: A schematic view of the scan geometries of the three TRMM primary rainfall sensors: TMI, PR, and VIRS (Kummerow et al. 1998).

Figure 2.1: TC Center locations of storms with accepted (a) IC, (b) IB, and (c) OB features with a PR 2A25 raining area $>5,000 \mathrm{~km}^{2}$. Parentheses indicate the total sample size.

Figure 2.2: Bar plots comparing PR 2A25 and TMI 2A12 mean raining area (a-b), mean rain rate (c-d), and mean volumetric rain (e-f) for inner cores (dark shade), inner bands (medium shade), and outer bands (light shade), divided by storm intensity. 38

Figure 2.3: PDF of raining area distributions for (a) IC, (b) IB, and (c) OB regions, divided by algorithm and intensity....

Figure 2.4: PDF of rain rate distributions for (a) IC, (b) IB, and (c) OB regions, divided by algorithm and intensity.

Figure 2.5: PDF of volumetric rain distributions for (a) IC, (b) IB, and (c) OB regions, divided by algorithm and intensity

Figure 2.6: Scatterplots of PR 2A25 vs. TMI 2A12 raining area, rain rate, and volumetric rain, divided by IC, IB, and OB. Correlation coefficients are in parentheses for each intensity category.

Figure 2.7: Scatterplots of TMI 2A12 rain rate vs. percent coverage of $85 \mathrm{GHz}$ PCT $<$ 250 and $225 \mathrm{~K}$. Plots are divided by IC, IB, and OB storm regions 
Figure 2.8: Scatterplots of PR 2A25 rain rate vs. percent coverage of PR reflectivity > 20,30 , and $40 \mathrm{dBZ}$. Plots are divided by IC, IB, and OB storm regions.

Figure 2.9: Scatterplots of the difference in PR and TMI rain rate (2A25 minus 2A12) vs. percent coverage of PR reflectivity greater than $40 \mathrm{dBZ}$ for(a) IC, (b) IB, and (c) OB regions.

Figure 3.1: Example plot of a TRMM overpass from 2004 Hurricane Jeanne compared with the MPE-IV 1-hour rainfall. The TRMM overpass occurred at 4:47 UTC and the MPE-IV rainfall is a total accumulation from 04-05 UTC. All data are averaged to a matching 1/7 degree grid. The algorithms are (a) PR 2A25 V6, (b) PR 2A25 V7, (c) MPE-IV, (d) TMI 2A12 V6, (e) TMI 2A12 V7, and (f) TMI Minimum $85 \mathrm{GHz}$ PCT.

Figure 3.2: Cumulative data functions (CDF) of the pixel level rain rates (black lines) and the grid averaged rain rages (grey lines) for the MPE-IV, PR V6, and TMI V6 rain rates. (b) CDF of the absolute difference between the grid averaged PR V6 rain rates compared with the one hour averaged PR V6 rain rates after being advected zonally at 5,10 , and $15 \mathrm{~ms}^{-1}$. Both panels exclusively use data from the TRMM orbit

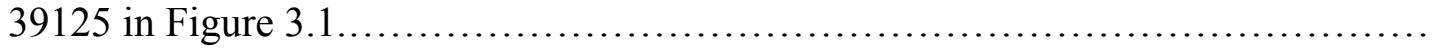

Figure 3.3: Geographical distribution of 1/7 degree grid boxes, color coded by TMI surface flag. Darker shades indicated higher data coverage. Grid boxes where the PR, TMI, and MPE-IV all estimate zero rain are not included in this figure.

Figure 3.4: Cumulative contribution (\%) to mean rain rate for TRMM algorithms compared with the MPE-IV reference dataset, divided by (a) ocean, (b) land, and (c)

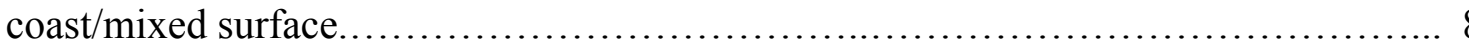

Figure 3.5: Contribution to mean rain rate for TRMM algorithms compared with the MPE-IV reference, divided by (a) ocean, (b) land, and (c) coast/mixed surface. Data

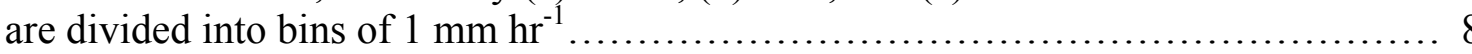

Fig 3.6: Probability of exceedance plots for TRMM algorithms compared with the MPE-IV reference dataset, divided by (a) ocean, (b) land, and (c) coast/mixed surface.

Figure 3.7: Probability density function (PDF) plots for TRMM algorithms compared with the MPE-IV reference dataset, divided by (a) ocean, (b) land, and (c) coast/mixed surface.

Figure 3.8: Quantile-Quantile plots of MPE-IV 1-hour rainfall vs. TRMM rain rate, divided by TRMM algorithm. The plots are arranged by TRMM algorithm (columns) and land, ocean, and coast/mixed (rows). 
Figure 3.9: Bar plots of mean bias, hit bias, miss bias, and false bias, divided by (a) ocean, (b) land, and (c) coast/mixed surface.

Figure 3.10: Geographic distribution of the percent of grid boxes by location with false positives (TRMM > 0, MPE-IV = 0), divided by (a) PR V6, (b) PR V7, (c) TMI V6, and (d) TMI V7

Figure 3.11: (a) Cumulative data functions (CDF) of pixel-level TMI V7 ocean rain rates from grid boxes defined as hits (black) and false positives (grey). (b) CDF of pixel-level TMI V7 ocean probabilities of rain from grid boxes defined as hits, misses, false rain, and all algorithms equal to zero

Figure 3.12: Distribution of mean rain rates as a function of the minimum $85 \mathrm{GHz}$ PCT $(\mathrm{K})$ in each grid box

Figure 3.13: Distribution of mean bias relative to MPE-IV as a function of the minimum $85 \mathrm{GHz} \mathrm{PCT}(\mathrm{K})$ in each grid box

Figure 3.14: Cumulative contribution (\%) to mean rain rate for TRMM algorithms compared with the minimum $85 \mathrm{GHz}$ PCT. 


\section{LIST OF ACRONYMS AND ABBREVIATIONS}

Bias

Category 1-2 Hurricane

Cat $1-2$

Category 3-5 Hurricane

Cat 3-5

Convective Available Potential Energy

CAPE

Cumulative Density Function

CDF

El Niño Southern Oscillation

ENSO

Electromagnetic Waves

EM-Waves

False rain Bias

FB

Field of View

FOV

Flux Density

Goddard Profiling Algorithm

GPROF

Ground Validation

GV

Inner Band

IB

Inner Core

IC

Joint Typhoon Warning Center

JTWC

Mean Square Error

MSE

Missed rain Bias

MB

Multisensor Precipitation Estimate

MPE

National Center for Environmental Prediction

NCEP

National Hurricane Center

$\mathrm{NHC}$

Next-Generation Radar

NEXRAD 
Numerical Weather Prediction $\quad$ NWP

$\begin{array}{ll}\text { Outer Rainband } & \text { OB }\end{array}$

$\begin{array}{ll}\text { Polarization Corrected brightness Temperature } & \text { PCT }\end{array}$

$\begin{array}{ll}\text { Precipitation Feature } & \text { PF }\end{array}$

Precipitation Radar $\quad$ PR

Probability Density Function $\quad$ PDF

Regional Forecast Center $\quad$ RFC

$\begin{array}{ll}\text { Sea Surface Temperature } & \text { SST }\end{array}$

$\begin{array}{ll}\text { Stage-IV S-IV } & \text { S }\end{array}$

Stationary Band Complex $\quad$ SBC

$\begin{array}{ll}\text { Tropical Cyclone } & \text { TC }\end{array}$

Tropical Cyclone Precipitation Feature $\quad$ TCPF

$\begin{array}{ll}\text { Tropical Depression } & \text { TD }\end{array}$

$\begin{array}{ll}\text { TRMM Microwave Imager } & \text { TMI }\end{array}$

TRMM Multi-satellite Precipitation Analysis $\quad$ TMPA

$\begin{array}{ll}\text { Tropical Rainfall Measuring Mission } & \text { TRMM }\end{array}$

$\begin{array}{ll}\text { Version } 6 & \text { V6 }\end{array}$

$\begin{array}{ll}\text { Version } 7 & \text { V7 }\end{array}$

Visible and Infrared Radiometer System VIRS

Weather Surveillance Radar 88 Doppler WSR-88D 


\section{INTRODUCTION AND BACKGROUND}

\subsection{Overview}

Quantifying precipitation of any kind is a difficult endeavor, as rainfall follows a spatially and temporally non-uniform distribution, evolves rapidly with time, and varies greatly over small distances. Obtaining observations of precipitating systems on a regional or global scale is an even greater challenge. Rain gauge and ground-based radar networks are sparsely distributed and often have questionable accuracy. Almost no ground data is available over oceans, which cover the majority of the globe. Meteorologists and climate researchers are particularly interested in the distribution of rainfall over the tropics and sub-tropics (within $35^{\circ}$ of the equator), which together account for more than two-thirds of global rainfall and the accompanying latent and sensible heat transfers between the surface, atmosphere, and outer space. For these reasons, the Tropical Rainfall Measuring Mission satellite (TRMM, Simpson et al. 1988, 1996; Kummerow et al. 1998, 2000) was conceived to provide precipitation measurements across the global tropics. From its launch in December 1997 to the present date, TRMM has contributed to improved understanding of a wide variety of tropical applications.

The original TRMM documentation emphasizes the importance of understanding large scale precipitation processes relating to the global climate and energy budget. Additionally, TRMM has also proven to be extremely useful for measuring smaller scale systems including Tropical Cyclones (TCs), which are the focus of this study. Since TRMM follows a polar orbit only about $400 \mathrm{~km}$ above the earth's surface, it views any given location in the tropics only once or twice per day. The orbital path is optimized to 
quantify the rainfall distribution of large scale, seasonal or annual climate events such as monsoons and the El Niño Southern Oscillation (ENSO). Observing TCs is much more random and an individual TC may only be viewed by TRMM a few times during its lifecycle. Still, the longevity of TRMM has resulted in over 10,000 instantaneous overpasses of TCs since 1998. Because TCs spend most of their life in data sparse areas over open ocean, the TRMM TC database is unique and is the largest of its kind.

\subsection{Tropical Cyclone Rainfall and Convection}

Similar to other intense weather systems, tropical cyclones derive their energy from inherent temperature instabilities in the earth's climate system. During the late summer and early autumn months, the instability between the warm tropical ocean waters $\left(26{ }^{\circ} \mathrm{C}\right.$ or higher) and the relatively cooler and drier tropical atmosphere reaches its maximum. A tropical cyclone is especially effective at exploiting this instability, as it gathers latent heat energy by evaporating tremendous amounts of ocean water and releasing the stored energy through condensation in vertical convection (Emanuel 1991). A tropical cyclone can be distinguished from ambient tropical convection by its characteristic closed low pressure center, warm inner core, spiral rainbands, and an eyewall and eye in more intense cyclones. Tropical cyclones are classified by their maximum sustained winds at ten meters above the surface. The formation stage is known as a tropical disturbance, which is defined as a cluster of thunderstorms of tropical or subtropical origin persisting near a trough of low pressure for at least 24 hours (Emanuel 2005). If the disturbance develops a closed surface cyclonic circulation, it becomes a tropical cyclone and is classified as a tropical depression (TD). If the sustained surface 
winds reach gale force on the Beaufort scale, or 34 knots $(39 \mathrm{mph})$, the storm is classified as a tropical storm (TS). The storm is upgraded to a hurricane when the sustained winds reach 64 knots. Hurricane intensity is commonly rated by the Saffir-Simpson scale, with category 3 or higher hurricanes (>96 knots) defined as major hurricanes. The above classifications are generally consistent with most countries around the globe, although some countries give hurricanes a different name such as "typhoon" and the United States uses a one minute average when calculating the ten meter sustained wind, compared with the World Meteorological Organization standard of ten minutes. Since exact in situ measurements are rarely available, the TC intensity is usually inferred using satellite observations.

Most pertinent to the present study is the organization of the rainfall within tropical cyclones. The evolution of the hurricane inner vortex is an intricate and constantly changing process, so an individual "snapshot" of a storm captured from a polar-orbiting satellite like TRMM will observe a wide range of rainfall and convective distributions. In hurricanes, the eyewall usually contains the strongest tangential (rotating) winds and updraft velocities, along with the heaviest rain rates. An eyewall is defined as "closed" when it completely surrounds the rain-free eye, but in many cases hurricanes have partial (open) eyewalls and/or concentric eyewalls. Airborne radar has estimated mean eyewall rain rates ranging from $11 \mathrm{~mm} \mathrm{hr}^{-1}$ in Hurricane Allen (Marks 1985) down to around 5-6 mm hr${ }^{-1}$ in Hurricanes Alicia and Elena (Burpee and Black 1989). Using 19.35 GHz passive microwave observations of 21 Pacific TCs, Rodgers and Adler (1981) found that rainfall concentrates toward the center during intensification and the relative contribution of the heavier rainfall rates increases with intensity. The spatial 
rainfall distribution also varies, as frictional convergence causes the inner core rain rate to be highest ahead of storm motion and vertical wind shear creates a rainfall asymmetry that favors the area downshear and to the left of the shear vector (e.g., Shapiro 1983; Marks 1985; Rodgers et al. 1994, 2003; Chen et al. 2006; Cecil 2007). Dynamical factors that are related to the evolution of the vortex and wind field such as eyewall replacement cycles can influence the convective and rainfall distributions as well.

The banded rainfall structure outside of the eyewall is often described by the Stationary Band Complex (SBC), which is defined using the precipitation returns on airborne radar (Willoughby et al. 1984). The most prominent banding feature is labeled the principal band, which spirals outward from either the eyewall or the region of stratiform precipitation in the inner rainband region surrounding the eyewall. New convection forms upwind of the principal band and spirals inward, becoming more stratiform in nature as the decaying convective cells approach the eyewall in a cyclonic, tangential motion (Houze 2010). Secondary band (or inner rainband) features are located inside of the principal band and immediately outside of the eyewall. These smaller, transient bands have fewer intense convective cells and a higher proportion of stratiform precipitation than the eyewall, as evidenced by the presence of a radar brightband (Cecil et al. 2002) and lower lightning frequencies (Molinari 1999). Convection in the inner bands is likely suppressed at upper levels by outflow from the primary eyewall (Houze 2010).

The outermost bands are located 150-200 km and beyond from the TC center and are mostly unconstrained by the vertical circulation associated with the inner vortex. The convective available potential energy (CAPE) is higher in the outer bands and most 
similar to the ambient tropical environment (Bogner et al. 2000). The greater vertical instability allows for deep and intense convective cells form along confluence lines spiraling into the inner vortex (Houze 2010). Inner and outer rainbands are influenced by vertical wind shear, as convection tends to form on the upshear side of the storm and organize into linear bands on the upshear-right and downshear-right side (Hence and Houze 2012). When there is at least moderate vertical shear $\left(>7.5 \mathrm{~ms}^{-1}\right)$, the rainfall asymmetry maximum is located downshear-left (Chen et al. 2006). Hence and Houze (2012) also noted that the vertical structure of the outer bands is relatively unaffected by changes in storm intensity, although cooler sea surface temperatures (SST) have been linked to a decrease in outer rainband convection.

Several implications for TC satellite rainfall detection are apparent from the above description of TC structure and convective features. First, a large number of interconnected dynamical and environmental factors contribute to TC rainfall distributions, which may increase the likelihood of biases in the rainfall estimates or accentuate biases that may be present on larger scales. All rainfall algorithms are dependent upon some assumed parameters that are not directly measured by the satellite. Variations in these parameters in a specific regime, such as TCs, will bias the rainfall estimates (Berg et al. 2006). The second issue is that satellite-based instruments are prone to saturation or attenuation in heavy rain rates, which are more common in TCs than other tropical regions. The following sections give an overview of the remote sensing theory most relevant to rainfall measurements. 


\subsection{Remote Sensing Background}

\subsubsection{Overview}

Rainfall cannot be directly measured from satellites. Instead, it must be inferred using satellite observations combined with other known or assumed parameters about clouds and precipitation processes. The TRMM satellite is unique in that is has the first spaceborne precipitation radar (an active sensor) and a microwave radiometer (a passive sensor). Each sensor is individually capable of generating a swath of rainfall estimates along the path of the satellite. It is possible to measure rainfall from space through the principles of remote sensing, defined as the measurement of the physical properties of the atmosphere from a distance. In order to interpret the information received by the satellite sensor, one must first understand how the earth's surface, atmospheric gases, and atmospheric hydrometers (cloud and rain droplets, ice, hail, or snow) interact with electromagnetic radiation.

\subsubsection{Electromagnetic spectrum}

Fundamentally, electromagnetic radiation is a combined electric field and magnetic field, which oscillate through space perpendicular to each other and perpendicular to the direction of propagation. Both fields are connected to each other: a changing electric field induces a magnetic field and vice-versa. In a vacuum, electromagnetic waves (EM-waves) propagate in three-dimensional space at the speed of light, $c$, which is approximately $3 \times 10^{8} \mathrm{~m} \mathrm{~s}^{-1}$. Electromagnetic waves are often described by their frequency $(v)$ or wavelength $(\lambda)$. Both quantities are related to the speed of light by the equation $\lambda=c / v$. Wavelength is defined as the distance between two 
adjacent wave crests and frequency is the number of crests that pass a point in a given time period. In the microwave spectrum, EM waves are most commonly referred to by their frequency, in Gigahertz ( $10^{9}$ Hertz, or $10^{9}$ cycles per second). All objects with a temperature above absolute zero emit electromagnetic radiation, meaning the objects convert some of their internal energy into radiant energy. In the atmosphere, the primary sources of EM waves are thermal emission from the sun, earth, and atmosphere itself.

\subsubsection{Blackbody Radiation}

In a vacuum, EM waves propagate indefinitely in a straight line. In a material medium such as the atmosphere, EM waves can be absorbed,
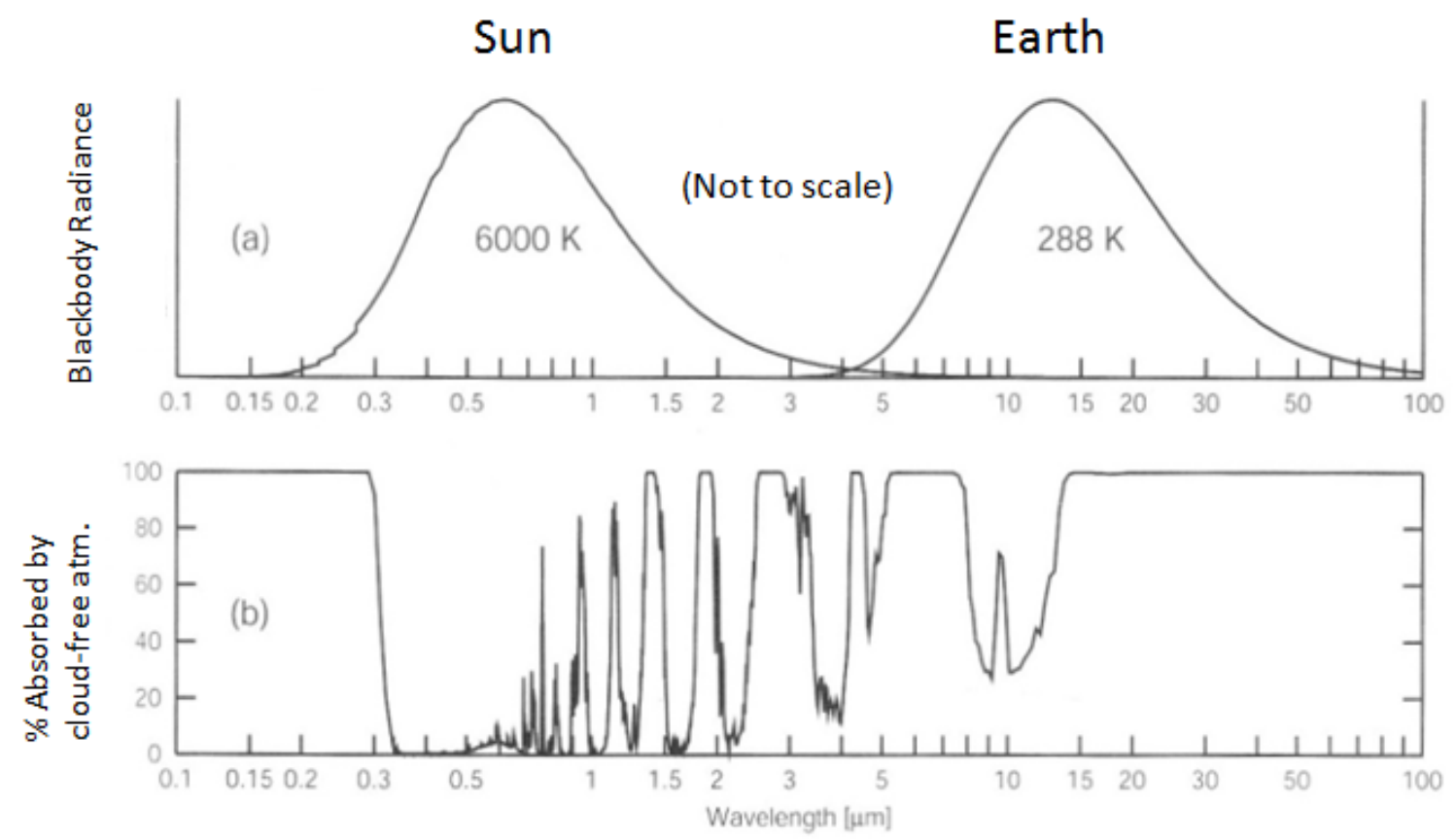

Figure 1.1: Overview of the relationship between solar and terrestrial emission spectrums. Panel (a) represents the normalized blackbody curves corresponding to the approximate blackbody temperature of the sun and earth. Panel (b) depicts the absorption spectrum of the cloud-free atmosphere. Modified with permission from $A$ First Course in Atmospheric Radiation, Second Edition, G. W. Petty, p. 65. 
scattered, and emitted. The "blackbody" approximation is often utilized to better understand these interactions. A blackbody is an object that absorbs all incident radiation perfectly, regardless of frequency or incident angle. A blackbody is also an ideal emitter, meaning it emits the theoretical maximum about of radiation for any given temperature and it emits the radiation isotropically in all directions. In 1900, Max Planck empirically derived an equation that determines the radiative intensity $\left(B_{\lambda}\right)$ of a blackbody for any given wavelength:

$$
B_{\lambda}(T)=\frac{2 h c^{2}}{\lambda^{5}\left(e^{h c / k_{B} \lambda T}-1\right)}
$$

where $c$ is the speed of light, $h=6.626 \times 10^{-34} \mathrm{~J} / \mathrm{s}$ is Planck's constant, and $k_{B}=1.381 \mathrm{x}$ $10^{-23} \mathrm{~J} / \mathrm{K}$ is Boltzmann's constant. Physically, $B_{\lambda}$ has units of intensity per unit wavelength, or $\mathrm{W} \mathrm{m}^{-2} \mu \mathrm{m}^{-1} \mathrm{sr}^{-1}$. Planck's function is strictly a function of the blackbody temperature for a given wavelength. Figure 1.1 (a) displays the blackbody radiance plotted as a function of temperature for the sun $(6000 \mathrm{~K})$ and the earth $(288 \mathrm{~K})$. The peak wavelength of these Planck functions is inversely proportional to temperature.

The wavelength where the emission is a maximum, or the peak of the Planck curve, can be found by differentiating Planck's law and setting the derivative equal to zero yielding:

$$
\lambda_{\max }=\frac{2897}{T}
$$

for a given temperature $\mathrm{T}$ in degrees Kelvin. This relationship, known as Wien's displacement law, shows why the sun's emission spectrum peaks at shorter wavelengths (visible) and the earth's emission spectrum peaks at longer wavelengths (infrared). The 
microwave spectrum, or where the wavelength is greater than $1 \mathrm{~mm}$, is of utmost importance to this study. In the limiting case of the microwave spectrum, the exponential in the denominator of Planck's law can be approximated by its first order Taylor expansion. The resulting expression is known as the Rayleigh-Jeans approximation and can be applied to simplify radiative transfer calculation in the microwave spectrum:

$$
B_{\lambda}(T) \approx \frac{2 c k_{B}}{\lambda^{4}} T
$$

Planck's function can also be integrated to yield the flux density (F) emitted by a blackbody over all wavelengths. The resulting expression is called the Stefan-Boltzmann law:

$$
F(T)=\sigma T^{4}
$$

where the Stefan-Boltzmann constant, $\sigma=5.67 \times 10^{-8} \mathrm{~W} \mathrm{~m}^{-2} \mathrm{~K}^{-4}$. The flux density is also known as irradiance and is graphically represented as the area under the Planck curve. Irradiance has SI units of watts per square meter, $\mathrm{W} \mathrm{m}{ }^{-2}$. In most cases, the StefanBoltzmann law does not directly apply because the emitting object is not a blackbody. These objects are known as graybodies and are characterized by their emissivity, $\varepsilon$, which is simply the ratio of what the object actually emits relative to the theoretical maximum emission if the object was a blackbody. The monochromatic emissivity, or the emissivity at a particular wavelength, is of most interest for remote sensing applications. If $I_{\lambda}$ is the monochromatic radiative intensity of an object, then the emissivity is:

$$
\varepsilon_{\lambda}=\frac{I_{\lambda}}{B_{\lambda}(T)}
$$


The same reasoning can be applied to a range of wavelengths using the StephenBoltzmann law, leading to a broadband or graybody emissivity:

$$
\varepsilon=\frac{F}{\sigma T^{4}}
$$

Emissivity is closely related to absorptivity, $a$, which is the ratio of what an object absorbs to what it would be absorbed as a blackbody. Kirchhoff's law states that emissivity and absorptivity are equal to each other for monochromatic radiation at a given wavelength:

$$
\varepsilon_{\lambda}=a_{\lambda}
$$

Kirchhoff's law holds for all practical remote sensing purposes, although it does break down when local thermodynamic equilibrium is violated. In most cases, objects are in radiative equilibrium, meaning that for each wavelength and along each ray path, an equal proportion of monochromatic intensity $\left(I_{\lambda}\right)$ is absorbed and re-emitted. Practically, Kirchhoff's law implies that good emitter is a good absorber and a poor emitter is a poor absorber.

The microwave emissivity of the earth's surface varies considerably in the microwave spectrum. Land surfaces have a high emissivity, often 0.80 or higher. Water has a much lower microwave emissivity, as low as 0.25 . The emissivity over land surfaces is neither uniform nor constant. Swamps, lakes, and vegetation have lower emissivities than drier surfaces. The land surface emissivity will decrease after a period of heavy precipitation. Changes in land emissivity are useful for estimating soil moisture, but they interfere with precipitation estimation because rain can be difficult or impossible to distinguish from wet land at frequencies less than $10 \mathrm{GHz}$. Over ocean, surface winds 
and the sea surface temperature are the two main factors affecting emissivity. Precipitation is the dominant microwave signal over ocean and is easily distinguishable from the background surface.

How is the theoretical concept of a blackbody related to the measurements from a microwave radiometer? As shown in Planck's function (equation 1.1), there is a direct relationship between the intensity of radiation emitted by a blackbody at a given wavelength and the blackbody's temperature. In other words, the monochromatic intensity measured by a satellite sensor can be converted to an equivalent blackbody temperature, more commonly known as brightness temperature $\left(T_{b}\right)$. The equation for $T_{b}$ is obtained from the inverse of Planck's function:

$$
T_{b}=B_{\lambda}^{-1}\left(I_{\lambda}\right)
$$

where the constants have the same values as equation 1.1. In the IR spectrum, the earth's surface and cloud layers both have an emissivity close to one, so the brightness temperature is a good approximation for the actual physical temperature. At microwave wavelengths, Rayleigh-Jeans approximation (1.3) implies a direct proportionality between intensity and brightness temperature. Equations 1.5 and 1.8 can then be combined to yield a simple relationship between temperature and emissivity:

$$
T_{B}=\varepsilon T
$$

The ability to remotely estimate the physical temperature of atmospheric constituents is an extremely valuable tool. However, using this relationship to estimate precipitation amounts requires additional understanding of how radiative transfer theory applies to particles of difference sizes. 


\subsection{Radiative Transfer Theory}

\subsubsection{Radiative Transfer Equation}

The previous discussion about blackbody theory (section 1.3) only considers the interaction between electromagnetic radiation and a fixed "body" or surface located some distance away from the sensor. The blackbody concept is appropriate for the earth's surface, but the atmosphere must be considered differently, as it is not a surface but rather a medium that can transmit radiation. To conceptualize this interaction, a beam of EM radiation is considered as it propagates through the atmosphere. The interactions between the beam and atmospheric constituents are referred to as attenuation, which reduces the strength of the transmitted beam. Attenuation can occur either by absorption or by scattering. Scattering refers to the redirection of radiation out of the original direction of propagation. Radiation can also be added to the beam from emission by the medium (atmospheric constituents in this case) or scattering into the beam from outside sources.

The amount of attenuation that occurs is linearly proportional to the intensity of the beam of radiation, the concentration of gases and particles that are responsible for the attenuation, and how effective the gases and particles are at attenuating the beam. Considering an infinitesimally thin layer of atmosphere along the path of a beam of radiation, the change in radiant intensity $d I$ along the path $d s$ can be written as:

$$
d I=d I_{e x t}+d I_{e m i t}+d I_{s c a t}
$$

The first term represents the depletion from extinction, including both absorption and scattering:

$$
d I_{e x t}=-\beta_{e} I d s
$$


where $\beta_{e}$ is an extinction coefficient that depends on the physical medium and on the wavelength of the radiation. The extinction coefficient can also be represented as $\beta_{e}=\beta_{s}+\beta_{a}$ where $\beta_{s}$ and $\beta_{a}$ are the scattering and absorption cross sections. The source term caused by emission can be as:

$$
d I_{\text {emis }}=\beta_{a} B(T) d s
$$

where $B(T)$ is Planck's function (equation 1.1). The most complicated term is the

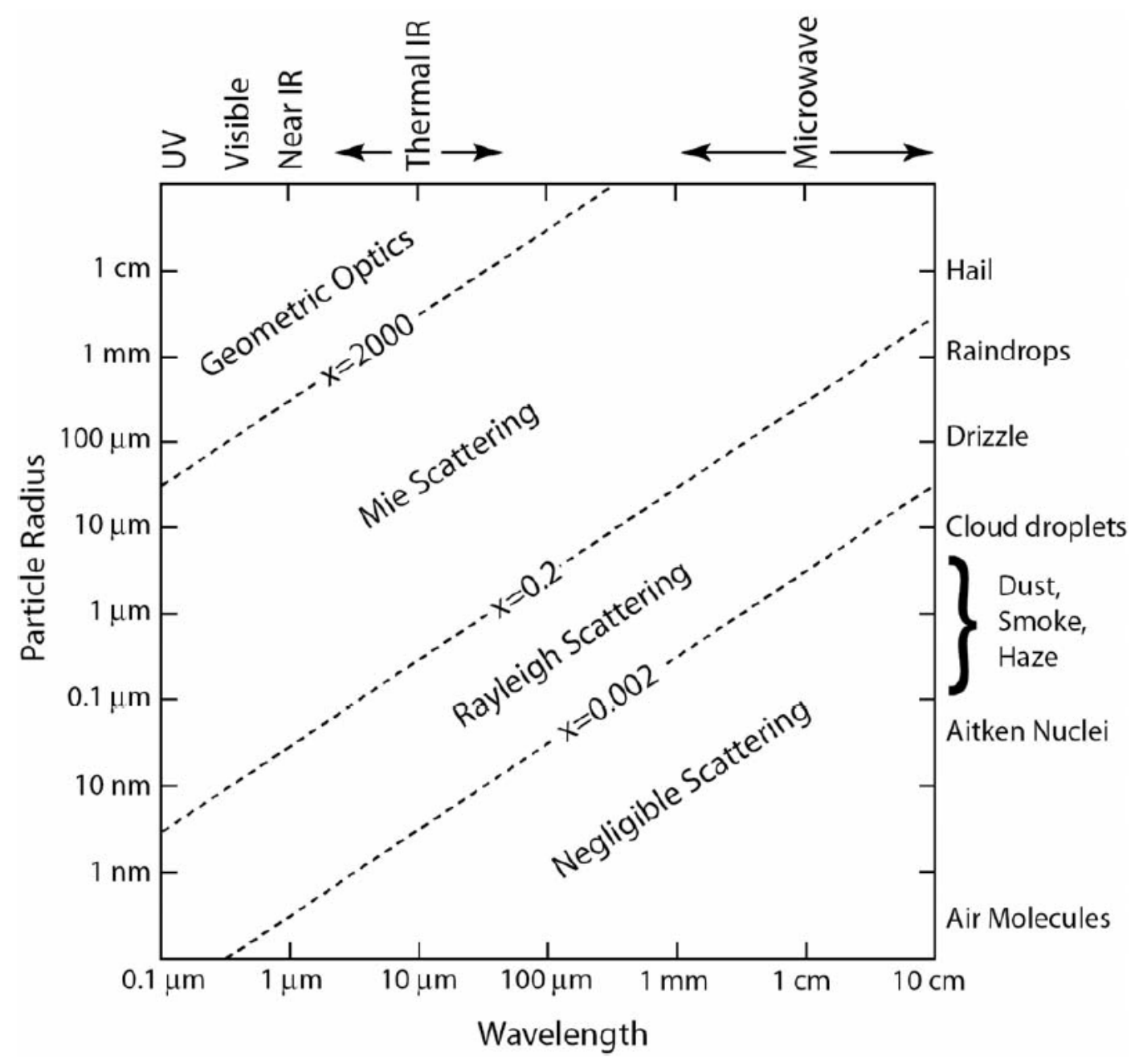

Figure 1.2: Relationship between particle size, radiation wavelength, and the size parameter for atmospheric constituents. Reproduced with permission from A First Course in Atmospheric Radiation, Second Edition, G. W. Petty, p. 346. 
scattering source term. Radiation can be scattered from any direction $\hat{\Omega}^{\prime}$ into the direction of the beam, $\hat{\Omega}$. The incoming radiation is represented by the scattering phase function, $p\left(\hat{\Omega}^{\prime}, \hat{\Omega}\right)$. The scattering phase function is integrated over all $4 \pi$ steradians of a solid angle, resulting in the source term:

$$
d I_{\text {scat }}=\frac{\beta_{s}}{4 \pi} \int_{4 \pi} p\left(\hat{\Omega}^{\prime}, \hat{\Omega}\right) I(\hat{\Omega}) d \omega^{\prime} d s
$$

Combining all source and extinction equations $(1.11,1.12$, and 1.13$)$ yields the complete radiative transfer equation:

$$
d I=-\beta_{e} I d s+\beta_{a} B(T) d s+\frac{\beta_{s}}{4 \pi} \int_{4 \pi} p\left(\hat{\Omega}^{\prime}, \hat{\Omega}\right) I(\hat{\Omega}) d \omega^{\prime} d s
$$

The radiative transfer equation appears in a number of different forms depending on the application. Various simplifications can be applied, especially to the scattering source term, in order to make the equation easier to compute. The scattering coefficient and scattering phase function depend on the size, phase, and number of particles. Of these, size is the most important characteristic. Scattering can often be neglected completely when the size of the particle is much smaller than the wavelength of interest. In cases where the size of the particle and the wavelength are closer together, Rayleigh theory and Mie theory are the two most commonly applied scattering theories in atmospheric remote sensing.

\subsubsection{Rayleigh and Mie Scattering}

The relationship between the size of the particle and the wavelength of the radiation of interest is determined using the dimensionless size parameter, $x$. The size 
parameter is simply the ratio of the cross-sectional area of a spherical particle of radius $r$ to the wavelength:

$$
x=\frac{2 \pi r}{\lambda}
$$

If $\lambda<<r$, the size parameter is very low and scattering can be neglected. Rayleigh scattering applies to the band from where the particle size and wavelength are close together up to where the particle is about three orders of magnitude larger than $\lambda$. The relationships are displayed graphically in Figure 1.2. In the microwave spectrum ( $\lambda>1 \mathrm{~mm}$ ), aerosols smaller than cloud droplets can generally be neglected. Raindrops fall mostly into the Rayleigh regime, especially for longer microwave wavelengths (lower frequencies). Scattering from larger particles such as hail falls in the Mie regime.

Mathematically, the distribution of scattered radiation can be expressed by a phase function that depends on the angle between the incident beam and the scattered beam, $\theta$, and $m$, the complex index of refraction of the surrounding air. The Rayleigh scattering phase function can be written as (Seinfeld and Pandis 1998):

$$
P(\theta)=\frac{\lambda^{2}}{8 \pi^{2}}\left(\frac{2 \pi r}{\lambda}\right)^{6}\left|\frac{m^{2}-1}{m^{2}+2}\right|\left(1+\cos ^{2} \theta\right) I_{\lambda}
$$

Several important characteristics of Rayleigh scattering are evident from this equation. The pattern of scattered radiation is symmetric in the forward and backward directions and independent of particle shape. The intensity of the scattered radiation is proportional to $1 / \lambda^{4}$, meaning that scattering decreases as wavelength becomes longer. A common example is the reddening of the sky at sunset as shorter (blue) visible wavelengths are scattered more efficiently by atmospheric aerosols. The scattered intensity is also 
proportional to $r^{6}$. The principle that larger particles backscatter more efficiently is the basis of precipitation estimation using weather radar.

Mie Theory is used when the size parameter is $\geq 1$. Mie theory is an analytical solution to Maxwell's equations expressed as a separable partial differential equation. The solution is easiest to express in terms of the extinction and scattering efficiencies, $Q_{e}$ and $Q_{s}$ :

$$
\begin{aligned}
& Q_{e}=\frac{2}{x^{2}} \sum_{n=1}^{\infty}(2 n+1) \operatorname{Re}\left(a_{n}+b_{n}\right) \\
& Q_{s}=\frac{2}{x^{2}} \sum_{n=1}^{\infty}(2 n+1)\left(\left|a_{n}\right|^{2}+\left|b_{n}\right|^{2}\right)
\end{aligned}
$$

where the Mie scattering coefficients $a_{n}$ and $b_{n}$ are functions of $x$ (size parameter) and $m$ (complex index of refraction). A version of 1.17 and 1.18 can also be computed for the Rayleigh regime when $x$ is well below one. The extinction efficiency oscillates for different size parameters, converging around 2 for larger values of $x$. In other words, the effective Mie scattering cross section is around twice the cross-sectional area. Unlike Rayleigh scattering, Mie scattering is generally independent of wavelength and preferential in the forward direction.

\subsection{Rainfall detection from Passive Sensors}

\subsubsection{Emission-based algorithms}

Rainfall algorithms from passive sensors (i.e., microwave radiometers) are generally divided into two categories: emission-based and scattering-based. From equation 1.9, ocean and land surfaces emit upwelling microwave radiation according to 
the emissivity and temperature of the surface. Over land, the surface emissivity is relatively high, making emission-based algorithms useful over ocean only. Over ocean, the emissivity depends on the microwave frequency, incidence angle, polarization, and the index of refraction (Kummerow et al. 1996). The microwave emissivity over the ocean is low, around 0.5 , and the ocean surface emissivity favors the vertically polarized direction. Raindrops have higher emissivity than the ocean surface and therefore have a warmer brightness temperature that contrasts the colder ocean surface.

Emission-based algorithms are generally derived from 10 and $19 \mathrm{GHz}$ microwave channels. These frequencies a size parameter too low to experience scattering by ice crystals, which also have a low emissivity. Besides liquid water droplets, absorption also occurs by water vapor and molecular oxygen. The bottom panel of Figure 1.1 shows atmospheric absorption as a function of wavelength. In the microwave regime, water vapor absorbs strongly around $22 \mathrm{GHz}$ and oxygen is a strong absorber around $60 \mathrm{GHz}$. Wilheit et al. (1977) derived the rain rate as a function of the $1.55 \mathrm{~cm}(19 \mathrm{GHz})$ brightness temperature. They found that Mie scattering by rain droplets has only a small impact on the $T_{B}$ - rain rate relationship. Furthermore, they determined that the drop size distribution depends only slightly on this relationship. With scattering neglected, it is relatively simple to derive the rain rate from the radiative transfer equation using an assumed hydrometer size model (1.14). Relatively high rain rates can be derived at these emission channels before saturation occurs, up to about $25 \mathrm{~mm} \mathrm{hr}^{-1}$ at $19 \mathrm{GHz}$ and $50 \mathrm{~mm}$ $\mathrm{hr}^{-1}$ at $10 \mathrm{GHz}$.

The downside to emission-based algorithms is that they are only useful at low frequencies, below the $22 \mathrm{GHz}$ water vapor channel. The earth's Planck curve peaks in 
the IR spectrum and decreases at longer wavelengths (lower frequencies) in the microwave spectrum. To compensate for the lesser upwelling radiation at low frequencies, a larger field of view (FOV) is required, resulting in poor resolution at 19 $\mathrm{GHz}$ and especially at $10 \mathrm{GHz}$. The TRMM $19 \mathrm{GHz}$ FOV is $30 \times 18 \mathrm{~km}$ and the $10 \mathrm{GHz}$ FOV is $63 \times 37 \mathrm{~km}$ (Kummerow et al. 1998). The actual rainfall within that FOV is nonuniformly distributed. An area of heavy rain is usually only on the order of a few kilometers at most. The satellite measures an average brightness temperature over the whole FOV and then converts it into an average rain rate. However, the $T_{B}$ - rain rate relationships from Wilheit et al. (1977) are non-linear, so the inferred average rain rate over a large FOV is less than the actual rainfall. This underestimation is commonly referred to as the beamfilling effect and it can be especially significant in tropical precipitation. Corrections with varying degrees of uncertainty are usually implemented to negate the beamfilling effect. Without corrections, the retrieved rain rate can differ from the actual rain rate by as much as $30-50 \%$. At higher resolutions, beamfilling is much less of an issue.

\subsubsection{Scattering-based algorithms}

Since the emission-based channels have resolutions too low to infer details of tropical convective systems, it is necessary to apply higher-frequency, higher-resolution scattering-based channels. Scattering in this context is defined as the process of atmospheric hydrometers deflecting upwelling radiation away from the satellite sensor. Stronger scattering results in a lower brightness temperature. The scattering-based channels also have the advantage of working over both land and water. The two main 
scattering-based channels on TRMM are the $37 \mathrm{GHz}$ and $85 \mathrm{GHz}$ channels. The $37 \mathrm{GHz}$ FOV is $16 \times 9 \mathrm{~km}$ and the $85 \mathrm{GHz}$ FOV is $7 \times 5 \mathrm{~km}$. The $37 \mathrm{GHz}$ channel is in an intermediate range, where both scattering and emission are distinguishable. At $85 \mathrm{GHz}$, scattering is the dominant signal.

Frozen hydrometers (ice crystals, hail, and graupel) are the source of the scattering. Ice scattering is only observed in precipitating systems that extend vertically beyond the freezing level, normally above about $6 \mathrm{~km}$ in the tropics. Mie scattering is strongly dependent on the relationship between the extinction efficiency (1.17) and the size parameter (1.14). The $37 \mathrm{GHz}$ frequency is low enough that only large, millimetersized ice particles scatter strongly, meaning the brightness temperature only depresses significantly in the presence of large hail and/or graupel. At $85 \mathrm{GHz}$, even small ice or snow crystals on the order of $0.1 \mathrm{~mm}$ are sufficient to decrease the brightness temperature.

The major limitation of a purely scattering-based algorithm is that it cannot resolve any raining system that does not reach the freezing level and is detectable only by its emission signature. This type of precipitation is referred to as warm rain because no part of the cloud reaches the freezing level and the raindrops form mostly through the collision-coalescence process. Warm rain makes up an appreciable portion of tropical rainfall, as Liu and Zipser (2009) estimated that 20\% of tropical oceanic rainfall and $7.5 \%$ of tropical land rainfall has a cloud-top temperature above $0{ }^{\circ} \mathrm{C}$. Without emission channels, the near-surface rainfall must be inferred from the ice content of the cloud, making scattering algorithms susceptible to regional and temporal biases (Kummerow et al. 1996). Another issue is that the ice is located in the upper levels of the cloud, so a 
convective system tilted by strong upper level winds will have ice scattering displaced downshear of the heaviest rainfall.

\subsubsection{Polarization-Corrected brightness Temperature}

In order to correctly locate areas of ice scattering, it is important to distinguish between low brightness temperatures caused by ice scattering and those caused by variations in the background brightness temperature. Water surface emissivity is a strong function of polarization when viewed from an oblique angle, while ice crystals are more randomly orientated and do not exhibit a preferred scatting direction. Spencer et al. (1989) defined the $85 \mathrm{GHz}$ Polarization corrected Brightness Temperature (PCT) as:

$$
P C T_{85}=1.818 T_{B_{v}}-0.818 T_{B_{h}}
$$

where $T_{B_{v}}$ and $T_{B_{h}}$ are the vertically and horizontally polarized $85 \mathrm{GHz}$ brightness temperatures and the constants are empirically modified from model calculations. A similar calculation can be performed for the $37 \mathrm{GHz}$ channel. The PCT is useful both as a proxy for rain rate and for convective intensity. It should be noted that PCT can be used over land surfaces also, as brightness temperature depressions caused by surface moisture or inland lakes can otherwise be mistaken for precipitation.

\subsubsection{Combined algorithm}

Emission- and scattering-based algorithms are often combined into what is commonly called a profiling algorithm. The properties of each channel are combined to create a vertical profile of the raining column. The TMI $2 \mathrm{~A} 12$ algorithm uses the Goddard Profiling Algorithm (GPROF), which employs an inversion procedure to 
compute the vertical hydrometer profile $(\vec{R})$ from the set of brightness temperatures $\left(\vec{T}_{B}\right)$. The algorithm applies Bayes' theorem to derive the probability of a particular profile, $\vec{R}$ given $\vec{T}_{B}$ measured from the satellite:

$$
\operatorname{Pr}\left(\vec{R} \mid \vec{T}_{B}\right)=\operatorname{Pr}(\vec{R}) \times \operatorname{Pr}\left(\vec{T}_{B} \mid \vec{R}\right)
$$

where $\operatorname{Pr}(\vec{R})$ is the probability that a certain profile will be observed and $\operatorname{Pr}\left(\vec{T}_{B} \mid \vec{R}\right)$ is the probability of observing the given set of brightness temperatures (Kummerow et al. 1996). The first term on the right is derived using a cloud microphysical model. The second term on the right is obtained through a number of radiative transfer calculations corresponding to the cloud model output. This type of scheme is most accurate over ocean where the emission and scatting channels can both be applied.

\subsection{Rainfall detection from Active Sensors}

Active sensors (radar in this case) are capable of more accurate and higher resolution rainfall estimates than passive sensors. The TRMM Precipitation Radar sends out a pulse of microwave radiation and measures the backscattering of cloud and precipitation particles. In the Rayleigh scattering regime, the backscattering cross section, $\sigma_{b}$, can be derived from the phase function (1.16):

$$
\sigma_{b}=\frac{\pi^{5} D^{6}}{\lambda^{4}}\left|\frac{m^{2}-1}{m^{2}+2}\right|
$$

where $D$ is the diameter of a spherical target. Since the radar scans multiple targets over a three-dimensional volume, the radar reflectivity, $\eta$, is defined as the sum of the individual backscattering cross sections in a unit volume (Rinehart 2004): 


$$
\eta=\frac{\pi^{5}|K|^{2} z}{\lambda^{4}}
$$

where $K$ is the complex index of refraction term from equation 1.21 and $z$ is the radar reflectivity factor, $z=\sum_{v o l} D^{6}$. The radar reflectivity factor has units of millimeters to the $6^{\text {th }}$ power per cubic meter. The radar reflectivity $\eta$ depends on the wavelength of the radar making the measurements, while the reflectivity factor $z$ is a property of the precipitating system and depends only on the raindrop size distribution. The complex index of refraction $K$ differs significantly between ice and water.

The radar antenna measures the backscattered power, $P$, in watts. The properties of any individual radar can be expressed in terms of a radar equation, which relates the radar-measured power to the characteristics of the radar and precipitation targets (Smith et al. 1996):

$$
P=\frac{C \times L \times Z}{r^{2}}
$$

In equation $1.23, C$ is a constant that includes radar-specific design parameters such as power transmission, beamwidth, wavelength, and antenna size. The loss of power by attenuation is represented by $L$ and the radar range is $r$. Attenuation is a significant source of uncertainty in TRMM PR measurements, especially in heavy precipitation. The logarithmic radar reflectivity factor, $Z$, is related to $z$ by the equation (Rinehart 2004):

$$
Z=10 \log _{10}\left(\frac{z}{1 m^{6} / m^{3}}\right)
$$

Reflectivity is converted to rainfall rate through a Z-R relationship of the form:

$$
R=a Z^{b}
$$


where $a$ and $b$ depend on the choice of drop size distribution (DSD). The TRMM PR uses different empirically-derived DSD models for stratiform and convective rain. The selection of an appropriate DSD model is more important at light rain rates, while the attenuation correction is more important for heavy rain (Iguchi et al. 2000).

\subsection{TRMM Satellite}

The Tropical Rainfall Measuring Mission (TRMM) satellite has been producing continuous measurements since December 1997. The primary goal of TRMM is to measure rainfall and latent heat (energy) exchange in the global tropics and subtropics (Simpson et al. 1988). The TRMM satellite orbits in a $350 \mathrm{~km}$ circular orbit with a $35^{\circ}$ inclination angle. To extend the mission lifetime, the orbit was boosted to $402 \mathrm{~km}$ in August, 2001. The satellite is well beyond its expected lifespan and could cease functioning at any time. Figure 1.3 shows the scanning properties of the primary TRMM instruments: the Precipitation Radar (PR), TRMM Microwave Imager (TMI), and Visible and Infrared Radiometer System (VIRS). This study only uses data from the PR and TMI. The TRMM satellite has lasted more than a decade beyond its original mission expectancy.

\subsubsection{Precipitation Radar}

The TRMM Precipitation Radar (PR) is the first spaceborne radar. It is a 13.8 $\mathrm{GHz}$ (2.17 $\mathrm{cm}$ wavelength) phased array radar than provides three dimensional observations of precipitation along its path. The $215 \mathrm{~km}$ PR swath width (Figure 1.3) increased to $247 \mathrm{~km}$ after the 2001 orbital boost. The horizontal resolution is approximately $4 \times 4 \mathrm{~km}(5 \times 5 \mathrm{~km}$ after boost). Vertically, the PR has a $0.25 \mathrm{~km}$ 


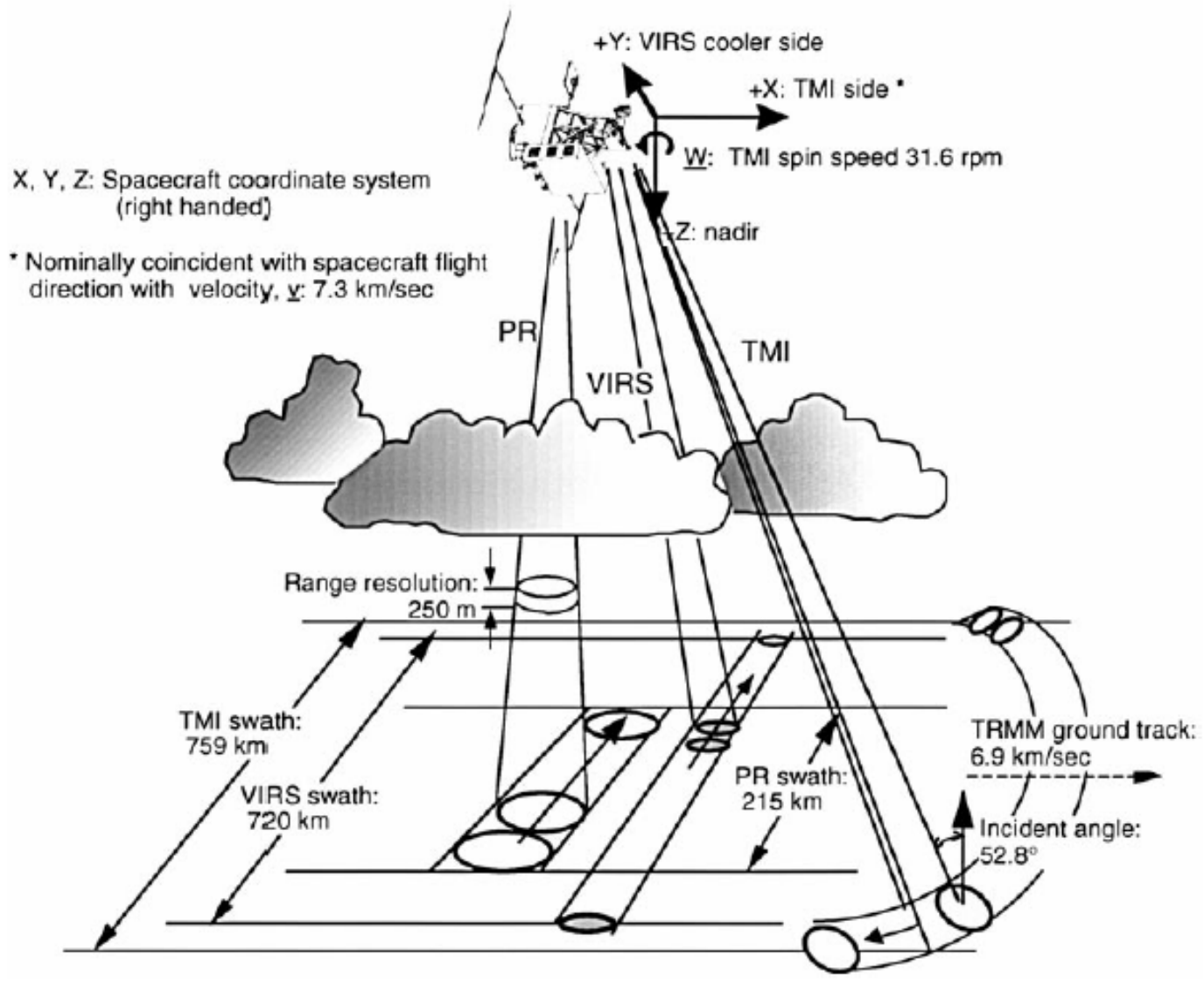

Figure 1.3: A schematic view of the scan geometries of the three TRMM primary rainfall sensors: TMI, PR, and VIRS (Kummerow et al. 1998)

resolution at nadir and observes from the surface up to a $15 \mathrm{~km}$ altitude. The cross-track scanning angle ranges from $-17^{\circ}$ to $+17^{\circ}$, resulting in a coarser resolution at the edges of the swath. Each scan has 64 independent samples. The minimum detectable signal is around 17-18 dBZ, which corresponds to a rain rate around $0.2 \mathrm{~mm} \mathrm{hr}^{-1}$.

\subsubsection{Microwave Imager}

The TRMM Microwave Imager (TMI) is a nine-channel passive microwave radiometer based on the design of the Special Sensor Microwave/Imager (SSM/I). The 
nine channels encompass five frequencies, four of which include horizontally and vertically polarized channels. The frequencies are $10.65 \mathrm{GHz}, 19.35 \mathrm{GHz}, 21.3 \mathrm{GHz}$ (vertically polarized only), 37.0 GHz, and 85.5 GHz. The TMI antenna views the earth at a $52.8^{\circ}$ incident angle. The antenna rotates about a nadir axis at a constant speed of 31.6 rpm, drawing a "circle" on the earth's surface. Only the front $130^{\circ}$ of the circle is used in data collection. The swath width is $760 \mathrm{~km}(878 \mathrm{~km}$ after boost). The satellite advances $13.9 \mathrm{~km}$ in for every 1.9 second scan, meaning there is a "gap" between the $7 \mathrm{~km}$ (alongtrack) $85 \mathrm{GHz}$ observations and an overlap in all higher frequency channels.

\subsection{Outline}

This thesis consists of two main sections, each of which addresses separate but related issues involving the use of the PR and TMI precipitation algorithms in tropical cyclones. The first section (chapter 2) uses a global database of tropical cyclones over ocean to compare version 6 of the algorithms. For a more detailed comparison, the TCs are divided by intensity and into the inner core, inner band, and outer band region. Finally, the properties of 85 and $37 \mathrm{GHz}$ ice scattering are related to the difference between the two algorithms. The second section (chapter 3) applies a more detailed statistical validation of the algorithms using a ground-based radar reference dataset. Storms are divided into oceanic, land, and coastal groups and both version 6 and version 7 of the algorithms are compared. Errors associated with detection (rain or no rain) and rainfall intensity are both assessed and specific deficiencies relative to the validation dataset are quantified. 
2. COMPARISON OF TRMM PR AND TMI VERSION 6 RAINFALL RETRIEVALS IN TROPICAL CYCLONE INNER CORES AND RAINBANDS

Abstract

Tropical Rainfall Measuring Mission (TRMM) rainfall retrieval algorithms are evaluated in tropical cyclone (TC) inner cores (IC), inner bands (IB) and outer rainbands (OB). A total of 1329 IC, 2149 IB, and 4627 OB storm regions are analyzed using data from a 12-year TRMM Tropical Cyclone Precipitation Feature (TCPF) database containing 1013 TCs viewed from Dec. 1997 to Dec. 2009. Attention is focused on the difference between the Precipitation Radar (PR) 2A25 and the TRMM Microwave Imager (TMI) 2A12 rainfall algorithms. The PR 2A25 produces larger mean rain rates than the TMI 2A12 in inner cores and inner bands, with the greatest difference occurring in hurricanes. This discrepancy is mostly caused by the TMI 2 A12 significantly underestimating regions of moderate to heavy rain $>15 \mathrm{~mm} \mathrm{hr}^{-1}$, or where the PR reflectivity is greater than $30 \mathrm{dBZ}$. The TMI $2 \mathrm{~A} 12$ rain rates are most closely related to the percent coverage of $85 \mathrm{GHz}$ Polarization Corrected brightness Temperature (PCT) < $225 \mathrm{~K}$ in the IC and $85 \mathrm{GHz} \mathrm{PCT}<250 \mathrm{~K}$ in the IB and OB. These convective parameters are good predictors of the mean TMI $2 \mathrm{~A} 12$ rain rate, but significant ice scattering is not always present in areas of heavy rain that are often widespread in TC inner regions. As a result, the TMI $2 \mathrm{~A} 12$ algorithm may poorly measure the rain rate, particularly in the inner core of hurricanes. 


\subsection{Introduction}

Satellite precipitation retrivals are one of the best ways to consistently observe the spatial distribution of precipitation in tropical cyclones (TCs). Rainfall observations from the Tropical Rainfall Measuring Mission (TRMM) satellite have helped to quantify the total precipitation in tropical systems, initialize and validate numerical models, and decipher the relationship between $\mathrm{TC}$ eyewall and rain band structure and intensity changes. However, these algorithms are calibrated on a global or regional scale and often show less agreement for smaller scale features such as TCs. The rainfall retrievals must be derived using a number of assumed parameters related to the microphysical properties of cloud, rain, and ice particles. Numerous studies have compared the TRMM rain retrieval algorithms for a wide variety of applications. Focus is usually on regional or temporal biases caused by empirical assumptions of cloud microphysical parameters (e.g., Berg et al. 2002, 2006; Nesbitt et al. 2004). Tropical cyclones present a unique challenge because they are especially sensitive to environmental parameters such as storm motion, wind shear and moisture distribution, all of which can affect the vertical profile of cloud water and ice. The relationship between vertical cloud profiles and nearsurface rainfall can be different in the inner and outer regions of TCs, and in TCs compared with the ambient environment. The spatial distribution of precipitation in TCs is influenced by a number of dynamical and environmental factors that govern their convective structure. Weaker TCs and outer bands often produce light and sporadic rainfall, while inner regions of intense TCs are more likely to be proficient heavy rain producers. 
The TRMM Microwave Imager (TMI) and Precipitation Radar (PR) provide independent and complimentary estimates of near-surface rainfall. The TMI (Kummerow et al. 1998) is a passive, multi-channel microwave radiometer with an $878 \mathrm{~km}$ swath width (760 km before 2001 orbital boost). The TMI 2A12 rainfall algorithm (Kummerow et al. 1996, 2001) retrieves surface rainfall from the full spectrum of TMI frequencies $(10,19,21,37$ and $85 \mathrm{GHz})$. The algorithm is based on the Goddard Profiling algorithm and uses a Bayesian approach, with several cloud model integrations used to pair surface rain rates with the corresponding set of upwelling microwave brightness temperatures. In contrast, the Precipitation Radar (PR) has a narrower 247-km swath width $(215 \mathrm{~km}$ before boost). The PR 2A25 algorithm (Iguchi et al. 2000) retrieves rain rates from observed radar reflectivities using a Z-R relationship. The underlying physics are more straightforward for the PR 2A25 algorithm than the TMI 2A12 algorithm, but still the PR 2A25 has to assume a particle size distribution model to derive rain rate from radar reflectivity. The most difficult part of the K-band TRMM radar rainfall retrieval is determining the beam attenuation, which increases with higher rain rates. The PR is generally considered to be accurate relative to ground data, but a few areas of greater uncertainty must be taken into consideration. Wolff and Fisher (2008) noted that PR 2A25 version 6 underestimates heavy rain rates relative to TRMM Ground Validation (GV) radar data over ocean. Schumacher and Houze (2000) compared the PR to the Sband Kwajalein oceanic validation radar and found that the PR's $17 \mathrm{dBZ}$ minimum reflectivity threshold limits its ability to detect rain rates below $0.2-0.4 \mathrm{~mm} \mathrm{hr}^{-1}$.

The TMI 2A12 algorithm has been most commonly used in previous TRMM TC rainfall studies because its wide swath accrues more observations. Lonfat et al. 
(2004)found the TMI 2A12 (version 5) azimuthally averaged rain rates vary by both storm intensity and basin, with the greatest differences occurring in the innermost $100 \mathrm{~km}$ of the storm. With the same data set, Chen et al. (2006) added a shear-relative coordinate system to conclude that TC rainfall asymmetries depend on the juxtaposition and relative magnitude of the storm motion and vertical wind shear vectors. Cecil (2007) also used the TMI 2A12 to show that inner core rainfall in highly-sheared Atlantic hurricanes is favored in the downshear-left quadrant, with mean rain rates of about $15-16 \mathrm{~mm} \mathrm{hr}^{-1}$ compared with 6-7 $\mathrm{mm} \mathrm{hr}^{-1}$ in the non-favored quadrants. The TMI $2 \mathrm{~A} 12$ is most directly compared with the PR 2A25 by Cecil and Wingo (2009). They resized the pixels to a $0.25^{\circ} \times 0.25^{\circ}$ grid and directly compared the new grid boxes in TCs of various intensities. The two algorithms were found to agree closely on mean rain rates except in the innermost $100 \mathrm{~km}$ of hurricanes, where the PR 2A25 rain rates are greater than the TMI 2A12 by $2.9 \mathrm{~mm} \mathrm{hr}^{-1}$ (9.5 vs. $6.6 \mathrm{~mm} \mathrm{hr}^{-1}$ ). Another important finding was that the PR $2 \mathrm{~A} 25$ contributes more rain to the mean from high rain rates while the TMI $2 \mathrm{~A} 12$ contributes more from light and moderate rain rates. When directly comparing the grid boxes, low PR 2A25 rain rates were most closely matched with moderate values for the TMI 2A12, while the highest PR 2A25 rain rates matched with only $10-15 \mathrm{~mm} \mathrm{hr}^{-1}$ rain rates for the TMI 2A12. The linear correlation between the algorithms (for hurricane inner cores) is only 0.61 at the $0.25^{\circ}$ grid size (Cecil and Wingo 2009).

The high frequency, high resolution TMI channels $(85$ and $37 \mathrm{GHz})$ are of utmost interest to understanding the TMI $2 \mathrm{~A} 12$ algorithm. Lower-frequency emission-based channels $(10,19 \mathrm{GHz})$ are more sensitive to near-surface rain, but their influence on the TMI 2A12 algorithm in TCs is limited by their low resolution (Shige et al. 2006). The 85 
and $37 \mathrm{GHz}$ Polarization Corrected brightness Temperatures (PCTs) are commonly used as proxies for rainfall and convective intensity in TCs (Spencer et al. 1989). The $85 \mathrm{GHz}$ PCT senses precipitation-sized frozen hydrometeors, with a lower PCT corresponding to more ice scattering and stronger convection. An $85 \mathrm{GHz}$ PCT around $275 \mathrm{~K}$ indicates the presence of frozen hydrometers. An $85 \mathrm{GHz}$ PCT below $250 \mathrm{~K}$ is an indicator of a lightto-moderate rain rate of at least $3 \mathrm{~mm} \mathrm{hr}^{-1}$. When the $85 \mathrm{GHz} \mathrm{PCT}$ is lower than $225 \mathrm{~K}$, the rain is considered to be convective with a rate of at least 10-12 $\mathrm{mm} \mathrm{hr}^{-1}$ (Mohr and Zipser 1996). Intense convection is present when the $85 \mathrm{GHz}$ PCT drops below $200 \mathrm{~K}$. The $37 \mathrm{GHz}$ PCT is sensitive to larger ice hydrometers. The $37 \mathrm{GHz}$ PCT has a smaller dynamic range than the $85 \mathrm{GHz}$ PCT and varies only from about 280 to $250 \mathrm{~K}$ in most cases (Cecil and Zipser 2002), although it is capable of dropping below $200 \mathrm{~K}$ in stronger convection. In practice, the relationship between ice scattering and surface rainfall is complicated. It is generally accepted that PCT criteria can be equated with near-surface rain rates in the terms described above, but in many cases the rain rates can vary drastically for similar PCT criteria. The exact value depends on several interconnected factors including the stage of the convective system (i.e. developing, mature, or dissipating). Furthermore, various geographical and environmental factors such as vertical wind shear and the presence of dry air can alter the microphysical properties of cloud liquid and ice and hence the precipitation retrievals.

The main goal of this study is to compare the properties of the TRMM PR 2A25 and TMI 2A12 rainfall retrieval algorithms in TC inner cores and rainbands. The methodology does not involve a pixel-by-pixel comparison, but rather an evaluation of the rainfall distributions in the storm regions (inner cores, inner rainbands, outer 
rainbands) as a whole. However, to make a fair comparison, a nearest neighborhood method is used to average PR 2A25 resolution to TMI 2A12 resolution (see section 2 for deatails). In the first part of this study (section 3), algorithm rain estimates are stratified by storm region and TC intensity and compared in three ways: mean values, histograms, and scatterplots. From this analysis, it becomes clear that there is a significant difference in the two algorithms in TCs, especially for the inner cores of intense storms. The second half of this study (section 4) looks at the relationship between 37 and $85 \mathrm{GHz}$ convective parameters and the rain rate retrievals. The properties of moderate and heavy rain are emphasized, as the highest rain rates contribute the most to the mean. The key issues in understanding why the algorithms disagree in TCs are: 1) how the TMI estimates heavy rain through the 37 and $85 \mathrm{GHz}$ scattering channels and 2) how the estimates of the moderate and heavy rain rates compare between the PR and the TMI. Understanding the characteristics of these retrievals is important for accurately interpreting tropical cyclone precipitation and improving future versions of satellite precipitation algorithms. Tropical cyclones offer some of the best extreme rain data, as heavy rain rates that are generally rare in the tropics are common in TCs. While this study focuses specifically on TRMM, the broader conclusions are applicable to a wide range of satellite-based tropical precipitation studies where accurate estimation of moderate and heavy rain rates influences the results.

\subsection{Data and Methods:}

This study utilizes the TRMM Tropical Cyclone Precipitation Feature (TCPF) database (Jiang et al., 2011) to compare rainfall retrievals in tropical cyclones. The TCPF 
database is a subset of the University of Utah (UU) TRMM Precipitation Feature (PF) database (Liu et al., 2008). The TCPF database includes global TC best track information, collocated PR and TMI measurments and retrievals, and environmental parameters derived from NCEP realanysis. The time frame spans 12 years from December 1997 through December 2009, during which time there were 13,677 individual TRMM overpasses of 1013 TCs. Two rainfall algorithms are compared: the Precipitation Radar 2A25 algorithm (PR 2A25) version 6 and the TRMM Microwave Imager 2A12 algorithm (TMI 2A12) version 6. The PR 2A25 product has a pixel size of $5 \times 5 \mathrm{~km} \mathrm{(4x}$ $4 \mathrm{~km}$ before boost) compared with $8 \times 6 \mathrm{~km}(7 \times 5 \mathrm{~km}$ before boost) for the TMI $2 \mathrm{~A} 12$ retrieval. Because of the resolution difference between the retrievals, the pixels can not be compared directly. This study uses a nearest-neighbor collocation method similar to Nesbitt et al. (2000) to average PR pixels to the TMI 2A12 product resolution. One note here is that the $2 \mathrm{~A} 12$ orbital product has retrieval estimates at every $85 \mathrm{GHz}$ field of view (FOV), while the actual resolution of the TMI retrieval estimate is complicated because the algorithm uses 10, 19, 37, and $85 \mathrm{GHz}$ channels, which have different FOVs. Here our comparison is based on the perspective of end users of the algorithm instead of an algorithm developer. Therefore, the PR resolution is reduced only to the resolution of the TMI $85 \mathrm{GHz}$ FOV and no further.

To compare the TC rainfall, the TCPFs are subjectively sub-classified into three subregions for detailed study. The motivation for the orbit divisions is described by Cecil et al. (2002) and the manual division of sub-regions was done by Jiang et al. (2012) for the 12-year TCPF database. Further details and an example are detailed by Jiang et al. (2012). The inner core (IC) region includes the eyewall and all near-center convection in 
storms without eyewalls. The inner rainband (IB) region includes banded or blob-like precipitation immediately outside the area of strongest $85 \mathrm{GHz}$ ice scattering associated with the IC. A rain-free region around 150-200 km from the center usually separates the IB from the outer rainband (OB), which includes outward spiraling rainbands and all outlying TC-related features. Each storm is assigned an IC, IB, and OB radius which represent the outer edge of the respective storm regions. Compared with a fixed 100-km radius, the subjective method accounts for varying TC-size and reduces the contamination between the IC and IB regions. Minor contamination still occurs in weak TCs and TCs where the boundaries between the regions are not easily distinguishable. The regions are always circular, so highly asymmetric TCs also exhibit some contamination. Storms are also divided into four intensity categories: Tropical depressions (TDs) have maximum sustained winds of 34 knots or less, tropical storms (TSs) have winds from 35-63 knots, Category 1-2 hurricanes (Cat. 1-2) have winds from 64-95 knots and Cat 3-5 hurricanes (Cat. 3-5) have winds of 96 knots or greater.

To generate the dataset, all PR pixels within one TMI FOV are averged to the TMI resolution. The TMI pixels and the corresponding PR pixels are then grouped into the IC, $\mathrm{IB}$, and $\mathrm{OB}$ regions. Only non-zero pixels are included, meaning that all rainfall statistics in this study are conditional rain rates. One exception is for zero rain PR pixels that are collocated to the same TMI pixel as a non-zero PR 2A25. In this way, both algorithms are compared at the lower resolution of the TMI 2A12 retrieval. The PR and TMI pixels for each storm are different in number, size, and coverage area depending on where each algorithm detects rain. To make a direct comparison, the saved PR and TMI raining pixels from each storm and region (IC, IB, and $\mathrm{OB}$ ) are integrated to form a single feature 


\begin{tabular}{|c|c|c|c|c|}
\hline Region & $\begin{array}{l}\text { Mean Radius } \\
(\mathrm{km})\end{array}$ & $\begin{array}{l}\text { Min Radius } \\
(\mathrm{km})\end{array}$ & $\begin{array}{l}\text { Max Radius } \\
(\mathrm{km})\end{array}$ & $\begin{array}{l}\text { Std. } \\
\text { Deviation }\end{array}$ \\
\hline IC & 87 & 45 & 170 & 18 \\
\hline IB & 164 & 90 & 270 & 28 \\
\hline $\mathrm{OB}$ & 505 & 300 & 900 & 123 \\
\hline
\end{tabular}

Table 2.1: Mean, minimum, maximum, and standard deviation of the outer edge of storm region separation radii.

for the IC, IB, and OB region of each storm. For a sample to be accepted, the TC center and all individual raining pixels must be centered over the ocean. Up to 5 pixels over a very small landmass such as an island are still accepted as being over ocean.

The regions are considered independently so that an IC can still be accepted even if some of the rainbands from the storm are located over land. To remove samples that capture only a small portion of the storm region, minimum PR 2A25 raining area criteria of $5000 \mathrm{~km}^{2}$ are also set for each individual region. The size criteria ensure that storm regions have approximate swath coverage (based on visual approximation) of at least $60 \%$ in the IC, $40 \%$ in the IB, and $20 \%$ in the OB. The mean swath coverage relative to the circular or annular storm region after applying the criteria is $79 \%$ in the IC, $56 \%$ in the IB, and $26 \%$ in the OB. Table 2.1 displays the characteristics of the storm region separation radii. The mean IC radius is 13\% (12 km) smaller in Cat. 3-5 Hurricanes than in TDs. The IB and OB radius do not change significantly with intensity. The TC center locations of the final sample are displayed in Figure 2.1, with the sample size in parentheses. In total, 1329 IC, 2149 IB, and 4627 OB regions are considered. Because of the relatively small size of the IC and IB regions relative to the OB, the PR swath often misses the inner regions entirely. 


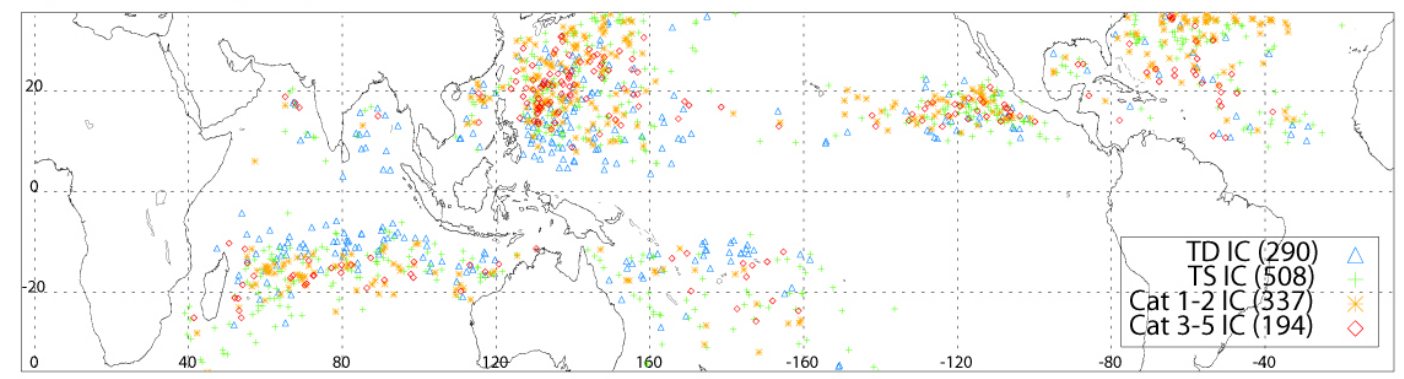

(b) IB Locations (2149)

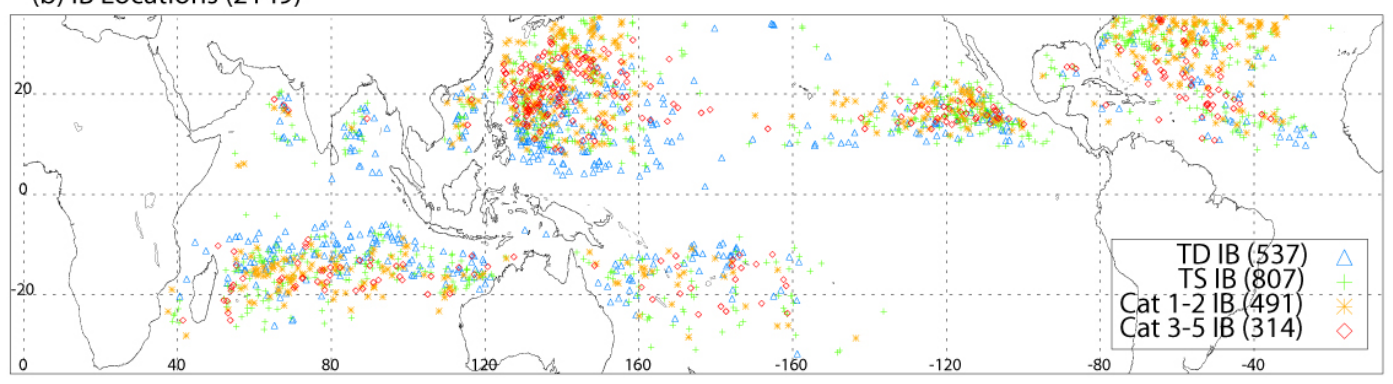

(c) OB Locations (4627)

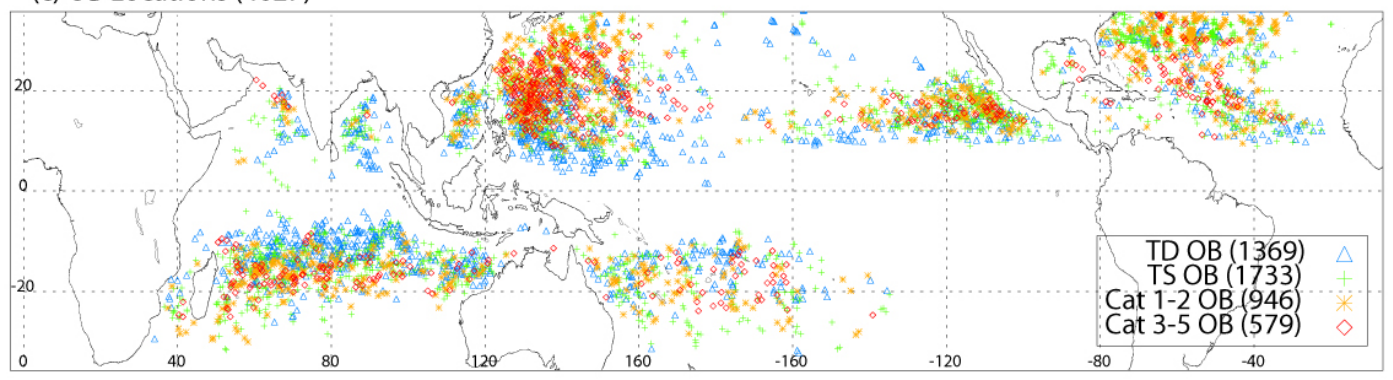

Figure 2.1: TC Center locations of storms with accepted (a) IC, (b) IB, and (c) OB features with a PR $2 \mathrm{~A} 25$ raining area $>5,000 \mathrm{~km}^{2}$. Parentheses indicate the total sample size.

A number of storm parameters from the TCPF database are calculated for each storm region. Storm parameters such as center location and intensity are derived from best track data, which are obtained from the National Hurricane Center (NHC) for the Atlantic and eastern North Pacific basins and from the Joint Typhoon Warning Center (JTWC) for all other basins. Two raining parameters are derived directly from satellite data: raining area $\left(\mathrm{km}^{2}\right)$ and rain rate $\left(\mathrm{mm} \mathrm{hr}^{-1}\right)$, both of which are calculated separately 
for the PR and TMI. These two parameters can be multiplied to measure the volumetric rainfall $\left(\mathrm{mm} \mathrm{hr}^{-1} \mathrm{~km}^{2}\right)$, which is defined as the rain flux (rain rate multiplied by raining area) at the instantaneous time of the overpass. Convective parameters include the TMI 37 and $85 \mathrm{GHz}$ PCT (K) and the PR reflectivity (dBZ). Traditionally, the minimum PCT value and maximum $20 \mathrm{dBZ}$ echo height $(\mathrm{km})$ are used to represent the strongest point of convection within a designated TC region. In this study, emphasis is placed on the aerial coverage of the PCT and near-surface PR reflectivity by calculating the percent coverage of these convective parameters in each storm region, relative to the total raining area. This method was also employed in Cecil and Zipser (1999) and is a convenient way to measure the fraction of raining area that meets various convective criteria. Specific criteria for the TMI (calculated relative to TMI 2A12 raining area) include the percentage of $37 \mathrm{GHz}$ PCT less than 250 and $225 \mathrm{~K}, 85 \mathrm{GHz}$ PCT less than 275, 250, 225, 200, and $175 \mathrm{~K}$. The percentage of 20,30 , and $40 \mathrm{dBZ}$ near-surface reflectivity (relative to PR 2A25 raining area) is also calculated. The percent coverage criteria are more closely related to TC rainfall than the minimum PCT criteria because they consider the convective properties over a larger area instead of just an individual point.

\subsection{Statistical Comparison of Rainfall Algorithms}

\subsubsection{Mean Rainfall Values}

Mean values (per storm region) are calculated to account for differences in sample sizes between the storm regions and intensities. Figure 2.2 displays the mean values for raining area, rain rate, and volumetric rain for storm regions of various intensities. Because each TRMM overpass covers a different fraction of the storm, the absolute 
raining area and volumetric rain values are not significant, only the relative difference between algorithms. In Figure 2.2 (a) and (b), the raining area for PR 2A25 is shown to be less than the raining area for TMI $2 \mathrm{~A} 12$ in all regions and intensities. The mean raining area $\left(\mathrm{km}^{2}\right)$ is the average area in each storm region where rainfall is non-zero. The difference between the algorithms is about the same across the board, with the TMI 2A12 producing a $10-20 \%$ larger raining area. More intense storms show an overall larger raining area in the IB and OB. The raining area also increases with intensity in the IC, but the trend is offset with this analysis method because the mean IC radius in hurricanes is about $10 \mathrm{~km}$ less than the radius in tropical depressions and storms.

Several factors cause the TMI 2A12 raining area to be larger than the PR 2A25. One issue is the TMI's lower resolution, which slightly overestimates the size of almost all raining features. Larger differences are observed in light banded rain features. In a typical light rain band, the PR 2A25 detects numerous small showers while the TMI 2A12 identifies a single large PF which in some instances can be five times or more than the sum of the individual 2A25 PFs. In many of these cases the low-frequency $(10,19$ GHz) TMI channels may have difficulties distinguishing between elevated cloud liquid water levels and light precipitation. It is also difficult for the algorithm to resolve small scale, warm rain features while incorporating the low resolution 10 and $19 \mathrm{GHz}$ channels. Additionally, the PR may be missing very light drizzle (rain rate $<0.3 \mathrm{~mm} \mathrm{hr}^{-1}$ ) because of its 17-18 dBZ minimum reflectivity threshold (Schumacher and Houze 2000; Berg et al. 2006). Independent ground validation data is required to decide whether it is raining or not in these situations. The TMI 2A12 raining area is also larger than PR 2A25 in areas of 

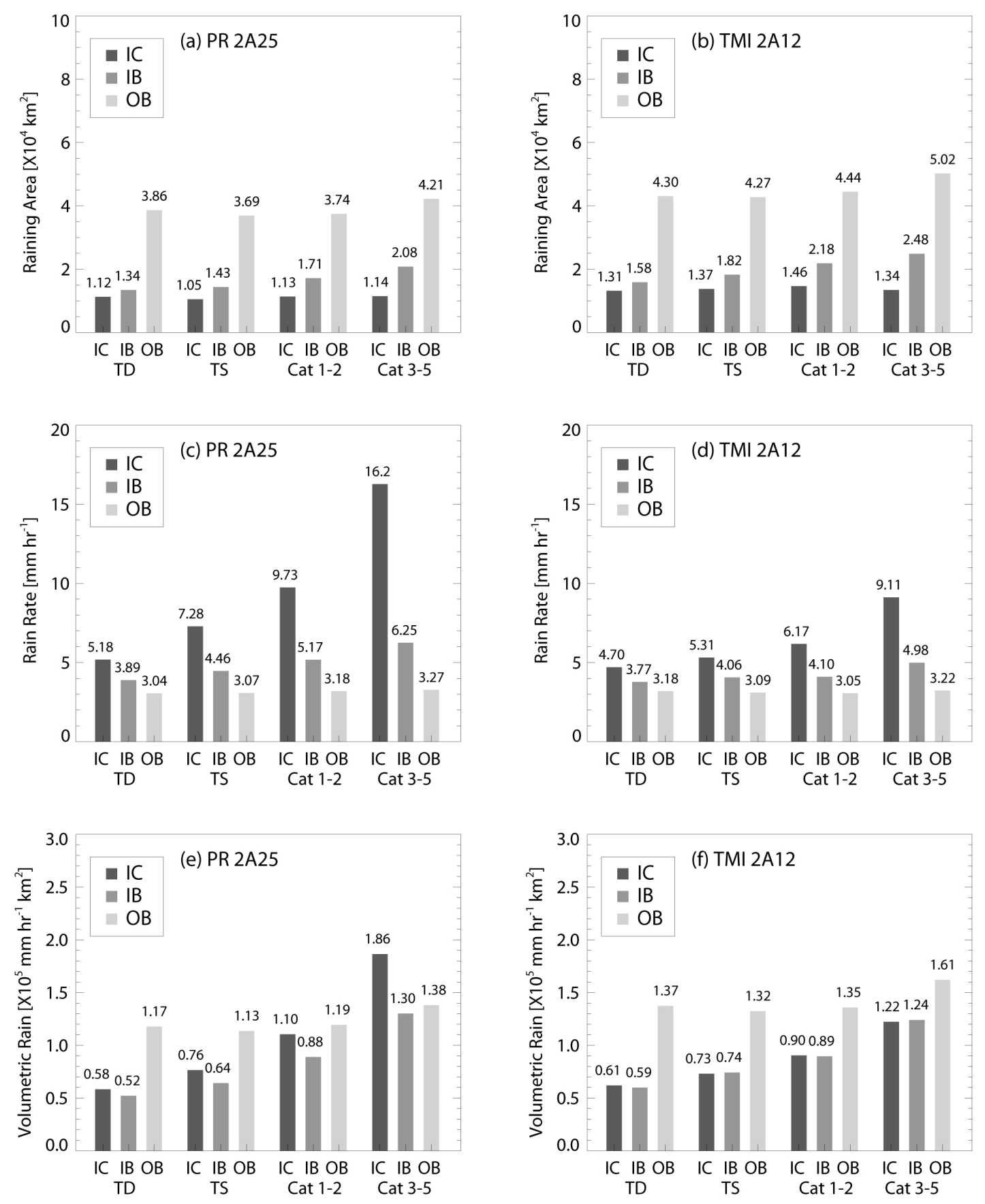

Figure 2.2: Bar plots comparing PR 2A25 and TMI 2A12 mean raining area (a-b), mean rain rate (c-d), and mean volumetric rain (e-f) for inner cores (dark shade), inner bands (medium shade), and outer bands (light shade), divided by storm intensity. 
deeper convection. The ice-scattering signature of heavier precipitation can extend beyond the region of surface precipitation such as into the rain-free eye of major hurricanes or downshear of a region of deep convection (Cecil et al. 2002).

The mean conditional rain rates are compared in Figures 2.2 (c) and (d). The PR $2 \mathrm{~A} 25$ produces larger rain rates than the TMI $2 \mathrm{~A} 12$ in the IC and IB, with the difference always increasing with greater storm intensity. In the OB region, both algorithms show similar mean rain rates between 3.0 and $3.3 \mathrm{~mm} \mathrm{hr}^{-1}$ for all intensities. The difference between PR 2A25 and TMI 2A12 is largest in the IC, especially hurricanes, where the mean PR 2A25 rain rate is over 50\% higher than the TMI 2A12. In absolute terms, the PR 2A25 is greater by only $0.5 \mathrm{~mm} \mathrm{hr}^{-1}$ in TD inner cores, but rises to $1.0 \mathrm{~mm} \mathrm{hr}^{-1}$ in TSs and 3.6 and $7.1 \mathrm{~mm} \mathrm{hr}^{-1}$ in cat 1-2 hurricanes and major hurricanes.. A modest difference is observed in the IB, ranging from $0.1 \mathrm{~mm} \mathrm{hr}^{-1}$ in TDs up to $1.3 \mathrm{~mm} \mathrm{hr}^{-1}$ in major hurricanes. Compared with Cecil and Wingo (2009) Figure 2, the rain rates for both algorithms in this study are significantly larger in all instances, from a factor of about a third in hurricane inner cores $(0-100 \mathrm{~km})$ up to a factor of 4-6 in both weaker storms and in the OB (200-500 km). Cecil and Wingo (2009) found close agreement between the algorithms everywhere except hurricane inner cores. The discrepancy between the studies is likely caused by Cecil and Wingo (2009) resizing the PR and TMI pixels to a $0.25^{\circ}$ grid. The large grid size lowers the mean rain rate by including non-raining pixels that are adjacent to raining pixels into the grid. The primary area of interest is the inner core, where the difference in rain rates cannot be explained by differences in instrument or sample resolution. 
Figure 2.2 (e) and (f) display the mean volumetric rain in the same manner. Volumetric rain is a useful comparison tool since it normalizes the difference in raining area between the two algorithms. Both algorithms again show the same general trends, with stronger intensity corresponding to more volumetric rainfall. The outer bands vary the least between intensity categories and all have about $15 \%$ more TMI 2 A12 volumetric rain. The inner bands actually show better agreement than the outer bands between the two algorithms. The most significant difference is again in the inner core of hurricanes, where the PR 2A25 is close to the TMI 2A12 in weaker storms but larger by up to about $50 \%$ in the Category 3-5 range. When considering the raining area, rain rate, and volumetric rain as a whole, several areas of interest emerge. In the outer bands, the higher TMI 2A12 volumetric rain totals can almost completely be explained by higher TMI $2 \mathrm{~A} 12$ raining areas, as the $\mathrm{OB}$ rain rates agree closely. In the inner regions, especially hurricane inner cores, higher PR 2A25 rain rates offset the larger TMI 2A12 raining areas, resulting in greater PR 2A25 volumetric rain totals relative to the TMI 2A12. In the outer regions and in weak storms, a large part of the inconsistency comes from differences in rain detection, as reflected in the differences in raining area. In strong storms with greater rain coverage, the actual rainfall intensity becomes the dominant source of disagreement.

\subsubsection{Rainfall Distributions}

To further analyze the source of the algorithm disagreement, the three PDFs are shown in Figure 2.3 for raining area in the (a) IC, (b) IB, and (c) OB. The PR 2A25 

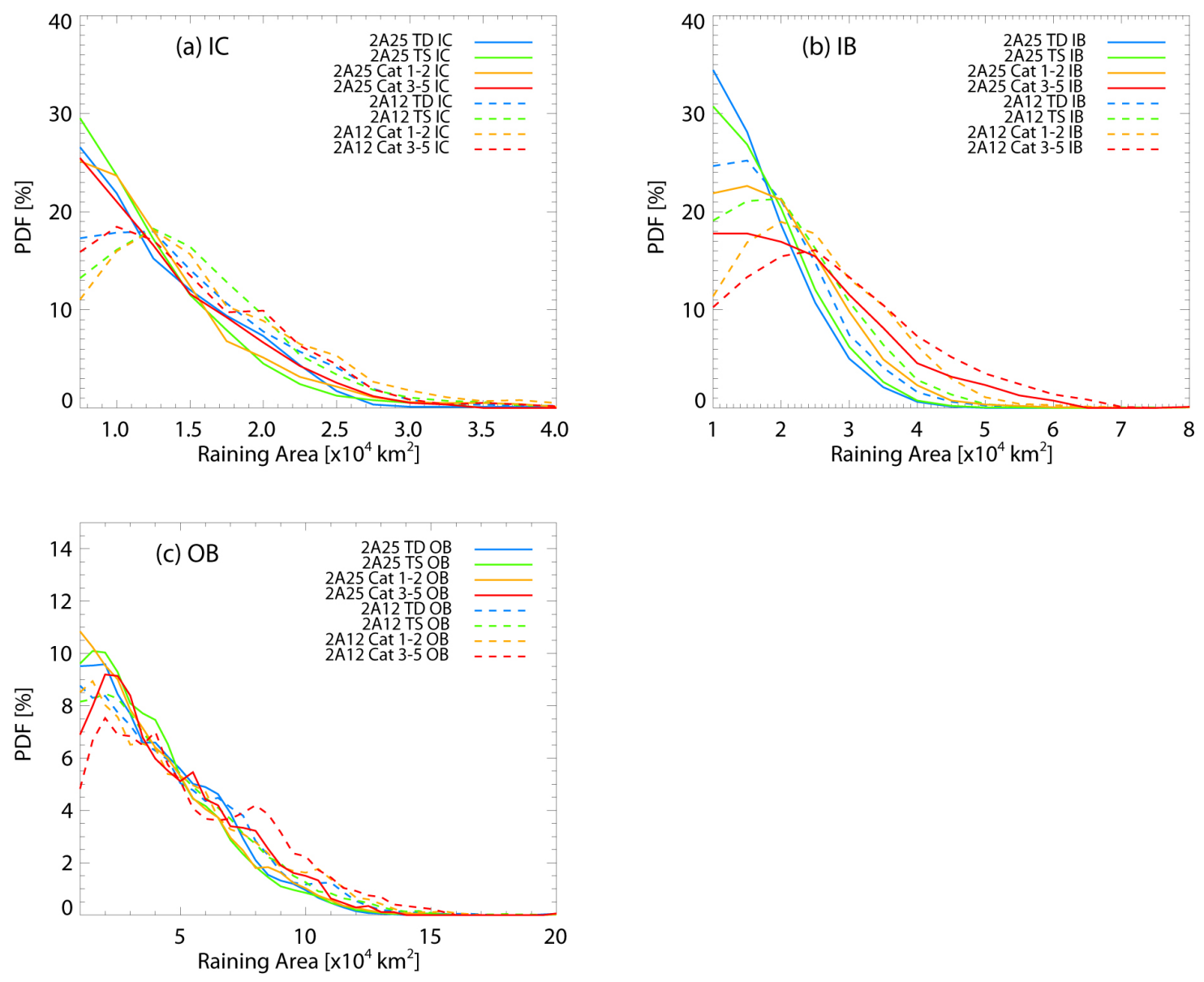

Figure 2.3: PDF of raining area distributions for (a) IC, (b) IB, and (c) OB regions, divided by algorithm and intensity.

estimates smaller raining areas in the $\mathrm{IB}$ and $\mathrm{OB}$, but the raining areas for stronger storms have a broader distribution. More intense storms tend to have larger raining areas, almost entirely because of the expansion of the rain field in the geographically larger IB and OB regions. The TD and TS curves are also closely grouped for the TMI, but there is some separation, especially in the IB. In the IC, storm intensity has almost no influence on raining area, except for a small increase in larger raining areas for PR 2A25 hurricanes. 
The distributions are grouped closely by algorithm, with the PR 2A25 finding much smaller raining areas compared with the TMI $2 \mathrm{~A} 12$.

The histograms for rain rate are displayed in Figure 2.4. In the IC, the distributions show high variability between algorithms and intensity categories. The algorithms are in best agreement for TDs and farthest apart for major hurricanes. All intensity categories follow the same pattern. The TMI $2 \mathrm{~A} 12$ distributions are closer to a Gaussian distribution and have lower modes than the PR 2A25. The PR 2A25 has broader distributions that become positively skewed and have higher modes for stronger intensity categories. The histograms for hurricanes are of most interest due to the significant disagreement between algorithms. The TMI 2A12 has only seven cases with a rain rate greater than $15 \mathrm{~mm} \mathrm{hr}^{-1}$, while the PR $2 \mathrm{~A} 25$ detects 103 inner cores with rain rates in the $15-40 \mathrm{~mm} \mathrm{hr}^{-1}$ range. These totals represent $53 \%$ of the PR $2 \mathrm{~A} 25$ and just $4 \%$ of the TMI 2A12 Category 3-5 inner cores. For Category 1-2 hurricanes, the PR 2A25 finds $16 \%$ of cases with a rain rate greater than $15 \mathrm{~mm} \mathrm{hr}^{-1}$ and not a single case for the TMI 2A12. The TMI 2A12 places the majority of hurricane ICs in the 5-15 $\mathrm{mm} \mathrm{hr}^{-1}$ range.

There are significant differences between this IC region-based distribution and the grid-based distribution in Cecil and Wingo (2009). For the $0.25^{\circ}$ grid scale, the $0-100 \mathrm{~km}$ PR 2A25 rain rate mode is always the $>0-1 \mathrm{~mm} \mathrm{hr}^{-1}$ bin for all intensities. Despite the abundance of low PR 2A25 rain rates, they found that about two-thirds of the mean Cat. 3-5 rain rate is derived from grids with rain rates greater than $15 \mathrm{~mm} \mathrm{hr}^{-1}$. In weaker storms, the PR 2A25 has a smaller fraction of heavy rain grids $\left(>15 \mathrm{~mm} \mathrm{hr}^{-1}\right)$ and more 

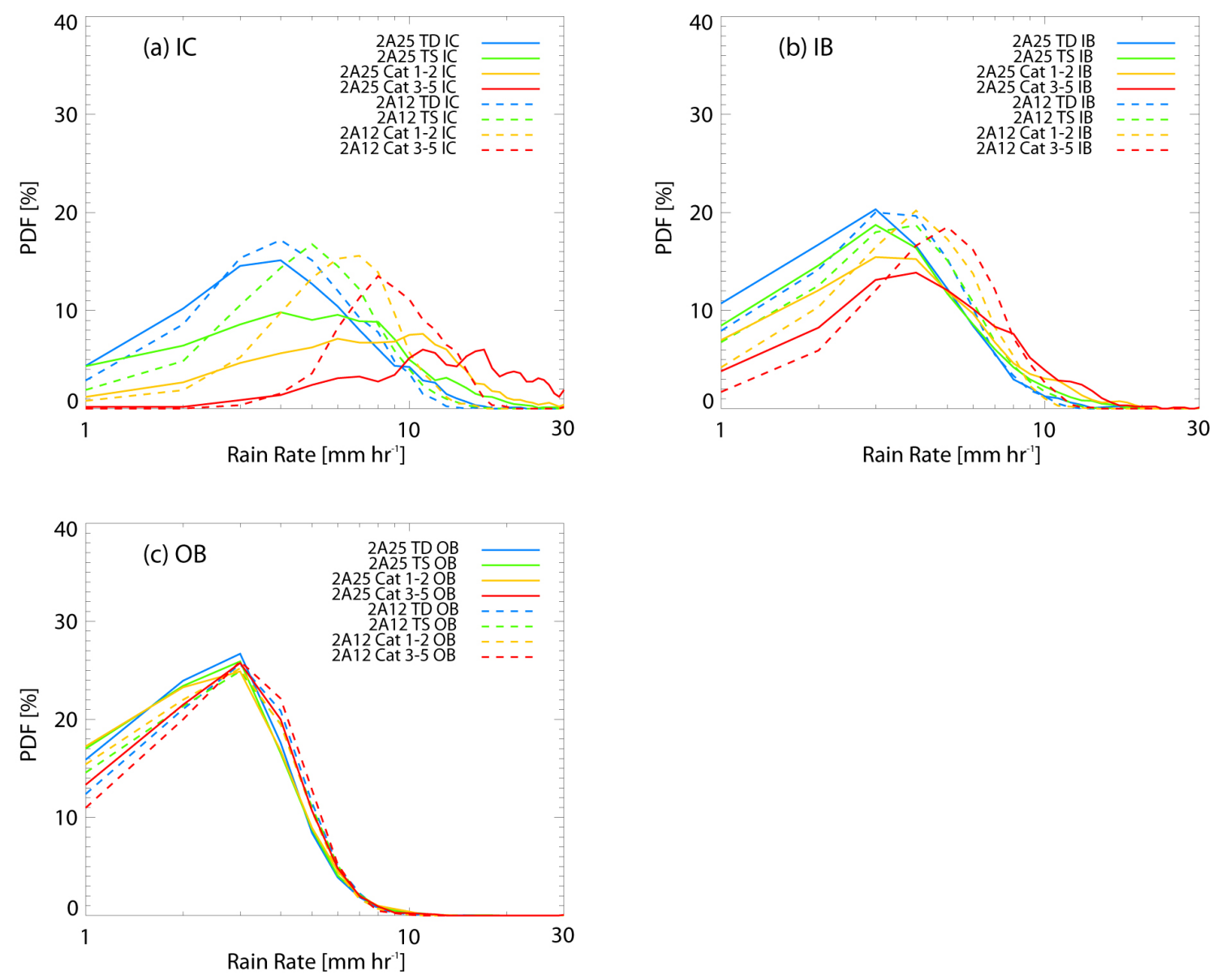

Figure 2.4: PDF of rain rate distributions for (a) IC, (b) IB, and (c) OB regions, divided by algorithm and intensity.

very light rain grids $\left(<3 \mathrm{~mm} \mathrm{hr}^{-1}\right)$. Therefore, the IC region PDF in Figure 2.4(a) peak in the mid-range because the relatively small sections of heavy PR 2A25 rain rates skew the histograms toward 5-15 $\mathrm{mm} \mathrm{hr}^{-1}$ rain rates, even though on a smaller grid or pixel level these rain rates are less common. For the TMI $2 \mathrm{~A} 12$, the $0.25^{\circ}$ grid-based rain rate histograms also show two separate peaks in hurricanes, but the higher peak is in the 5-15 $\mathrm{mm} \mathrm{hr}{ }^{-1}$ range. The region-based analysis is in fairly close agreement to the grid-based analysis for the TMI 2A12 except that the peak at low rain rates $\left(<2 \mathrm{~mm} \mathrm{hr}^{-1}\right)$ does not 
appear in this study because the low rain rates only contribute a small portion of the total rain rate and are averaged out when computing for the entire inner core.

Inner bands also exhibit broader PR 2A25 distributions compared with the TMI $2 \mathrm{~A} 12$, as the IB is still skewed slightly toward higher PR $2 \mathrm{~A} 25$ and TMI $2 \mathrm{~A} 12$ rain rates. There is not as much of a spread between different intensities in the IB, but the region of $10-20 \mathrm{~mm} \mathrm{hr}^{-1}$ rain rates is still largely absent for the TMI $2 \mathrm{~A} 12$. In the OB, the standard deviation is the lowest and there is almost no difference between the algorithms. The mode is always the $2-3 \mathrm{~mm} \mathrm{hr}^{-1}$ bin in the $\mathrm{OB}$ and does not increase with intensity like in the IC and IB. Overall, the storm-based PDFs are good compliments to the grid-based PDFs from Cecil and Wingo (2009). The grid-based PDFs show that each algorithm derives its mean rain rates from a different set of rain rates. The storm region-based PDFs show that each intensity category also consists of a climatologically wide range of mean rain rates, especially in the inner regions. The PR 2A25 suggests that an individual hurricane has a wider range of possible mean rain rates than what would be expected from the TMI $2 \mathrm{~A} 12$.

Volumetric rain distributions are displayed in Figure 2.5. In the IC, the spread is about the same in storms of TD and TS intensity, with good agreement between the algorithms. The only major difference is found in Category 3-5 hurricanes, which are skewed toward higher rain totals. The separation between the algorithms in hurricanes is caused by the long tail of PR 2A25 inner cores with volumetric rain greater than $4 \times 10^{4}$ $\mathrm{mmhr}^{-1} \mathrm{~km}^{-2}$. A similar pattern is observed in the inner bands, except with higher mean values and a larger spread between the intensity categories. The best agreement between the algorithms is found in the $\mathrm{OB}$. The $2 \mathrm{~A} 25$ does find more storms with small amounts 

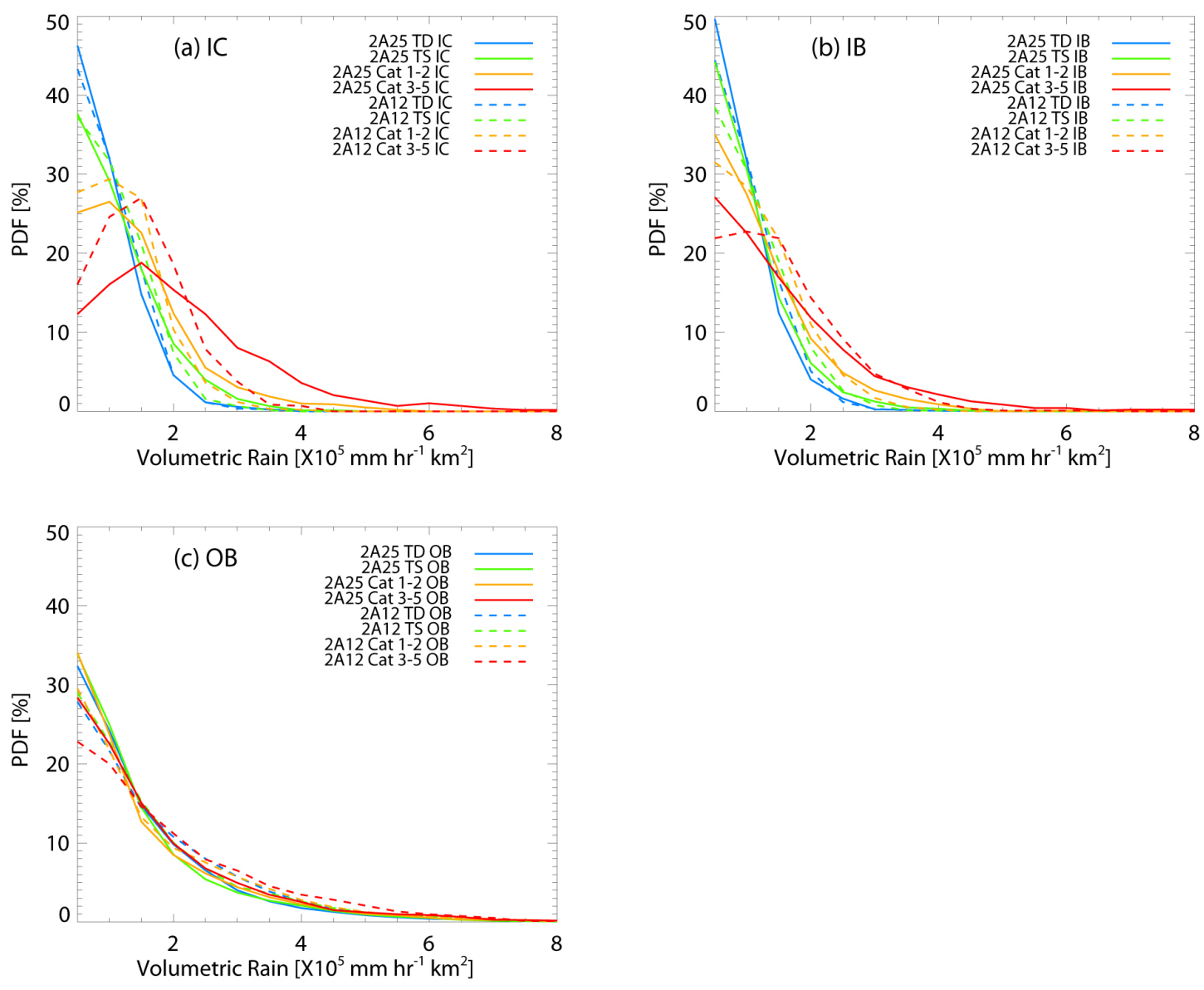

Figure 2.5: PDF of volumetric rain distributions for (a) IC, (b) IB, and (c) OB regions, divided by algorithm and intensity.

of rain, but the distributions are nearly equal in storms with more rain. Increased intensity produces almost no increase in $\mathrm{OB}$ volumetric rain.

\subsubsection{Algorithm Correlations}

Scatterplots of the volumetric rain, rain area, and rain rate (Figure 2.6) are useful for comparing the algorithms on a case-by-case basis. In panels (a), (b), and (c), the raining area is shown to be higher for the TMI $2 \mathrm{~A} 12$ almost every case for all three 

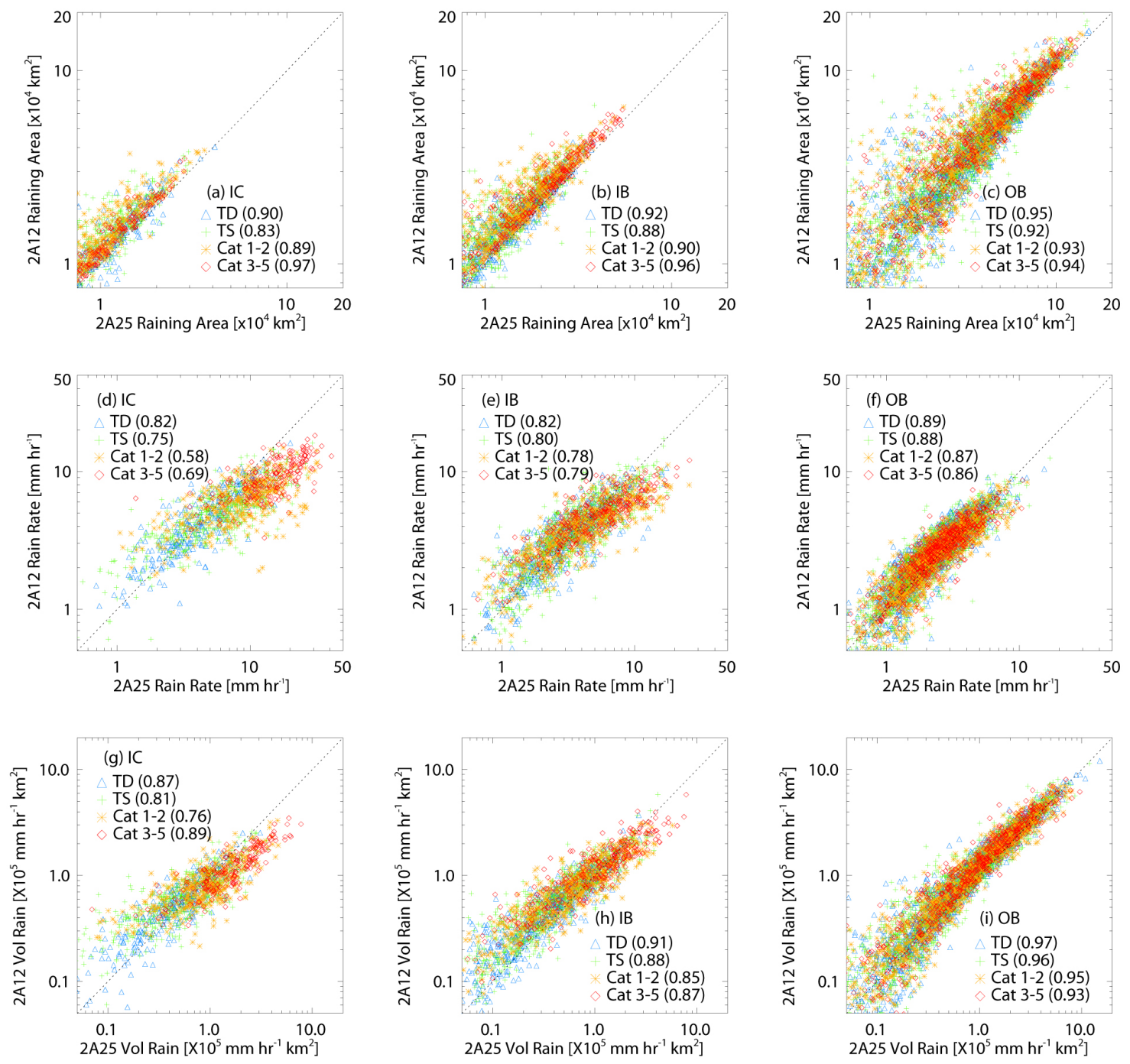

Figure 2.6: Scatterplots of PR 2A25 vs. TMI 2A12 raining area, rain rate, and volumetric rain, divided by IC, IB, and OB. Correlation coefficients are in parentheses for each intensity category.

regions. The algorithms correlate well, with a fairly uniform bias toward the TMI 2A12. Regions with a smaller raining area still strongly favor the TMI 2A12, although there is a little more spread than for larger raining areas. It is possible for the PR 2A25 area to be larger than the TMI 2A12, especially in the OB, but it usually only occurs in small, isolated areas where the PR detects extremely light rain. The uniform nature of the TMI 
$2 \mathrm{~A} 12$ bias suggests that the discrepancy between the raining areas is not related to the environmental conditions. Storm intensity and convective intensity (i.e., minimum 37 and $85 \mathrm{GHz}$ PCT) do not affect the correlations in any significant way.

The scatterplot for IC rain rate (2.6.d) shows a strong bias toward higher PR 2A25 rain rates, especially for intense storms with heavy PR 2A25 rain rates. Most Category 35 ICs have a higher PR 2A25 rain rate by a significant margin. In the most extreme cases, the IC rain rate is $20-30 \mathrm{~mm} \mathrm{hr}^{-1}$ greater than the TMI $2 \mathrm{~A} 12$. Still, many ICs including some hurricanes show very good agreement between the algorithms. In $58 \%$ of ICs, the algorithms are within $2 \mathrm{~mm} \mathrm{hr}^{-1}$ of each other. For rain rates above $10 \mathrm{~mm} \mathrm{hr}^{-1}$, the PR $2 \mathrm{~A} 25$ rain rate is almost always higher. If the rain rate is below $10 \mathrm{~mm} \mathrm{hr}^{-1}$, about one quarter of ICs have a higher TMI 2A12 rain rate. Most of the storms with lighter rain rates are below hurricane strength, so it is not surprising that the correlation coefficient is highest for weaker storms $(\geq 0.75)$.

In the IB, storms of different intensities are not as separated. Around one-half of IBs have a higher TMI 2A12 rain rate, the highest percentage for rain rate out of the three storm regions. As in the IC, the storms with higher PR 2A25 rain rate are still consistently biased toward the PR 2A25. Finally for the OB, the correlations are higher than in the IC or IB, but the scatterplot is shifted more consistently toward the PR 2A25 than in the other regions. Less than $10 \%$ of OBs have a higher TMI $2 \mathrm{~A} 12$ rain rate. The more tightly clustered rain rates in the $\mathrm{OB}$ are likely caused by the lack of large regions of heavy precipitation in the outer regions of TCs. The PR 2A25 rain rate rarely exceeds 10-12 $\mathrm{mm} \mathrm{hr}^{-1}$ in the OB. The grid-based scatterplot in Cecil and Wingo (2009) shows TMI 2A12 rain rates topping out at $10-15 \mathrm{~mm} \mathrm{hr}^{-1}$ within $100 \mathrm{~km}$ of the TC center. 
Higher PR 2A25 rain rates are less common in the outer bands, even for hurricanes, so the differences between the algorithms are less substantial.

Correlations are very high for volumetric rain, with values around $0.80-0.90$ in the IB and IC and over 0.90 in the OB. Storms in the IC are split almost exactly between having more PR 2A25 and more TMI 2A12 rain, with weak storms and lower volumetric rain values highly biased toward the TMI 2A12 and strong storms (especially Cat. 3-5 hurricanes) and higher volumetric rain values biased toward the PR 2A25. In the IB, the trend is similar but shifted more toward the TMI 2A12. There is also less of an intensity bias, with the majority of storms clustered in the middle and not separated by intensity. The OB has virtually no separation by intensity categories and the correlation coefficient is remarkably close to one, with almost no bias for high volumetric rain values. There is a slight bias towards the TMI $2 \mathrm{~A} 12$, as about $75 \%$ of outer bands have more TMI $2 \mathrm{~A} 12$ rainfall. For the storms with the most volumetric rain the bias still shifts slightly toward the PR 2A25. As a whole, the volumetric rain agrees best between the algorithms because of a higher TMI 2A12 raining area multiplied by higher PR 2A25 rain rates. Light rain rates favor more TMI 2A12 volumetric rain. Heavier rain rates favor more PR 2A25 volumetric rain.

2.4. Rain rate in relation to convective parameters

\subsubsection{5 and $37 \mathrm{GHz}$ PCT}

The raining area, rain rate, and volumetric rain plots provide a comprehensive analysis of the differences in algorithm retrievals between TC regions with various intensities. The remainder of this paper shifts focus to finding physical insights that can 
help to explain variations in the observed rainfall retrievals. For the PR, the relationship between rain rate and near-surface reflectivity is relatively straightforward. The percentage of raining area greater than 20,30 , and $40 \mathrm{dBZ}$ quantifies the relative frequency of light, moderate, and heavy rain. The TMI 2A12 algorithm is less direct since it employs Bayesian probability to retrieve the rain rate from the full set of brightness temperatures at multiple TMI frequencies. Low frequency emission-based channels (10.7, $19 \mathrm{GHz})$ are most sensitive to near-surface rainfall and do not saturate until they reach high rain rates $>25 \mathrm{~mm} \mathrm{hr}^{-1}$. Unfortunately, the low frequency channels have a much lower resolution than the TMI $2 \mathrm{~A} 12$ pixel size, so they are not capable of resolving any finer-scale details of TC precipitation (Kummerow et al. 1996). Higher frequency scattering-based channels $(37,85 \mathrm{GHz})$ have a better resolution, but are sensitive mostly to ice-scattering in the upper levels of the cloud. The $85 \mathrm{GHz}$ frequency is the only channel with the same horizontal resolution as the TMI $2 \mathrm{~A} 12$ algorithm, so its properties are of most interest to understanding the TMI $2 \mathrm{~A} 12$ rain retrievals. The 85 and $37 \mathrm{GHz}$ PCT are also commonly used as measures of convective intensity, as the PCT values can drop precipitously in deep convection with strong ice scattering.

One convenient analysis method is to evaluate the mean distributions of various raining/convective parameters. Table 2.2 displays results for the percent coverage 85 and $37 \mathrm{GHz}$ PCT and 20,30, and $40 \mathrm{dBZ}$ reflectivity thresholds relative to raining area. All of the parameters have the highest percent coverage in the IC and the lowest in the OB. The parameters that represent more intense convection (lower PCT, higher reflectivity) represent a smaller portion of each storm compared with the parameters representing light or moderate rain (higher PCT, lower reflectivity). In the IC, Cat. 3-5 Hurricanes have the 

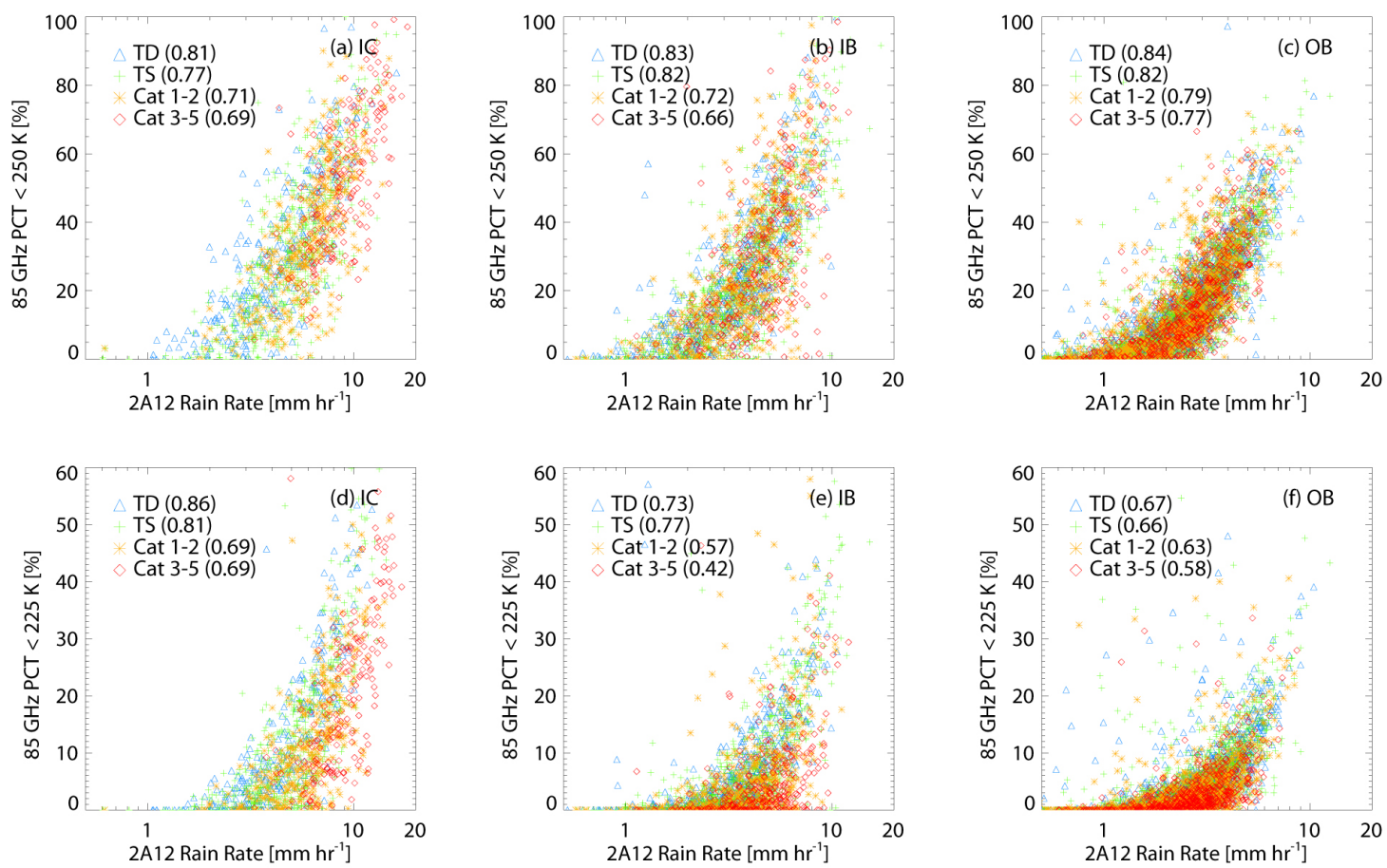

Figure 2.7: Scatterplots of TMI 2A12 rain rate vs. percent coverage of $85 \mathrm{GHz} \mathrm{PCT}<250$ and $225 \mathrm{~K}$. Plots are divided by IC, IB, and OB storm regions.

highest percentage of all of the displayed parameters, but the difference is most significant for $85 \mathrm{GHz}$ PCT $<250$ and $225 \mathrm{~K}$ and $37 \mathrm{GHz}$ PCT $<275 \mathrm{~K}$. This result is consistent with Cecil and Zipser (1999), who also found aerial coverage of $85 \mathrm{GHz}$ PCT $<250 \mathrm{~K}$ in the IC region to be correlated with stronger storm intensity. Notably, the IC coverage of $85 \mathrm{GHz}$ PCT $<250 \mathrm{~K}$ changes little between TDs, TSs, and Cat. 1-2 hurricanes. The IC coverage of $85 \mathrm{GHz}$ PCT $<225 \mathrm{~K}$ actually has a slight decrease in Cat. 1-2 hurricanes compared with TDs and TSs. Category 3-5 hurricanes show a significant jump in $85 \mathrm{GHz} \mathrm{PCT}<250 \mathrm{~K}$ coverage, up over $15 \%$ from Cat. 1-2 hurricanes. The same pattern is observed for $85 \mathrm{GHz}$ PCT $<225 \mathrm{~K}$ coverage, with a jump 
from $12.7 \%$ to $20.6 \%$ between hurricanes and major hurricanes. Parameters indicative of stronger ice scattering $(85 \mathrm{GHz}$ PCT $<200 \mathrm{~K}, 37 \mathrm{GHz} \mathrm{PCT}<250 \mathrm{~K})$ also show the same pattern in the IC. The lowest coverage occurs in Cat. 1-2 hurricanes and the highest coverage is in Cat. 3-5 hurricanes. However, the coverage of deeper convection is relatively limited, averaging less than $6 \%$ of raining area at most. A sizeable portion of the ICs (about a quarter of TD, TS, and Cat. 1-2 and 15\% of Cat. 3-5) have a minimum $85 \mathrm{GHz}$ PCT above $200 \mathrm{~K}$, indicating no deep convection at all. The $85 \mathrm{GHz}$ PCT only drops below $175 \mathrm{~K}$ in about half of all ICs.

The coverage of TMI convective parameters in the IB is similar to the IC with a few notable exceptions. The percent coverage of $85 \mathrm{GHz}$ PCT $<275$ and $250 \mathrm{~K}$ show modest increases for Cat. 3-5 hurricanes, but the coverage of $85 \mathrm{GHz}$ PCT $<225 \mathrm{~K}$ is actually highest in weaker storms, both in terms of physical area $\left(\mathrm{km}^{2}\right)$ and percentage of raining area. The relative lack of convection in hurricane inner bands was first observed using lightning data by Molinari et al. (1999) and is documented using a TRMM convective parameters similar to this study by Jiang et al. (2012). The convective minimum in the inner bands indicates that the ratio of stratiform rain to convective rain is higher in the inner bands than the inner core. In the $\mathrm{OB}$, the convective parameters show little change between intensity categories. Only about one-sixth of the OB raining area has an $85 \mathrm{GHz}$ PCT below $250 \mathrm{~K}$ and less than $5 \%$ of OB raining area meets the $85 \mathrm{GHz}$ $<225 \mathrm{~K}$ criteria for moderate rain. The percentage coverage by deep convection in the OB region is about the same as the IB, as the minimum $85 \mathrm{GHz}$ PCT drops below 200 and $175 \mathrm{~K}$ in about the same fraction of outer bands as inner bands. 
All of the 85 and $37 \mathrm{GHz}$ PCT coverage parameters can be compared with the TMI 2A12 rain rate for each respective storm. Only the higher PCT values can be correlated with rain rate, as the lower values $(85 \mathrm{GHz} \mathrm{PCT}<200 \mathrm{~K}, 37 \mathrm{GHz} \mathrm{PCT}<250$ K) have coverage too low to be significant. The two parameters with the best correlation are displayed in Figure 2.7: the coverage of $85 \mathrm{GHz}$ PCT $<250$ and $225 \mathrm{~K}$. In the IC, the TMI 2A12 rain rate retrievals are well correlated with the coverage of $85 \mathrm{GHz} \mathrm{PCT}<250$ and $225 \mathrm{~K}$. In the IB and $\mathrm{OB}$, the rain rate correlates best with the area of $85 \mathrm{GHz}$ PCT $<$ $250 \mathrm{~K}$. Weaker storms (tropical depressions and storms) tend to have a higher correlation than hurricanes. For 85 and $37 \mathrm{GHz} \mathrm{PCT}<275 \mathrm{~K}$ (not pictured), the correlations between percent coverage and TMI $2 \mathrm{~A} 12$ rain rate are still fairly high (0.4-0.7), but not as high as the scatterplots in Figure 2.7. In general, there is not much difference in scatter between storms of different intensities. In the IC, Category 3-5 hurricanes tend to have higher rain rates and convective coverage, which clusters the points and lowers the correlation coefficient. Differences are more subtle in the OB. Category 3-5 OBs actually show the opposite tendency and rarely have more than $20 \%$ coverage of $85 \mathrm{GHz} \mathrm{PCT}<225 \mathrm{~K}$. The physical area of $85 \mathrm{GHz}$ PCT $<225 \mathrm{~K}$ does actually slightly expand in Cat 3-5 OBs relative to TD OBs, but the increase is offset by a larger increase in the raining area. The outer bands consist of mostly warm PCTs (about $85 \%$ of raining area $>250 \mathrm{~K}$ ) and only isolated patches of ice scattering with little relation to storm intensity. Deep convection is localized and is likely not a strong contributor to the difference in PR 2A25 and TMI $2 \mathrm{~A} 12$ rain rates. In the IB and $\mathrm{OB}$, the deep convective bursts that trigger $85 \mathrm{GHz} \mathrm{PCT}$ values below $200 \mathrm{~K}$ are no more widespread in intense hurricanes than they are in tropical depressions or storms. 


\begin{tabular}{|l|l|c|c|c|c|c|c|c|c|c|}
\hline Region & Intensity & $\begin{array}{l}85 \mathrm{GHz} \\
\mathrm{PCT}< \\
275 \mathrm{~K}\end{array}$ & $\begin{array}{l}85 \mathrm{GHz} \\
\mathrm{PCT}< \\
250 \mathrm{~K}\end{array}$ & $\begin{array}{l}85 \mathrm{GHz} \\
\mathrm{PCT}< \\
225 \mathrm{~K}\end{array}$ & $\begin{array}{l}85 \mathrm{GHz} \\
\mathrm{PCT}< \\
200 \mathrm{~K}\end{array}$ & $\begin{array}{l}37 \mathrm{GHz} \\
\mathrm{PCT}< \\
275 \mathrm{~K}\end{array}$ & $\begin{array}{l}37 \mathrm{GHz} \\
\mathrm{PCT}< \\
250 \mathrm{~K}\end{array}$ & $\begin{array}{l}\text { PR refl. } \\
>20 \\
\mathrm{dBZ}\end{array}$ & $\begin{array}{l}\text { PR refl. } \\
>30 \\
\mathrm{dBZ}\end{array}$ & $\begin{array}{l}\text { PR refl. } \\
>40 \\
\mathrm{dBZ}\end{array}$ \\
\hline IC & TD & 70.4 & 30.7 & 11.7 & 4.9 & 43.6 & 1.6 & 48.5 & 24.2 & 4.2 \\
\hline & TS & 68.3 & 31.5 & 12.8 & 5.4 & 47.7 & 1.8 & 50.4 & 27.7 & 5.9 \\
\hline & Cat 1-2 & 76.9 & 36.4 & 12.7 & 4.1 & 59.4 & 1.2 & 52.5 & 33.2 & 8.3 \\
\hline & Cat 3-5 & 85.8 & 52.1 & 20.6 & 6.2 & 73.1 & 2.1 & 57.0 & 41.3 & 12.2 \\
\hline & & & & & & & & & & \\
\hline IB & TD & 63.2 & 23.0 & 6.7 & 2.3 & 35.3 & 0.8 & 42.4 & 18.6 & 2.3 \\
\hline & TS & 62.4 & 24.2 & 7.7 & 2.2 & 42.3 & 0.8 & 44.1 & 21.0 & 2.7 \\
\hline & Cat 1-2 & 70.2 & 26.2 & 5.6 & 1.1 & 53.5 & 0.5 & 46.5 & 23.6 & 3.1 \\
\hline & Cat 3-5 & 79.2 & 30.9 & 5.7 & 1.0 & 59.7 & 0.6 & 47.6 & 25.7 & 3.1 \\
\hline & & & & & & & & & & \\
\hline OB & TD & 52.0 & 15.6 & 4.4 & 1.7 & 25.2 & 0.7 & 35.4 & 13.4 & 1.4 \\
\hline & TS & 50.8 & 15.4 & 4.2 & 1.5 & 29.0 & 0.6 & 35.3 & 13.7 & 1.4 \\
\hline & Cat 1-2 & 51.1 & 15.5 & 3.3 & 1.0 & 33.3 & 0.5 & 35.2 & 13.7 & 1.4 \\
\hline & Cat 3-5 & 55.3 & 16.6 & 3.1 & 0.9 & 35.2 & 0.3 & 35.4 & 13.8 & 1.3 \\
\hline
\end{tabular}

Table 2.2: Percentage of raining pixels meeting various convective thresholds. For 85 and $37 \mathrm{GHz}$ PCT criteria, the percent is calculated relative to TPF raining pixels. For PR reflectivity criteria, the percent is calculated relative to RPF raining pixels. All values are sorted by storm region and intensity. 


\subsubsection{0, 30, and 40 dBZ PR Reflectivity}

Using the TRMM Precipitation Radar, the percent coverage of near-surface reflectivity greater than 20,30, and $40 \mathrm{dBZ}$ relative to PR $2 \mathrm{~A} 25$ raining area is displayed in Table 2.2. As expected, the largest portions of high reflectivities occur in the IC. Nevertheless, around half of the IC has a PR reflectivity below $20 \mathrm{dBZ}$, indicating very light rain rates of approximately $1 \mathrm{~mm} \mathrm{hr}-1$ or less. About one-sixth of the included PR pixels have zero rain but are included when downgrading the resolution to match the TMI. The IC coverage of $>20 \mathrm{dBZ}$ reflectivity increases gradually with intensity, while the $>30$ and $40 \mathrm{dBZ}$ coverage increases significantly for stronger storms. For $30 \mathrm{dBZ}$, coverage increases from $24 \%$ to $41 \%$ between TD and Cat 3-5 ICs. Coverage of reflectivity above $40 \mathrm{dBZ}$ rises from $4 \%$ in TDs to $12 \%$ in Cat 3-5 hurricanes. The coverage for Cat $1-2$ hurricanes is more separated from tropical storms than it is for $85 \mathrm{GHz}$ PCT $<225$ and $250 \mathrm{~K}$. The IB and OB both have modest decreases in reflectivity coverage. The OB is the most uniform between intensity categories. The PR 2 A25 rain rate can also be correlated with the coverage of PR reflectivity greater than 20,30, and $40 \mathrm{dBZ}$, as displayed in Figure 2.8. The correlation coefficient is always highest for the $40 \mathrm{dBZ}$ category, not a surprising result since heavy rain contributes most to the mean rain rates. Correlations are always between 0.8 and 0.9 , regardless of intensity. For the lower reflectivity categories, the spread increases and the correlation coefficients drop. The 20 $\mathrm{dBZ}$ coverage does correlate fairly well with mean rain rate in the $\mathrm{OB}$, but in the inner regions, the higher prevalence of $>30 \mathrm{dBZ}$ echoes becomes the dominant signal. 

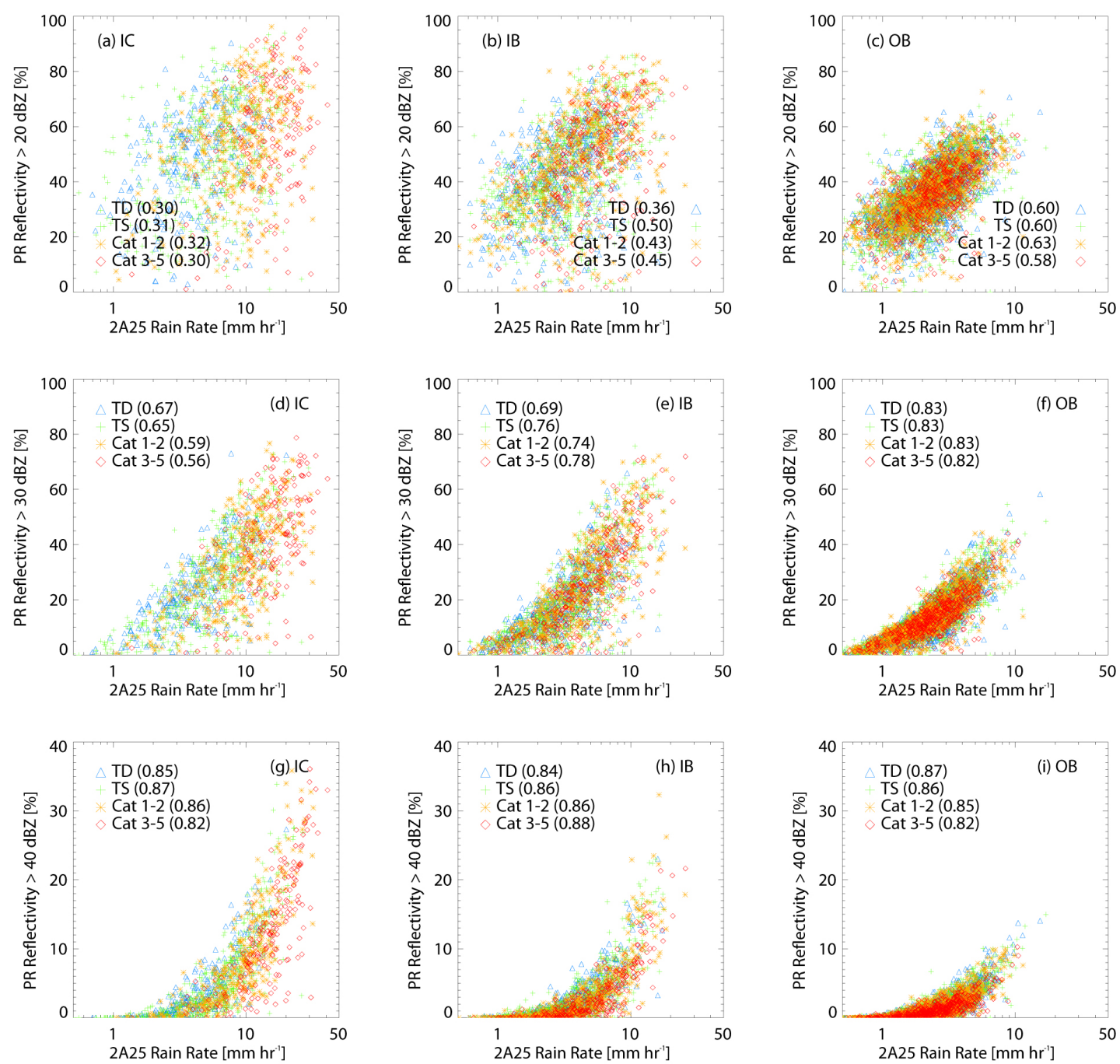

Figure 2.8: Scatterplots of PR 2A25 rain rate vs. percent coverage of PR reflectivity $>20,30$, and $40 \mathrm{dBZ}$. Plots are divided by IC, IB, and OB storm regions.

\subsubsection{Relating convective parameters to algorithm differences}

To examine whether the difference between the PR 2A25 and TMI 2A12 rain estimates can be given as a function of convective parameters, correlation coefficients are calculated between the difference of the PR 2A25 and TMI 2A12 rain estimates and the percent coverage of 37 and $85 \mathrm{GHz}$ PCT less than certain values or PR reflectivity 

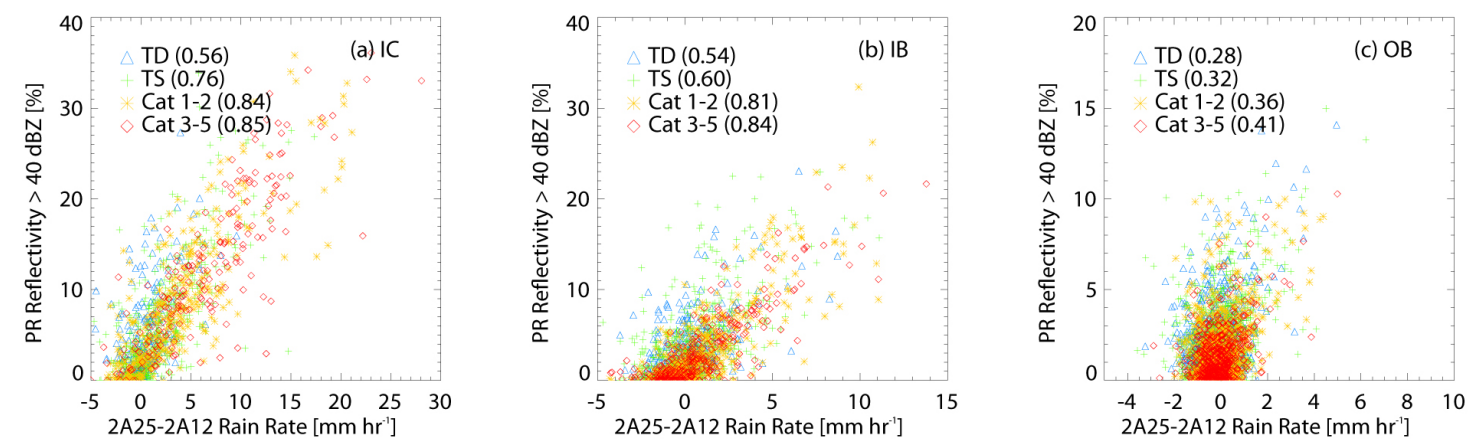

Figure 2.9: Scatterplots of the difference in PR and TMI rain rate (2A25 minus 2A12) vs. percent coverage of PR reflectivity greater than $40 \mathrm{dBZ}$ for (a) IC, (b) IB, and (c) OB regions.

greater than certain values. Not surprisingly, the percent coverage of 37 and $85 \mathrm{GHz}$ PCT is not strongly related to the difference in rain rates. The storm regions that have a large difference in rain rate have a highly variable coverage of the various PCT parameters and there is no evidence that the $37 / 85 \mathrm{GHz}$ channels have any additional insight to improve the TMI rain retrieval. Conversely, the coverage of PR reflectivity is more closely related to the rain rate difference, especially $40 \mathrm{dBZ}$, as pictured in the scatterplots in Figure 2.9. A distinctive linear relationship exists between the difference in rain rate and the percent coverage of PR reflectivity $>40 \mathrm{dBZ}$. Correlations are highest in hurricane inner cores and inner bands $(\geq 0.80)$, while the outer band region has much lower correlations. The large difference in the algorithms is mostly caused by the TMI significantly underestimating these areas of heavy rain. Weaker storms do not have as strong of a relationship between algorithm differences and heavy rain because most only have a small percentage $(<10 \%)$ of rain with a PR reflectivity higher than $40 \mathrm{dBZ}$. 


\subsection{Discussion and Conclusions}

Using the Tropical Cyclone Precipitation Feature (TCPF) database, TRMM overpasses of TCs over ocean are divided into the inner core (IC), inner band (IB) and outer band $(\mathrm{OB})$ regions. Rainfall and convective parameters are then calculated for each region. Emphasis is placed on comparing conditional rain rates because they are a direct estimate that does not depend on the orbital coverage. The PR 2A25 produces larger mean rain rates than the TMI $2 \mathrm{~A} 12$ in the inner core and inner bands, with the difference always increasing with greater storm intensity. In hurricane ICs, the PR 2A25 mean rain rate is nearly double the TMI $2 \mathrm{~A} 12$ mean rain rate. In the outer bands, the algorithms show good agreement on rain rates, with the PR 2A25 measuring slightly higher rain rates than the TMI 2A12 in hurricanes and slightly lower rain rates than the TMI 2A12 in storms below hurricane strength. The outer bands of tropical depressions are most similar to the ambient, non-TC related tropical oceanic environment, which is known to have generally higher TMI 2A12 rain rates when averaged over monthly or annual time scales. In these outer rainband regions, the predominant source of disagreement is rainfall detection. The larger disagreements in inner areas are related to rainfall intensity.

Because the TMI 2A12 has consistently larger raining areas, the volumetric rain (rain rate multiplied by raining area) is useful as an independent parameter to compare the total rainfall measured by the algorithms. The PR $2 \mathrm{~A} 25$ volumetric rain is greater than the TMI 2A12 only in the inner regions (IC and IB) of Category 3-5 hurricanes. In all storm regions, the TMI 2A12 volumetric rain exceeds the PR 2A25. The differences in volumetric rain arise because the greatest contribution to the mean rain rate comes from much higher maximum rain rates for the PR 2A25 compared with the TMI 2A12 (Cecil 
and Wingo 2009). The algorithms show the greatest disagreement when a large percentage of heavy rain is present, sometimes disagreeing by a mean rain rate of 20-30 $\mathrm{mm} \mathrm{hr}{ }^{-1}$ in hurricane inner cores. The TMI $2 \mathrm{~A} 12$ rarely detects rain rates about $15 \mathrm{~mm}$ $\mathrm{hr}^{-1}$, while the PR 2A25 can reach 40-50 $\mathrm{mm} \mathrm{hr}^{-1}$ averaged over some inner cores because of its better sensitivity to high rain rates.

Despite large differences in the mean rain rates of hurricane inner cores, in $58 \%$ of ICs, the algorithms are within $2 \mathrm{~mm} \mathrm{hr}^{-1}$ of each other. Specifically, the difference between the algorithms (PR 2A25 minus TMI 2A12) is most closely correlated with the percent coverage of PR reflectivity greater than $40 \mathrm{dBZ}$. The large difference in the algorithms is mostly caused by the TMI significantly underestimating moderate to heavy rain. In the IC, the TMI $2 \mathrm{~A} 12$ rain rate retrievals are more closely correlated with the area of $85 \mathrm{GHz}$ PCT $<225 \mathrm{~K}$ (relative to raining area). In the $\mathrm{IB}$ and $\mathrm{OB}$, the rain rate correlates best with the area of $85 \mathrm{GHz}$ PCT $<250 \mathrm{~K}$. The TMI $2 \mathrm{~A} 12$ rain rate also correlates well with the aerial coverage of $37 \mathrm{GHz}$ PCT $<275 \mathrm{~K}$, especially in outer bands and weaker storms. These convective parameters are good predictors of the mean TMI 2A12 rain rate, but they are poor indicators of the high PR 2A25 rain rates that cause the largest differences between the algorithms. Significant ice scattering is not a strong indicator that a $\mathrm{TC}$ will have high mean rain rates.

It is necessary to consider the $85 \mathrm{GHz}$ channel in order to achieve high resolution rainfall retrievals. The downside is that the $85 \mathrm{GHz}$ PCT is not an effective estimator of rain rates above about $15 \mathrm{~mm} \mathrm{hr}^{-1}$. Higher rain rates are detectable when a deep convective burst creates strong ice scattering, but other uncertainties remain such as upper level winds can displace the ice scattering downshear of the low-level rain. Strong 
ice scattering $(85 \mathrm{GHz} \mathrm{PCT}<225 \mathrm{~K})$ is sometime isolated and is not always present in heavy rain. Large areas of heavy precipitation are common in the IC and IB regions, often without enough ice scattering above the precipitation to significantly depress the brightness temperature. The ice scattering can also look about the same, but with only light precipitation below. In outer bands, heavy rain is usually both isolated and associated with strong $85 \mathrm{GHz}$ ice scattering. As a result, the TMI 2A12 and PR 2A25 agree better when estimating outer band rain rates.

Based on these results, several possibilities for improving the TMI $2 \mathrm{~A} 12$ algorithm appear promising. The latest version of the TMI 2A12 algorithm (version 7) includes the addition of PR vertical profiles to the TMI Bayesian precipitation profiles, which appears to reduce uncertainties in the TMI brightness temperate - rain rate relationship and improve the detection of moderate rain in the $15-25 \mathrm{~mm} \mathrm{hr}^{-1}$ range. The PR is especially useful for identifying the regions where the TMI $2 \mathrm{~A} 12$ is most significantly underestimating rain rates. Another option to consider is lowering the TMI 2A12 resolution to the $37 \mathrm{GHz}$ or $19 \mathrm{GHz}$ footprint. In TC rainfall, the $37 \mathrm{GHz}$ channel is most sensitive in the $260-270 \mathrm{~K}$ range, although the combination of emission and scattering from both rain and ice hydrometers makes quantitative interpretation challenging. The relationship between the $37 \mathrm{GHz}$ channel and rain rates is being investigated in more detail. Lowering the resolution below the $19 \mathrm{GHz}$ footprint size prevents the rain bands from being adequately resolved. Finally, it may be advantageous to consider TCs as a separate regime with a modified TMI algorithm.

This study highlights several important issues pertaining to those using TMI 2A12 V6 in Tropical Cyclones. Previous studies that use the TMI 2A12 algorithm to quantify 
the mean spatial distribution of precipitation (i.e., Lonfat et al. 2004; Chen et al. 2006) likely underestimate the rainfall in the inner 100-200 km of hurricanes. Because the areas of heaviest rain are localized, it is likely that asymmetric TCs have a higher percentage of their rainfall in the favored quadrants than what is inferred with the TMI 2A12. Since there are now over 14 years of PR data available, some aspects of these studies will be reconsidered using the PR 2A25 algorithm instead. The TMI 2A12 also fails to capture the high storm-to-storm variability of mean IC rainfall in hurricanes, as indicated in Figure 2.4(a). In order for the TMI $2 \mathrm{~A} 12$ to be applied to a small or localized set of case studies, it needs to be able to better resolve the unique properties of each individual storm, especially in extreme precipitation events. Computing the magnitude and extent of the heaviest precipitation areas is of utmost importance for determining the location and strength of a TC's inner regions and for assessing the flood potential as a storm approaches landfall. Continued improvement of the TMI 2A12 algorithm will allow for passive sensors to be more effectively utilized for these applications. 
3. INVESTIGATION OF PR AND TMI VERSION 6 AND VERSION 7 RAINFALL ALGORITHMS IN LANDFALLING TROPICAL CYCLONES RELATIVE TO THE NEXRAD STAGE-IV MULTI-SENSOR PRECIPITATION ESTIMATE DATASET

Abstract:

Rainfall estimates from Version 6 and Version 7 of the TRMM Precipitation Radar (PR) 2A25 and Microwave Imager (TMI) 2A12 algorithms are compared relative to the NEXRAD Multi-sensor Precipitation Estimate Stage-IV (MPE-IV) hourly rainfall product. The dataset consists of 252 TRMM overpasses of Tropical Cyclones from 20022010 within a $230 \mathrm{~km}$ range of Southeast US WSR-88D radar sites. All rainfall estimates are averaged to a uniform 1/7 degree square grid. The grid boxes are also divided by their TMI surface designation (land, ocean, or coast). A detailed statistical analysis is undertaken to determine how changes to the TRMM rainfall algorithms in the latest version (V7) are influencing the rainfall retrievals relative to ground reference data. Version 7 of the PR 2A25 is the best performing algorithm over all three surface types. Over ocean, TMI $2 \mathrm{~A} 12 \mathrm{~V} 7$ is improved relative to V6 at high rain rates. At low rain rates, the new ocean TMI V7 probability of rain parameter creates ambiguity in differentiating light rain $\left(\leq 0.5 \mathrm{~mm} \mathrm{hr}^{-1}\right)$ and non-raining areas. Over land, TMI V7 underestimates MPE-IV more than V6 at a wide range of rain rates, resulting in an increased negative bias. Both versions of the TMI coastal algorithm are also negatively biased at both moderate and heavy rain rates. Some of the TMI biases can be explained by uncertain relationships between rain rate and $85 \mathrm{GHz}$ ice scattering. 


\subsection{Introduction}

The recent release of Version 7 of the Tropical Rainfall Measuring Mission (TRMM) Precipitation Radar (PR) 2A25 and Microwave Imager (TMI) 2A12 rainfall algorithms presents an opportunity to compare the new version (V7) to the previous release (V6). It is commonly accepted that these algorithms perform well on large spatial and temporal scales, but they often have more significant local errors that are problematic on a case by case basis. These errors tend to be amplified in tropical cyclones (TCs), which produce anomalously high rain rates that are difficult to capture using passive microwave techniques. Since inland flooding is a major cause of deaths and damages in TCs, satellite precipitation algorithms have potential to be a valuable tool for forecasters to pinpoint the location of the heaviest rainfall ahead of a TC landfall, when the storm is still out of range of ground-based radar. Combined algorithms like the TRMM Multisatellite Precipitation Analysis (TMPA; Huffman et al. 2007) also use microwave algorithms similar to the TMI $2 \mathrm{~A} 12$ as a data source and for calibration. Over the open ocean, satellite-derived precipitation algorithms are the best tool for real-time precipitation analysis. Numerical weather prediction (NWP) output can also provide rainfall information, but it often has questionable accuracy in convective systems including TCs (Ebert et al. 2007). The main goal of this study is to quantify the errors and sources of bias in the TRMM precipitation algorithms using a surface reference dataset. This study investigates TCs, which represent a specific meteorological regime that is individually selected from the monthly and annual datasets. Interpreting satellite precipitation algorithms for a particular regime can be difficult because the algorithms have higher levels of uncertainty on smaller scales. Biases in the algorithm code that are 
usually negligible may be accentuated in tropical cyclones. In order to reduce any variance related to a particular storm, this study uses a large dataset of 252 TRMM overpasses of TCs near land, landfalling TCs, and post-landfall TCs across the entire Southeast US.

Satellite precipitation algorithms are usually divided into three categories: ocean, land, and coast. Ocean algorithms derived from microwave radiometer measurements can use both low-frequency emission-based channels and high-frequency scattering-based channels. Land algorithms can only use the high-frequency scattering channels, as high and variable land surface emissivity combine to mask the emission signature of liquid precipitation. Coastal algorithms rely mostly on scattering-based channels while removing artificial rain signatures associated with different fractions of land and ocean in each microwave footprint (McCollum and Ferraro 2004). Retrieval over land is more difficult without the emission channels, as the scattering signatures characterize processes higher in the cloud that do not directly relate to surface rainfall (Wilheit et al. 2003). Oceanic algorithms are also dependent on the scattering channels in order to achieve a higher resolution than the emission channels can independently provide. The difference between land and ocean causes fewer uncertainties in the Precipitation Radar algorithm, although variations in the surface cross section can bias the rain rate. Over ocean, the backscatter is related to sea surface wind; while over land, a soil surface and vegetation backscattering model must be used (Seto and Iguchi 2007). The PR's $2.17 \mathrm{~cm}$ wavelength (13.8 GHz frequency) also results in attenuation, especially in heavy rainfall (Iguchi et al. 2000). 
Version 7 is relatively new, so most previous studies compare Version 6 relative to reference data. Studies that use instantaneous data are most relevant to this work, along with seasonal comparisons focusing on the summer, fall, and/or wet season. Wolff and Fisher (2008) evaluated PR and TMI V6 at the TMI footprint scale over land, ocean, and coast at the TRMM Ground Validation (GV) sites. They found that PR V6 underestimates rainfall relative to $\mathrm{GV}$, with the most significant underestimation occurring over land and coast and at rain rates greater than about $10-20 \mathrm{~mm} \mathrm{hr}^{-1}$. The TMI V6 underestimates GV and PR over ocean and coast at both lower and high rain rates, but is greater than the PR for $>20 \mathrm{~mm} \mathrm{hr}^{-1}$ rain rates over land. Wang et al. (2009) highlighted several known TMI V6 inconsistencies over land, including overestimation in deep convection and underestimation in warm rain regimes relative to PR V6 and rain gauges. Gopalan et al. (2010) describes the steps taken in the TMI V7 land algorithm to correct these issues. Specifically, they added a more comprehensive set of TMI-PR collocations to improve the relationship between TMI rain rates and the $85 \mathrm{GHz}$ channel. Their results show that while TMI V7 improves on the global "wet" bias, it does not reduce regional biases that are driven mostly by surface screening, emissivity, warm rainfall, and deep convection. They also stress that since the TMI algorithm is trained using PR data, it is important to perform validations using an independent dataset. The main changes to PR V7 include several adjustments to the attenuation correction and the implementation of a new drop size distribution model. The most significant change to the TMI V7 ocean algorithm is the addition of a probability of precipitation parameter. Pixels are no longer screened as raining or nonraining before the Bayesian scheme is applied. As a result, many pixels that were previously classified as nonraining in V6 are now 
assigned a percent probability of rain with a nonzero raining rate in V7. The algorithm documentation recommends using a 50\% probability of rain threshold in the field of view when comparing instantaneous PR and TMI rain rates (NASA GFSC, 2012). Over land, pixels are still screened as raining or nonraining. The only change to the TMI coastal algorithm is a change in the land/ocean classification (see section 2.c). Use of the MPEIV reference (discussed in section 2.a) in this study allows for independent evaluation of all 4 TRMM algorithms (PR V6, PR V7, TMI V6, and TMI V7).

\subsection{Data}

\subsubsection{Databases}

This study utilizes satellite data from TRMM and ground-based radar data from the NEXRAD Multisensor Precipitation Estimates (MPE) product (Fulton et al. 1998; Fulton 2002). The multisensor radar estimates are derived from a combination of Weather Surveillance Radar-1988 Doppler (WSR-88D) radar precipitation estimates (Fulton et al. 1998) and real-time surface rain gauge observations from the Hydrometeorological Automated Data System (HADS). Specifically, this study uses the Stage IV dataset, which is a mosaicked national product available from the National Center for Environmental Prediction (NCEP). The Stage-IV data is convenient because it combines precipitation data from the regional forecasting centers (RFCs) into a single product available in an hourly format. A major advantage of the MPE-IV dataset is that it covers a larger geographical area than the TRMM Ground Validation (GV) program (Wolff et al. 2005). Previous studies have identified various biases within the MPE-IV dataset. By comparing two MPE-IV pixels with rain gauges at an hourly time scale, 
Habib et al. (2009b) found a conditional bias, with overestimation at rain rates less than $0.5 \mathrm{~mm} \mathrm{hr}^{-1}$ and underestimation at rain rates greater than $10 \mathrm{~mm} \mathrm{hr}^{-1}$. The MPE-IV hourly estimates correlate well with surface rain gauges (0.8-0.9), with more scatter and lower correlations at light rain rates. The main concern for this study is the high event scale bias which was found to reach up to $\pm 25 \%$ of the event total rainfall in half of events.

The MPE-IV data is compared with two TRMM rainfall algorithms, the Precipitation Radar (PR) 2A25 algorithm (Iguchi et al. 2001) and the TRMM Microwave Imager (TMI) 2A12 algorithm (Kummerow et al. 1996, 1998). The TRMM data source is the Tropical Cyclone Precipitation Feature (TCPF) database (Jiang et al. 2011). The TCPF database includes global TC best track information, collocated PR and TMI measurements and retrievals, and environmental parameters derived from NCEP realanysis. Versions 6 and 7 of the algorithms are used, resulting in a total of four TRMM rainfall estimates for each overpass. Only data within the PR swath is considered, which has a $247-\mathrm{km}$ width for the period of interest (after 2001 orbital boost). The TRMM and MPE-IV dataset are both available for the 2002-2010 Atlantic hurricane seasons. The PR has a minimum reflectivity threshold of $17-18 \mathrm{dBZ}$ which limits its ability to resolve rain rates below $0.2-0.4 \mathrm{~mm} \mathrm{hr}^{-1}$. The TMI $2 \mathrm{~A} 12$ estimates rain rates as low as $0.1 \mathrm{~mm} \mathrm{hr}^{-1}$ but has limited ability to accurately detect warm rainfall over land. As a result, any comparison between the estimates has lowest confidence at the lightest rain rates. 


\subsubsection{Data Selection}

A semi-automatic matching algorithm is applied to find TRMM overpasses within range of ground-based radar data. First, overpasses of interest are identified by comparing the latitude and longitude coordinates of the best-track TC center with the lat/lon of WSR-88D radar locations in the Southeast US. Second, the overpasses are manually filtered to remove storms where the PR-swath is too far from the coast and storms where a negligible amount of TC-related raining features are within range of the ground-based radars. The subjective criteria in this step are relatively loose: overpasses are accepted if any TC-related precipitation area is identified within TRMM and radar range. The total of 252 overpasses include some cases where the TC center is not necessarily located right along the coast, as the outer bands in large TCs can extend up to $500 \mathrm{~km}$ or more from the TC center. Since the PR swath does not cover the entire storm, all overpasses are only representative of a small portion of the TC, mostly the outer bands. The other subjective step in the data selection process is determining the cutoff between TC and non-TC related rain features. A rectangular box is manually drawn around each swath to designate the area around all TC-related precipitation within the PR swath.

After the data are selected, the pixel-level algorithm datasets are averaged to a common resolution. The grid averaging process must be considered carefully, since any change to the algorithms' native resolution will introduce additional random errors into the comparisons. The MPE-IV, PR 2A25, and TMI 2A12 datasets all have different resolutions. The MPE-IV resolution is $4 \mathrm{~km} \times 4 \mathrm{~km}$, the PR $2 \mathrm{~A} 25$ is $5 \mathrm{~km} \times 5 \mathrm{~km}$ and the TMI 2A12 is about $5.5 \mathrm{~km} \times 12 \mathrm{~km}$. The TMI 2A12 dataset has the lowest resolution and therefore limits the resolution of the grid for comparison. The TMI $2 \mathrm{~A} 12$ is aligned so the 
$5.5 \mathrm{~km}$ side is across-swath (perpendicular to the satellite motion) and the $12 \mathrm{~km}$ side is along-swath. However, observations from the lower-resolution 10, 19, and $37 \mathrm{GHz}$ channels are included in the TMI 2A12 algorithm, so the effective field of view is much larger than the footprint. This study uses relatively small grid boxes with a $1 / 7$ by $1 / 7$ degree resolution, which equates to about $16 \mathrm{~km}$ latitude by $13 \mathrm{~km}$ longitude. All pixellevel observations are averaged into each grid-based rain rate. The probability of rain was not considered when selecting TMI V7 pixels over ocean, although the parameter is discussed separately in section 3.g.

The temporal resolution of the different datasets must also be considered in the matching process. The TRMM data are instantaneous rain rates $\left(\mathrm{mm} \mathrm{hr}^{-1}\right)$, while the MPE-IV dataset is an hourly rainfall accumulation $(\mathrm{mm})$ based primarily on the aggregate precipitation estimates from all individual WSR-88D volume scans within that hour period. Although it is possible to choose the individual radar scan closest to the TRMM overpass time, the raw radar data can experience errors from radar calibration, anomalous propagation, bright band enhancement, radar beam blockage, nonuniform vertical package of reflectivity, and uncertain microphysical parameters such as the Z-R coefficients (e.g., Smith et al. 1996; Nelson et al. 2010; Breidenbach and Bradberry 2001). Raw radar rainfall estimates do not benefit from the mosaicing, bias corrections and rain gauge data in the MPE-IV dataset. The main additional source of error from the MPE-IV data is the change in rain rate as the precipitation evolves and propagates over an hourly period. The errors should be at their lowest when the TRMM overpass occurs around thirty minutes past the hour and when the bands within the TC are relatively stationary. If the TRMM overpass is within 10 minutes of an hour, the two closest MPE- 
IV estimates are averaged together. For convenience, this study often refers to the MPEIV data in units of rain rate $\left(\mathrm{mm} \mathrm{hr}^{-1}\right)$, even though it is actually a one hour accumulation.

An example of the averaged data is shown in Figure 3.1. Hurricane Jeanne (2004) was captured by TRMM on September 26, 2004 at 4:47 UTC. The one-hour MPE-IV estimate from 04-05 UTC is used as the reference dataset. The TMI $85 \mathrm{GHz}$ PolarizationCorrected brightness Temperature (PCT; Spencer et al. 1989) is included for reference in panel (f). The $85 \mathrm{GHz}$ PCT is adjusted to the same grid scale by taking the lowest brightness temperature value within each grid box. In panels (a) - (e), the gray boxes represent accepted data points with zero rain. A qualitative comparison between the TRMM algorithms and MPE-IV dataset reveals that the eye, inner core, and rain bands line up fairly well between the different estimates at the pixel level. The location of the heaviest rain is different in each image. The MPE-IV has the heaviest rain totals $(>35 \mathrm{~mm}$ $\mathrm{hr}^{-1}$ ) over land, while the PR has the highest rates over ocean. Version 6 and 7 of the PR show surprisingly large differences, although in most other cases they are in much closer agreement than this example. The center is correctly located by the TMI algorithms, but the banding structures are not as well defined. Another error source is visible over ocean in the TMI V7, as the TMI V7 detects rain everywhere to the northeast of the center, while all the other algorithms have a rain-free area between the bands. This discrepancy is seen on almost all TMI overpasses over ocean and arises as a result of the TMI V7 probability of rain parameter. 

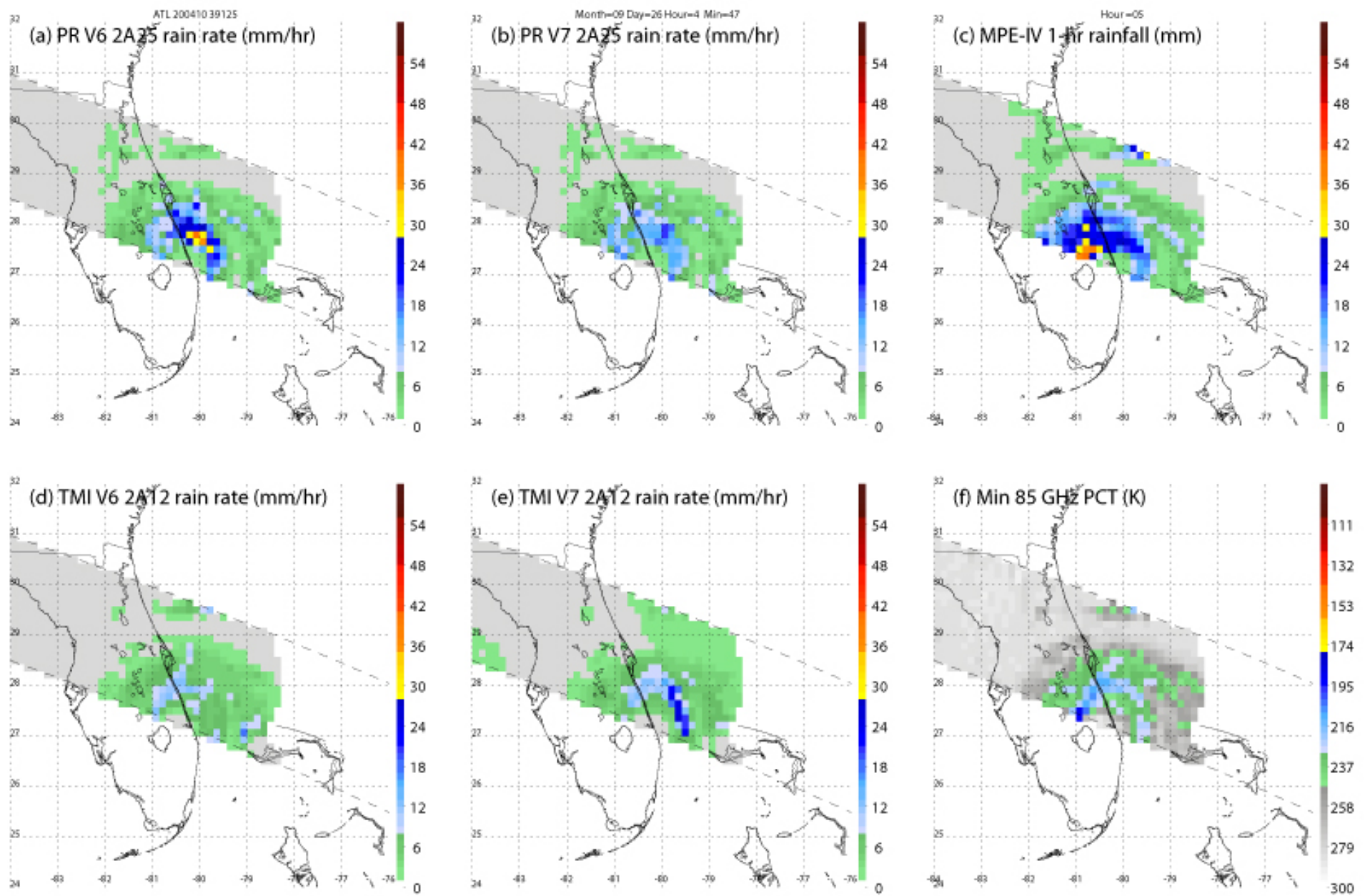

Figure 3.1: Example plot of a TRMM overpass from 2004 Hurricane Jeanne compared with the MPE-IV 1-hour rainfall. The TRMM overpass occurred at 4:47 UTC and the MPE-IV rainfall is a total accumulation from 04-05 UTC. All data are averaged to a matching 1/7 degree grid. The algorithms are (a) PR 2A25 V6, (b) PR 2A25 V7, (c) MPE-IV, (d) TMI 2A12 V6, (e) TMI 2A12 V7, and (f) TMI Minimum 85 GHz PCT. 

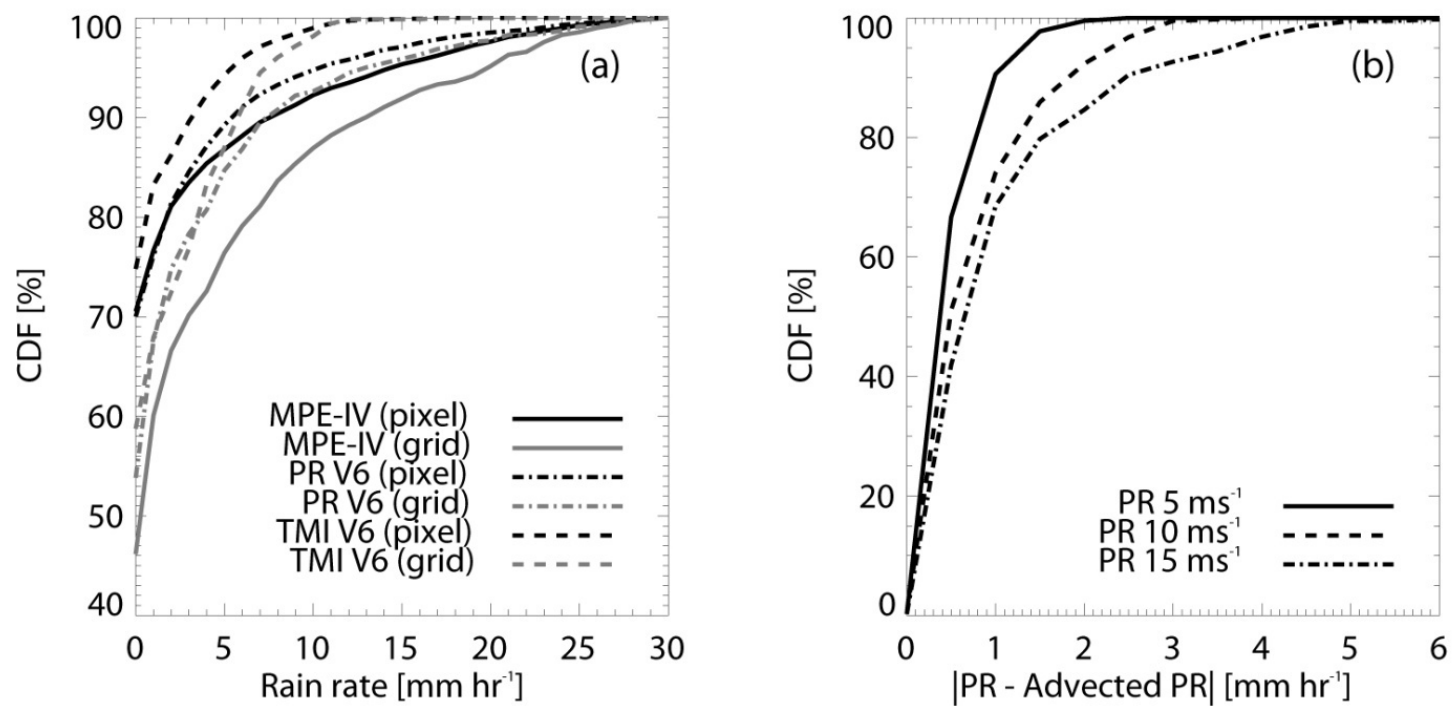

Figure 3.2: (a) Cumulative data functions (CDF) of the pixel level rain rates (black lines) and the grid averaged rain rages (grey lines) for the MPE-IV, PR V6, and TMI V6 rain rates. (b) CDF of the absolute difference between the grid averaged PR V6 rain rates compared with the one hour averaged PR V6 rain rates after being advected zonally at 5, 10 , and $15 \mathrm{~m} \mathrm{~s}^{-1}$. Both panels exclusively use data from the TRMM orbit 39125 in Figure 3.1 .

\subsubsection{Spatial and Temporal Averaging}

The errors introduced by the spatial and temporal grid averaging are estimated by comparing the raw pixel-level rain rates to the gridded data from the example overpass in Figure 3.1. Figure 3.2 (a) shows the CDF distribution of the raw pixel-level data compared with the grid averaged rain rates. The main difference caused by decreasing the resolution with grid averaging is an increase in the raining area from non-raining rain pixels that get averaged with raining pixels. Grid averaging increases the MPE-IV raining area by $20-25 \%$ and the PR and TMI raining areas by $15-20 \%$ relative to pixel-level raining areas. Bins with light rain rates are also affected, but the dominant difference between the distributions at rain rates greater than zero is caused by the 
(a) TRMM V6 and MPE-IV matches (PR, TMI, or MPE-IV > 0)

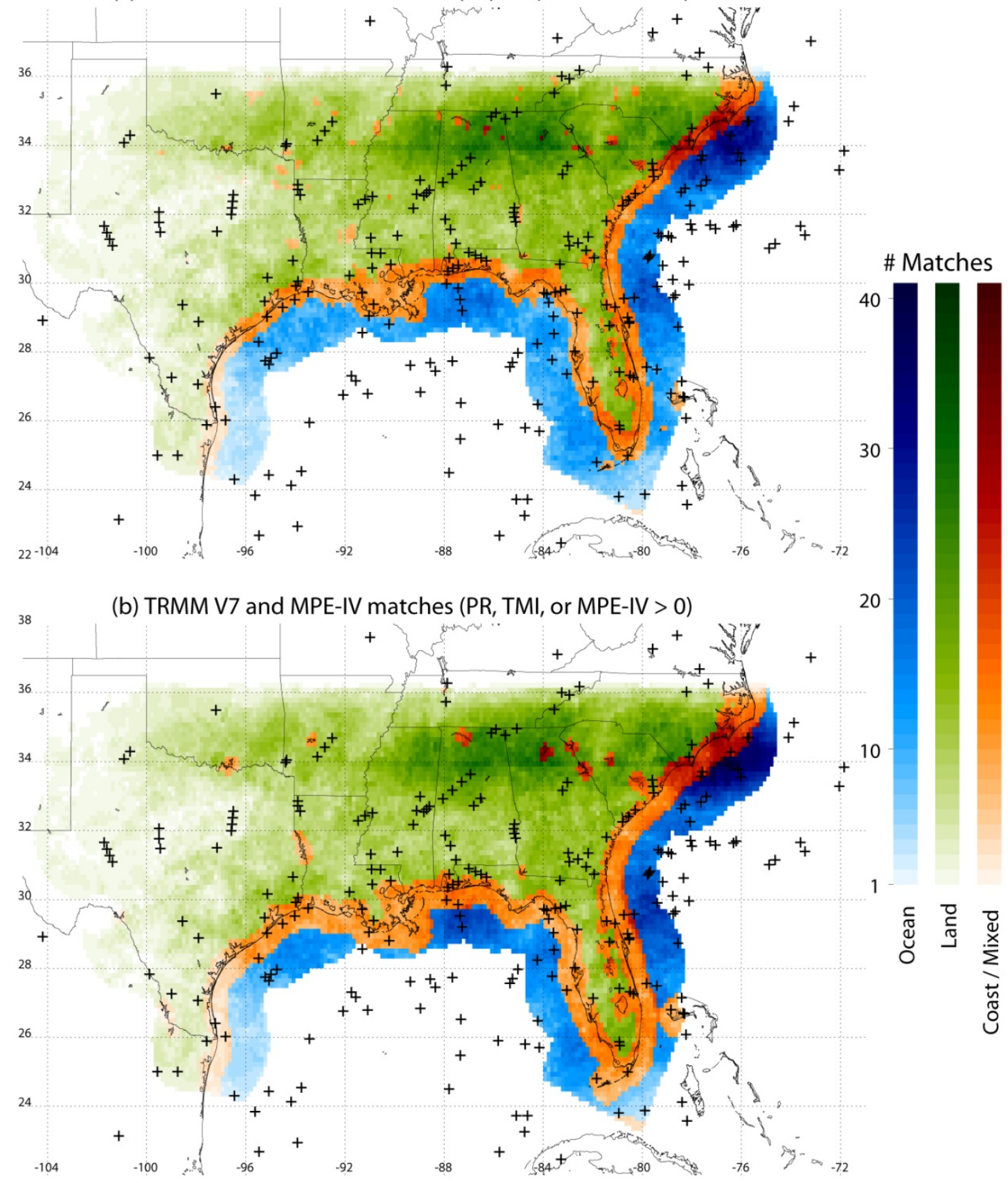

Figure 3.3: Geographical distribution of 1/7 degree grid boxes, color coded by TMI surface flag. Darker shades indicated higher data coverage. Grid boxes where the PR, TMI, and MPE-IV all estimate zero rain are not included in this figure. 
algorithms themselves and not the grid averaging. The CDFs are shifted to the right and converge at moderate to high rain rates.

The uncertainty from precipitation advecting over the hourly MPE period can also be roughly estimated. The PR V6 overpass in Figure 3.1 is hypothetically advected at a constant zonal velocity of 5,10 , and $15 \mathrm{~ms}^{-1}$ using one minute time steps over a onehour period. Figure 3.2 (b) displays CDFs of the absolute difference between the conditional $(>0)$ grid-averaged PR V6 rain rates and the same rain rates averaged over the one hour period after being advected. The average absolute difference between the original and advected orbits is $0.8,1.4$, and $1.9 \mathrm{~mm} \mathrm{hr}^{-1}$ for the respective 5,10 , and 15 $\mathrm{ms}^{-1}$ advection speeds. For the 252 storms in this study, the average storm center speed is $5.3 \mathrm{~ms}^{-1}$ and only 15 storms are moving faster than $10 \mathrm{~ms}^{-1}$. However, individual bands and storm cells also evolve relative to the storm center, so the actual difference between the instantaneous and hourly averaged PR rain rates is likely between the 5 and $10 \mathrm{~ms}^{-}$ ${ }^{1}$ distributions. The advection error is equally likely to be positive or negative relative to the instantaneous overpass. For the most part, the spatial and temporal errors are randomly distributed. The overall rain rate distributions should accurately reflect the algorithms themselves, although caution is required when comparing individual grid boxes directly.

\subsubsection{Final Dataset}

The final dataset is divided into land, ocean, and coastal/mixed components using the TMI surface flag. The surface flag is stored at the TMI $2 \mathrm{~A} 12$ resolution, so some of the lower resolution grid boxes inevitably have two types of surface flags. To resolve this 
issue, grid boxes with less than two-thirds ocean or land surface flags were added to the coast/mixed category. Some of the surface flag definitions changed between V6 and V7, resulting in a different number of grid boxes for each surface category for the two algorithm versions. A graphical representation of the final dataset is displayed in Figure 3.3. The red colored coast/mixed category extends farther out to sea and covers only large inland lakes in V7. Grid boxes where all three version 6 or 7 estimates (PR, TMI, and MPE-IV) agree on a zero rain rate are removed from the dataset leaving only the matches where at least one estimate has a non-zero rain rate. As a result, a total of 210,741 grid boxes are reduced to 116,025 for V6 and 120,447 for V7. The color shading in Figure 3.3 represents the number of times that each grid box is included for a storm in the dataset. In V6, the dataset is $25 \%$ ocean, $58 \%$ land, and $17 \%$ coast/mixed. In V7, the different surface flags change the distribution to $22 \%$ ocean, $56 \%$ land, and $21 \%$ coast $/$ mixed. It is unlikely that the change in surface flag designations has a quantifiable effect on the results of this study.

The spatial range of the dataset cuts off to the north at the apex of the TRMM orbit, $35^{\circ} \mathrm{N}$. Over ocean, the cutoff is $230 \mathrm{~km}$ from the nearest WSR-88D radar location. The MPE-IV oceanic dataset has more uncertainty than the land dataset as it does not benefit from gauge validation and likely suffers from range degradation associated with beam overshoot and partial beam filling (Breidenbach and Bradberry 2001). Using seasonal WSR-88D rainfall estimates in Oklahoma, Smith et al. (1996) found that warmseason underestimations are most pronounced beyond $150 \mathrm{~km}$ and the problem is primarily caused by lack of detection. The MPE-IV dataset might be missing some shallow precipitation over the oceanic range, although deeper, convective rainfall should 
be detected. However, the results from this study suggest that MPE-IV actually has greater rain coverage over ocean than the PR. Near the Florida Straits, the MPE-IV data range cuts off within $230 \mathrm{~km}$ of the Key West and Miami radars, so the edge of the dataset takes on a square appearance in that area. The number of observations varies geographically because of both the climatological storm tracks and the TRMM orbital geometry. The North Carolina coast has the most observations, including 9 from one storm: 2005 Hurricane Ophelia. Another maximum occurs around the northern coast of Florida, which saw several slow-moving storms in 2004. Farther south, the TRMM orbital track makes PR swath more likely to miss the storm, resulting in a smaller number of observations.

Figure 3.3 also designates the location of the TC centers at the time of the TRMM overpasses using '+' signs. Most of the TC centers are located within about $250 \mathrm{~km}$ of the coastline, but a few are located well inland and others are $500 \mathrm{~km}$ or more from the coast. Some of the points from the same storm are clustered together, indicating that the storm was seen by TRMM on consecutive orbits. Large, slow moving storms north of $30^{\circ}$ latitude were observed by as many as four overpasses in a row, with each over pass coming about 90 minutes apart. In terms of TC intensity, the dataset includes 94 TDs, 104 TSs, 40 category 1-2 hurricanes, and 15 category 3-5 hurricanes. Many of the tropical storms and depressions were originally landfalling hurricanes that still had a much larger and more intense rain field than an average storm of that intensity. Because there are 252 overpasses included, any local or storm-specific biases should not factor strongly into the overall results. No regional biases were detected. 


\subsection{Statistical Methods}

Several statistical methods are utilized to compare the algorithms. Mean rain rates (conditional and unconditional) are computed to determine the overall rainfall magnitudes. The unconditional rain rate is calculated as the average of all grid boxes, including those which are raining and non-raining. The conditional rain rate includes only the raining, or non-zero grid points from each individual algorithm. The conditional rain rate has a different sample size for each algorithm depending on how often it assigns nonzero rain rates. The percentage of pixels with rain rates $>0,>1,>5$, and $>10 \mathrm{~mm} \mathrm{hr}^{-1}$ are provided to aid in the comparison. Other commonly used statistics in this study include the use of probability density functions (PDFs), scatterplots, and Pearson's correlation coefficient.

\subsubsection{Bias Decomposition}

Bias statistics are most useful when each of the 4 TRMM algorithms is individually evaluated relative to the MPE-IV estimates. For example, the PR 2A25 Version 6 and MPE-IV algorithm can be compared for only the pixels where either of the two algorithms is $>0$. The individual comparison removes any bias that PR V7 or the TMI algorithms have on the sample selection. From these results, the mean bias is the mean difference in rain rate between the respective TRMM algorithm $\left(\mathrm{R}_{\mathrm{T}}\right)$ and the MPEIV estimate $\left(\mathrm{R}_{\mathrm{IV}}\right)$ :

$$
B=\frac{1}{n} \sum\left(R_{T}-R_{I V}\right)
$$


where $n$ is the sample size where either $R_{T}$ or $R_{I V}$ is greater than zero. It is also desirable to decompose the mean bias into three components, following the formulas used in Habib et al. (2009a). The hit bias (HB) is defined as the portion of the mean bias contributed from grid points where the TRMM and MPE-IV algorithms both agree that the rain is non-zero:

$$
H B=\frac{1}{n} \sum\left(R_{T}\left(R_{T}>0 \& R_{I V}>0\right)-R_{I V}\left(R_{T}>0 \& R_{I V}>0\right)\right)
$$

The missed rain bias (MB) is the portion of the mean bias contributed from grid points where the TRMM rain rate is equal to zero and the MPE-IV rain rate is non-zero:

$$
M B=\frac{1}{n} \sum R_{I V}\left(R_{T}=0 \& R_{I V}>0\right)
$$

More simply put, the missed rain bias is computed where the TRMM algorithm estimated zero rain in a grid box where rain was detected by MPE-IV. Finally, the false rain bias (FB) is the portion of the mean bias contributed from grid points where the TRMM rain rate is non-zero and the MPE-IV rain rate is equal to zero, or where the TRMM algorithm falsely estimated non-zero rain:

$$
F B=\frac{1}{n} \sum R_{T R M M}\left(R_{T R M M}>0 \& R_{I V}=0\right)
$$

The three components of bias add up to the mean bias. The bias decomposition is most useful for determining the percentage of the total bias that can be attributed to detection issues (i.e. missed and false bias) relative to the rain rate magnitude (hit bias). 


\subsubsection{Mean error decomposition}

The root mean square error (RMSE) is a commonly used statistic which is applied in this study to compute the average difference between the TRMM algorithms and the MPE-IV reference dataset. Using simple linear regression, the RMSE can also be decomposed to provide insight on what fraction of the difference between the PR/TMI and MPE-IV can be attributed to systematic $\left(\mathrm{RMSE}_{\mathrm{s}}\right)$ and random $\left(\mathrm{RMSE}_{\mathrm{r}}\right)$ errors, which add up to the total RMSE:

$$
R M S E=R M S E_{s}+R M S E_{r}=\sqrt{\frac{1}{n} \sum\left(R_{T}-R_{I V}\right)^{2}}
$$

From Wilmott (1982), the systematic RMSE is defined as:

$$
R M S E_{s}=\sqrt{\frac{1}{n} \sum\left(R_{T}^{\prime}-R_{I V}\right)^{2}}
$$

and the random RMSE is:

$$
R M S E_{r}=\sqrt{\frac{1}{n} \sum\left(R_{T}-R_{T}^{\prime}\right)^{2}}
$$

In the above equations, $R_{T}$ is the rain rate for a TRMM grid box, $R_{I V}$ is the corresponding MPE-IV rain rate for the grid box, and $R_{T}^{\prime}$ is the TRMM rain rate predicted by leastsquares regression of the TRMM rain rates,

$$
R_{T}^{\prime}=a+b \times R_{I V}
$$

In other words, the systematic error is the mean squared difference between the predicted TRMM distribution and the MPE-IV estimate. The random error is the mean squared difference between the TRMM estimate and the predicted TRMM distribution. The percentage of the MSE that is attributed to systematic error is simply $R M S E_{s} / R M S E$. 
These statistics were originally used to evaluate model performance (Wilmott 1982, Wilmott et al. 1983), although they have more recently been used in Habib et al. (2009a, 2009b) to compare MPE-IV data to TRMM and rain gauge observations. One issue with this decomposition method is that the MPE-IV dataset is assumed to be correct. It is not possible to determine if the systematic error can be attributed to the TRMM or MPE-IV dataset, just that there are systematic differences between them. However, the relative difference in systematic error between the PR and TMI datasets compared with the same MPE-IV reference does give information about how much systematic error can be attributed to each TRMM dataset.

\subsection{Results}

\subsubsection{Mean Values}

The mean values from the combined dataset of 252 storms are displayed in Table 3.1. The leftmost section displays the number of grid boxes, which is separate for V6 and V7 because of the difference in land, ocean, and coastal surface designations. Consequently, the MPE-IV rain rates are calculated independently using the different surface flags in V6 and V7. Unlike most other statistics in this study, these sample sizes add up to the total sample of around 210,000 grid boxes that includes zero rain boxes. The mean rain rates are easiest to interpret by comparing with Table 3.2, which displays the percentage of all grid boxes with rain rates greater than $0,1,5$, and $10 \mathrm{~mm} \mathrm{hr}^{-1}$ for each algorithm. 
Over ocean, the unconditional mean rain rates are all within about $10 \%$ of each other. In V6, the PR and TMI have lower unconditional rain rates and greater conditional rain rates than the MPE-IV reference. By comparing to Table 3.2, it is apparent that this discrepancy is caused by the MPE-IV detecting $8-9 \%$ more nonzero grid boxes than the TRMM algorithms. The TMI has the highest conditional rain rate out of the V6 ocean algorithms because of a combination of less raining grid boxes and a greater contribution from grid boxes with rain rates $>5 \mathrm{~mm} \mathrm{hr}^{-1}$. The number of PR V7 raining grid boxes increase slightly at all rain rate criteria relative to V6, including an $11 \%$ increase in the percent of grid boxes with rain rates greater than 5 and $10 \mathrm{~mm} \mathrm{hr}^{-1}$ relative to V6. It is somewhat surprising that the MPE-IV dataset finds more areas of light rain than the PR in both V6 and V7 because the oceanic dataset is almost completely located between 100 $\mathrm{km}$ and $230 \mathrm{~km}$ from the nearest ground-based radar site. It is expected that some shallow and/or stratiform precipitation would be underneath the lowest elevation radar scan. However, the PR does have a 17-18 dBZ minimum detection threshold, so it is possible that both datasets are missing some very light precipitation. The TMI V7 has over a 30\% increase in grid boxes $>0$ relative to $\mathrm{V} 6$, a consequence of the probability of rain parameter (see section 3.g).

The mean rain rates over land are generally much lower than over ocean. Based on the unconditional rain rate, the PR and TMI V6 appear to agree almost exactly, but the distribution of rain rates in Table 3.2 suggests that the TMI V6 is assigning zero rain to some of the grid boxes with PR V6 and MPE-IV rain rates between 0 and $1 \mathrm{~mm} \mathrm{hr}^{-1}$. Light rainfall is notoriously difficult to detect over land, although it appears that rain rates $>1 \mathrm{~mm} \mathrm{hr}^{-1}$ are mostly being detected successfully. When the criteria rises to $>1 \mathrm{~mm}$ 
$\mathrm{hr}^{-1}$, TMI V6 is more closely in line with MPE-IV than the PR. In V7, the percentage of grid boxes $>0$ remains almost exactly the same relative to V6, but the TMI V7 mean rain rates are considerably lower than V6. The TMI V7 land algorithm finds less grid boxes in the $>1$ and $>5 \mathrm{~mm} \mathrm{hr}^{-1}$ rain rate ranges. All of the TRMM land algorithms find a significantly smaller percentage of raining grid boxes over land relative to over ocean. The MPE-IV reference is also lower over land, but by a much lower margin. Lower raining coverage and rain rate over land relative to ocean is reasonable, since TCs are weaker after landfall, but it is likely that the decrease between land and ocean in the PR and especially the TMI is too steep. The mean rain rates over coastal areas are generally in between the ocean and land values. Figure 3.3 shows that the majority of coast/mixed pixels are over coastal oceanic areas, so it is not surprising that the MPE-IV unconditional rain rates are closer to the oceanic estimate. However, in both V6 and V7, the PR detects about $10 \%$ less grid boxes $>0$ than the MPE-IV, which is similar to what is observed over land. The coast/mixed mean rain rates do not change much between V6 and V7 because the TMI coastal algorithm was not updated in V7 (NASA GFSC, 2012).

\subsubsection{Contributions to Mean Rain Rate}

The mean rain rate analysis is a good starting point, but it is incomplete without additional information about the distribution of rain rates and their relative contributions to the mean rain rate. From Table 3.2, about half of the non-zero grid boxes have a rain rate less than $1 \mathrm{~mm} \mathrm{hr}^{-1}$ and only around 6-8\% have a rain rate greater than $5 \mathrm{~mm} \mathrm{hr}^{-1}$. Although the higher rain rates make up just a small portion of the sample, they have a disproportionately large influence on the mean rain rates and hence the disagreements 


\begin{tabular}{|c|c|c|c|c|c|c|c|c|c|}
\hline & \multicolumn{3}{|c|}{ \# Grid Boxes $>=0$} & \multicolumn{3}{|c|}{ Unconditional Mean rain rate } & \multicolumn{3}{|c|}{ Conditional Mean rain rate } \\
\hline Algorithm & Ocean & Land & Coast/Mix & Ocean & Land & Coast & Ocean & Land & Coast \\
\hline MPE-IV (V6) & \multirow{3}{*}{47426} & \multirow{3}{*}{126446} & \multirow{3}{*}{36869} & 1.33 & 1.07 & 1.27 & 2.52 & 2.20 & 2.60 \\
\hline PR V6 & & & & 1.25 & 0.83 & 0.98 & 2.79 & 2.21 & 2.57 \\
\hline TMI V6 & & & & 1.28 & 0.83 & 0.83 & 2.90 & 2.73 & 3.05 \\
\hline MPE-IV (V7) & \multirow{3}{*}{34590} & \multirow{3}{*}{128356} & \multirow{3}{*}{47620} & 1.37 & 1.07 & 1.26 & 2.55 & 2.21 & 2.54 \\
\hline PR V7 & & & & 1.34 & 0.85 & 1.06 & 2.95 & 2.31 & 2.74 \\
\hline TMI V7 & & & & 1.44 & 0.65 & 0.81 & 1.89 & 2.16 & 3.05 \\
\hline
\end{tabular}

Table 3.1: Sample size of all grid boxes including zero rain rates, unconditional mean rain rate (including all grid boxes) and conditional mean rain rate (including only grid boxes with nonzero rain rates).

\begin{tabular}{|l|c|c|c|c|c|c|c|c|c|c|c|c|}
\hline & \multicolumn{3}{|c|}{$\%$ Grid Boxes $>0$} & \multicolumn{2}{c|}{$\%$ Grid Boxes $>1$} & \multicolumn{2}{c|}{$\%$ Grid Boxes $>5$} & \multicolumn{3}{c|}{$\%$ Grid Boxes $>10$} \\
\hline Algorithm & Ocean & Land & Coast & Ocean & Land & Coast & Ocean & Land & Coast & Ocean & Land & Coast \\
\hline $\begin{array}{l}\text { MPE-IV } \\
\text { (V6) }\end{array}$ & $52.8 \%$ & $48.7 \%$ & $48.8 \%$ & $26.4 \%$ & $22.8 \%$ & $22.7 \%$ & $7.8 \%$ & $6.3 \%$ & $7.5 \%$ & $2.7 \%$ & $2.0 \%$ & $3.0 \%$ \\
\hline PR V6 & $44.6 \%$ & $37.6 \%$ & $38.2 \%$ & $23.0 \%$ & $18.6 \%$ & $19.2 \%$ & $7.0 \%$ & $4.8 \%$ & $5.6 \%$ & $2.7 \%$ & $1.1 \%$ & $1.9 \%$ \\
\hline TMI V6 & $44.1 \%$ & $30.4 \%$ & $27.3 \%$ & $25.2 \%$ & $24.1 \%$ & $20.0 \%$ & $8.6 \%$ & $3.4 \%$ & $4.7 \%$ & $2.5 \%$ & $0.8 \%$ & $1.0 \%$ \\
\hline $\begin{array}{l}\text { MPE-IV } \\
\text { (V7) }\end{array}$ & $53.5 \%$ & $48.5 \%$ & $49.8 \%$ & $26.9 \%$ & $22.1 \%$ & $23.6 \%$ & $8.0 \%$ & $6.3 \%$ & $7.5 \%$ & $2.8 \%$ & $2.0 \%$ & $2.8 \%$ \\
\hline PR V7 & $45.4 \%$ & $36.8 \%$ & $38.6 \%$ & $24.1 \%$ & $18.7 \%$ & $20.1 \%$ & $7.8 \%$ & $4.6 \%$ & $6.2 \%$ & $3.0 \%$ & $1.3 \%$ & $2.2 \%$ \\
\hline TMI V7 & $75.8 \%$ & $30.0 \%$ & $26.6 \%$ & $27.7 \%$ & $19.6 \%$ & $19.3 \%$ & $7.8 \%$ & $1.9 \%$ & $4.6 \%$ & $2.6 \%$ & $0.7 \%$ & $0.9 \%$ \\
\hline
\end{tabular}

Table 3.2: Percentage of all grid boxes with rain rates greater than $0,1,5$, and 10 , divided by algorithm and surface flag. 

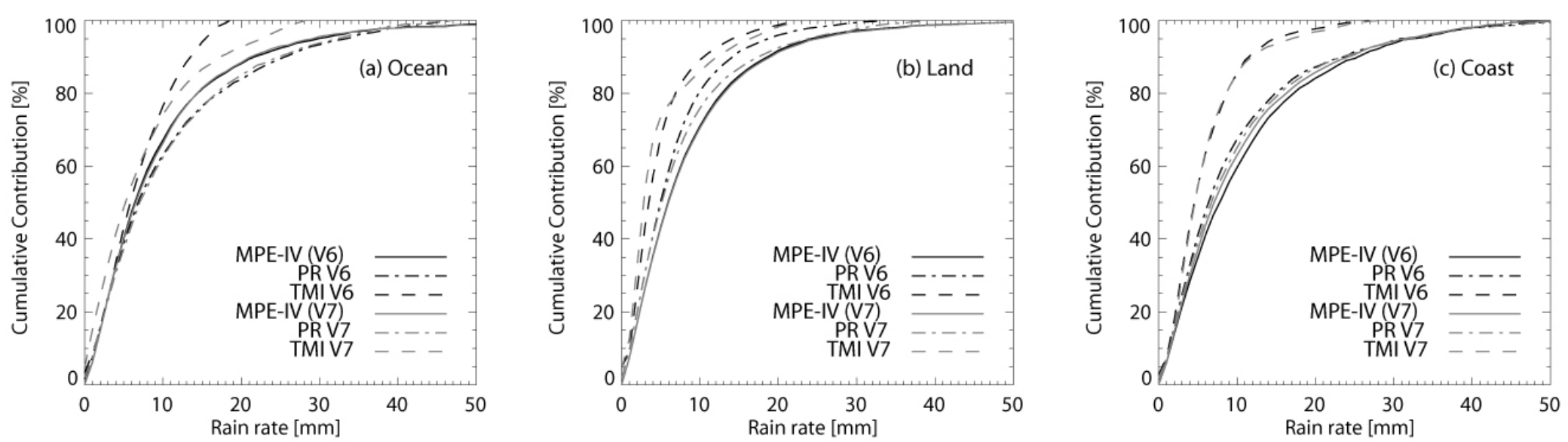

Figure 3.4: Cumulative contribution (\%) to mean rain rate for TRMM algorithms compared with the MPE-IV reference dataset, divided by (a) ocean, (b) land, and (c) coast/mixed surface.
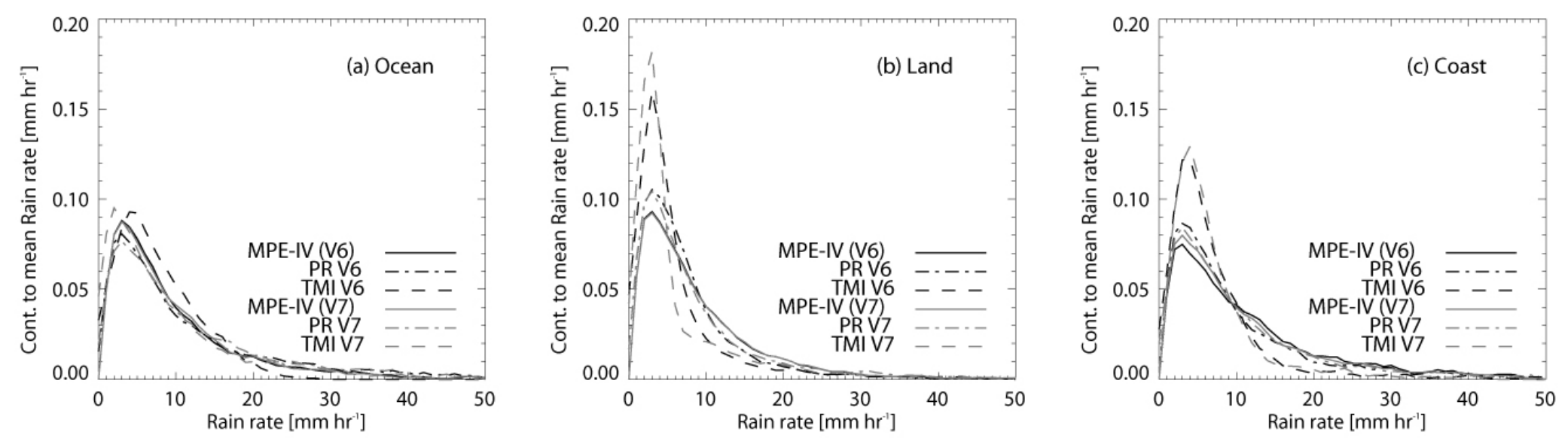

Figure 3.5: Contribution to mean rain rate for TRMM algorithms compared with the MPE-IV reference, divided by (a) ocean, (b) land, and (c) coast/mixed surface. Data are divided into bins of $1 \mathrm{~mm} \mathrm{hr}^{-1}$ 

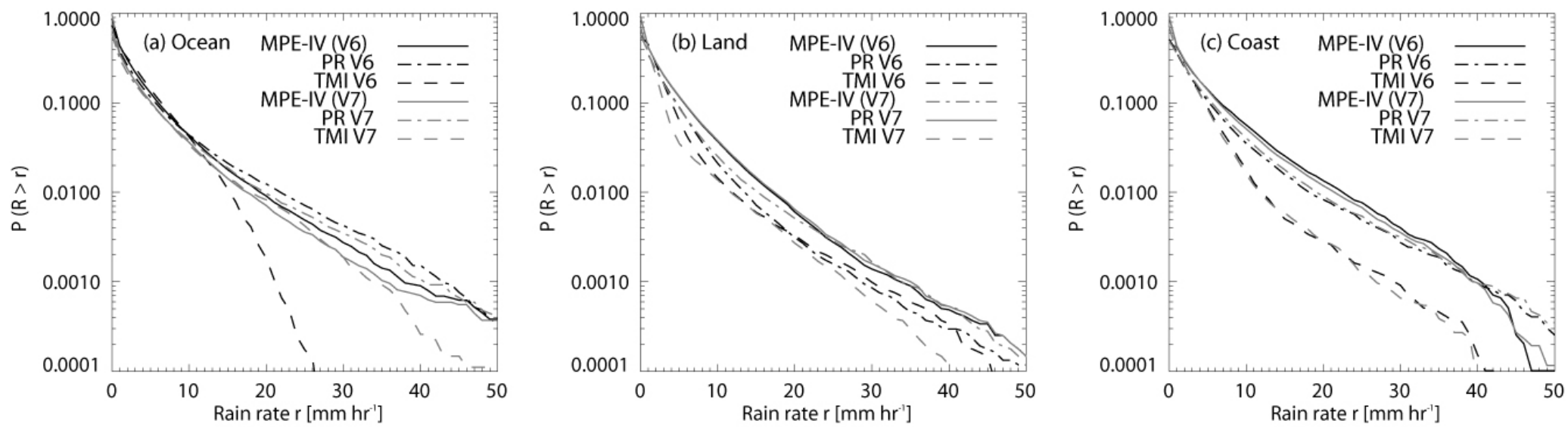

Figure 3.6: Probability of exceedance plots for TRMM algorithms compared with the MPE-IV reference dataset, divided by (a) ocean, (b) land, and (c) coast/mixed surface.
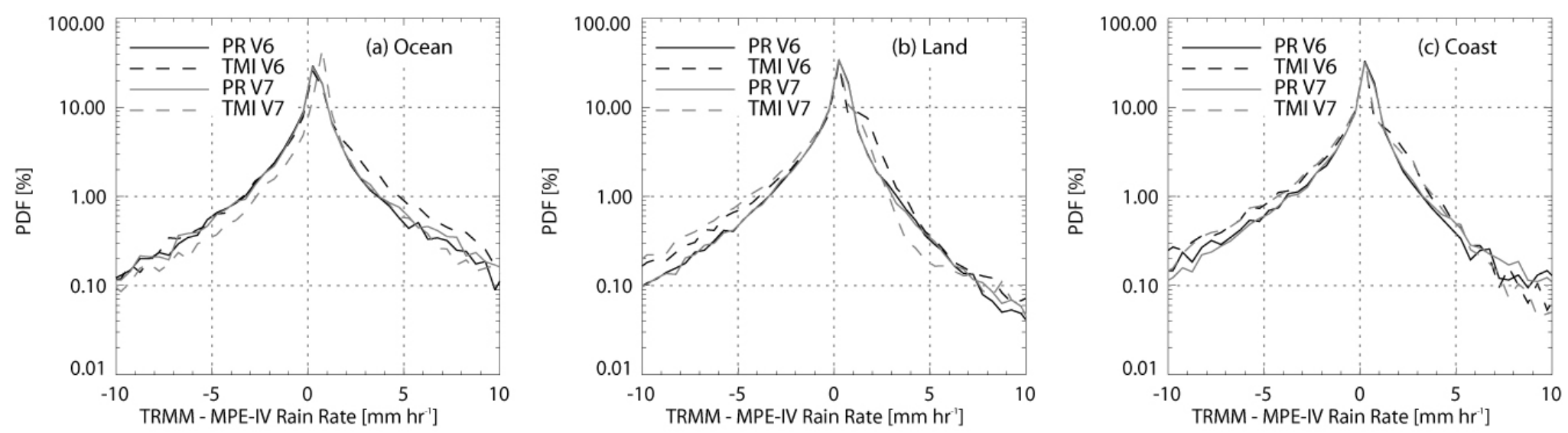

Figure 3.7: Probability distribution for the difference between TRMM algorithms and the MPE-IV rain rate, divided by (a) ocean, (b) land, and (c) coast/mixed surface 
between the algorithms. Figures 3.4 and 3.5 both show the contribution to the mean rain rate from all of the individual rain rates in $1 \mathrm{~mm} \mathrm{hr}^{-1}$ bins. Compared with a traditional CDF plot, the cumulative contribution is better distributed across the full range of rain rates. The oceanic plot (Figure 3.4.a) reveals that about $60 \%$ of the mean rain rate is derived from grid boxes with rain rates below $10 \mathrm{~mm} \mathrm{hr}^{-1}$. The TMI V7 ocean algorithm derives the most rainfall from light rain rates, the rest of the ocean algorithms agree at $<5$ $\mathrm{mm} \mathrm{hr}{ }^{-1}$ rates and diverge in the $5-10 \mathrm{~mm} \mathrm{hr}^{-1}$ range. Version 7 of the TMI is clearly improved relative to V6 at higher rain rates. However, TMI V7 is still not getting enough contribution from $>10 \mathrm{~mm} \mathrm{hr}^{-1}$ rain rates. This plotting method does not pick up much difference between PR V6 and V7 over ocean, although both have slightly less contribution to the mean than MPE-IV starting around $5 \mathrm{~mm} \mathrm{hr}^{-1}$ and up. The numerical contribution to mean rain rate in Figure 3.5 shows similar trends but emphasize the rain rate ranges that contribute the most to the mean. It is interesting that TMI V6 has more contribution from 5-15 mm hr${ }^{-1}$ rain rates than the PR, which is consistent with other studies of TMI V6 over ocean in tropical cyclones (Cecil and Wingo, 2009; Zagrodnik and Jiang, 2013). It appears likely that TMI V6 is identifying the areas of moderate rain, but assigning rain rates of $5-15 \mathrm{~mm} \mathrm{hr}^{-1}$ to a number of pixels that should have rain rates of $15-30 \mathrm{~mm} \mathrm{hr}^{-1}$ or higher.

The cumulative contribution over land (Figure 3.4.b) has an MPE-IV curve that looks about the same as the oceanic curve, but noticeably different PR and TMI distributions. There is a major difference between the MPE-IV and TMI at light rain rates. The TMI algorithms derive about $80 \%$ of their mean rain rates from $<5 \mathrm{~mm} \mathrm{hr}^{-1}$ rain rates, but the MPE-IV only finds about $50 \%$ of the mean rain rate comes from the $<$ 
$5 \mathrm{~mm} \mathrm{hr}^{-1}$ bins. The MPE-IV estimate suggests that about $10 \%$ of the mean should come from rain rates above $20 \mathrm{~mm} \mathrm{hr}^{-1}$; however, both TMI algorithms also get essentially zero contribution from the heavy rain rates. The PR curves show some difference over land, with PR V7 coming much closer to MPE-IV above $5 \mathrm{~mm} \mathrm{hr}^{-1}$ and especially above 15 $\mathrm{mm} \mathrm{hr}{ }^{-1}$. Figure 3.5 suggests that the TMI needs to have less contribution from the 3-6 $\mathrm{mm} \mathrm{hr}^{-1}$ rain rates and more in the $7-20 \mathrm{~mm} \mathrm{hr}^{-1}$ range. The coastal plots are similar to the land plots. The PR is closer to the MPE-IV reference and the most significant area of TMI underestimation is higher than over land, in the $10-30 \mathrm{~mm} \mathrm{hr}^{-1}$ range.

\subsubsection{Probability distributions}

The probability distributions look at the difference in rain rates without considering the contribution to the mean. In Figure 3.6, the probability of exceedance function is calculated for each algorithm. The probability of exceedance is the probability that the rain rate in a given grid box $(\mathrm{R})$ exceeds a certain threshold (r). A logarithmic plot is used on the $y$-axis because the relative frequency of high rain rates is quite rare. Panel (a) shows that only around 5\% of oceanic grid boxes have rain rates exceeding 10 $\mathrm{mm} \mathrm{hr}^{-1}$. The cumulative contribution (Figure 3.4.a) demonstrates that these $>10 \mathrm{~mm} \mathrm{hr}^{-1}$ boxes account for about $40 \%$ of the cumulative rainfall. Over ocean, the TRMM algorithms find about the same number of grid boxes as MPE-IV up to about $15 \mathrm{~mm} \mathrm{hr}^{-1}$. The improvement TMI V7 high rain rates over ocean is limited to rain rates below $35 \mathrm{~mm}$ $\mathrm{hr}^{-1}$. Both PR V6 and V7 have a higher probability of rain rates exceeding $20 \mathrm{~mm} \mathrm{hr}^{-1}$ than the MPE-IV dataset. The discrepancy at high rain rates is reflected in the high PR conditional mean rain rates in Table 3.1. 
The TMI land algorithms have a lower probability of exceedance than MPE-IV starting at rain rates of $5 \mathrm{~mm} \mathrm{hr}^{-1}$ and up. The large difference in the $5-10 \mathrm{~mm} \mathrm{hr}^{-1}$ range is emphasized in Figure 3.5 because there are a large number of grid boxes in this range. The TMI V6 distribution is overall much closer to MPE-IV than TMI V7. The PR V7 probability of exceedence curve almost exactly matches MPE-IV above $20 \mathrm{~mm} \mathrm{hr}^{-1}$, while PR V6 has less moderate and heavy raining grid boxes. The underestimation of rain over land in $\mathrm{V} 6$ has been noted by the algorithm developers and appears to be mostly corrected in V7. The $5-20 \mathrm{~mm} \mathrm{hr}^{-1}$ range still is showing some underestimation, but it is improved relative to V6. Figures 3.4-3.6 all demonstrate that Version 7 of the PR is easily the best performing TRMM algorithm over land at higher rain rates. Over coasts, the TMI significantly underestimates both moderate and heavy rain rates relative to MPE-IV. Above $20 \mathrm{~mm} \mathrm{hr}^{-1}$, the TMI probability of exceedance is nearly a full order of magnitude too low. The PR coastal algorithm shows less grid boxes than MPE-IV exceeding rain rates of 5-40 $\mathrm{mm} \mathrm{hr}^{-1}$. Above $40 \mathrm{~mm} \mathrm{hr}^{-1}$, the PR, TMI, and MPE-IV all diverge, although the sample size at these rain rates is too low to have high confidence in that disagreement.

The probability distribution can also be viewed as a function of the MPE-IV rain rate subtracted from the TRMM rain rate, as seen in Figure 3.7. Over ocean, both PR algorithms and TMI V6 peak in the positive $0-0.5 \mathrm{~mm} \mathrm{hr}^{-1}$ bin, suggesting that these algorithms usually slightly overestimate MPE-IV as opposed to slightly underestimating it. A total of $40-45 \%$ of the grid boxes overestimate MPE-IV by $0-1 \mathrm{~mm} \mathrm{hr}^{-1}$. The higher peak of TMI V7 grid boxes in the $0-1 \mathrm{~mm} \mathrm{hr}^{-1}$ range represents the large number of false rain cases (further discussed in section 3.f). Cases of large over and under estimation are 
about equally distributed. All 4 TRMM algorithms in the land and coast PDFs peak in the positive $0-0.5 \mathrm{~mm} \mathrm{hr}^{-1}$ bin and are more prone to underestimation of $>5 \mathrm{~mm} \mathrm{hr}^{-1}$ than overestimation of $>5 \mathrm{~mm} \mathrm{hr}^{-1}$.

\subsubsection{Quantile Plots}

The quantile plots of all individual grid points (Figure 3.8) help illustrate the conditional bias between the algorithms. The correlation coefficients $(r)$ are also included to gauge the degree of disagreement. Wang et al. (2009) used a single case study of Hurricane Katrina over land to compare TMI V6 and MPE-IV and found a correlation coefficient of 0.71 on a $0.25^{\circ}$ grid. However, the correlation between TMI V6 and TRMM GV at Melbourne over a 5 -year period is only 0.51 , which compares favorably with $r=0.47$ for the 252 storms in this study. The additional MPE-IV raining area relative to the PR (Table 2) results in the PR quantiles favoring MPE-IV at light rain rates. The PR - MPE-IV correlation coefficient is actually lowest over ocean, seemingly a result of PR overestimation at moderate rain rates that is apparent in the probability distributions.

The TMI ocean algorithms have almost as high of a correlation coefficient as the PR and there are no major biases present. The improved agreement in the $>10 \mathrm{~mm} \mathrm{hr}^{-1}$ range in panel (d) relative to (c) represents a noticeable improvement in the V6 deficiency that was mentioned earlier in Figures 5 and 7. Over land, TMI V6 and V7 show similar biases relative to MPE-IV. The quantiles are biased toward MPE-IV at rain rates below $0.5 \mathrm{~mm}$ $\mathrm{hr}^{-1}$ and rain rates from 5-15 $\mathrm{mm} \mathrm{hr}^{-1}$.Panels (g) and (h) have correlation coefficients 

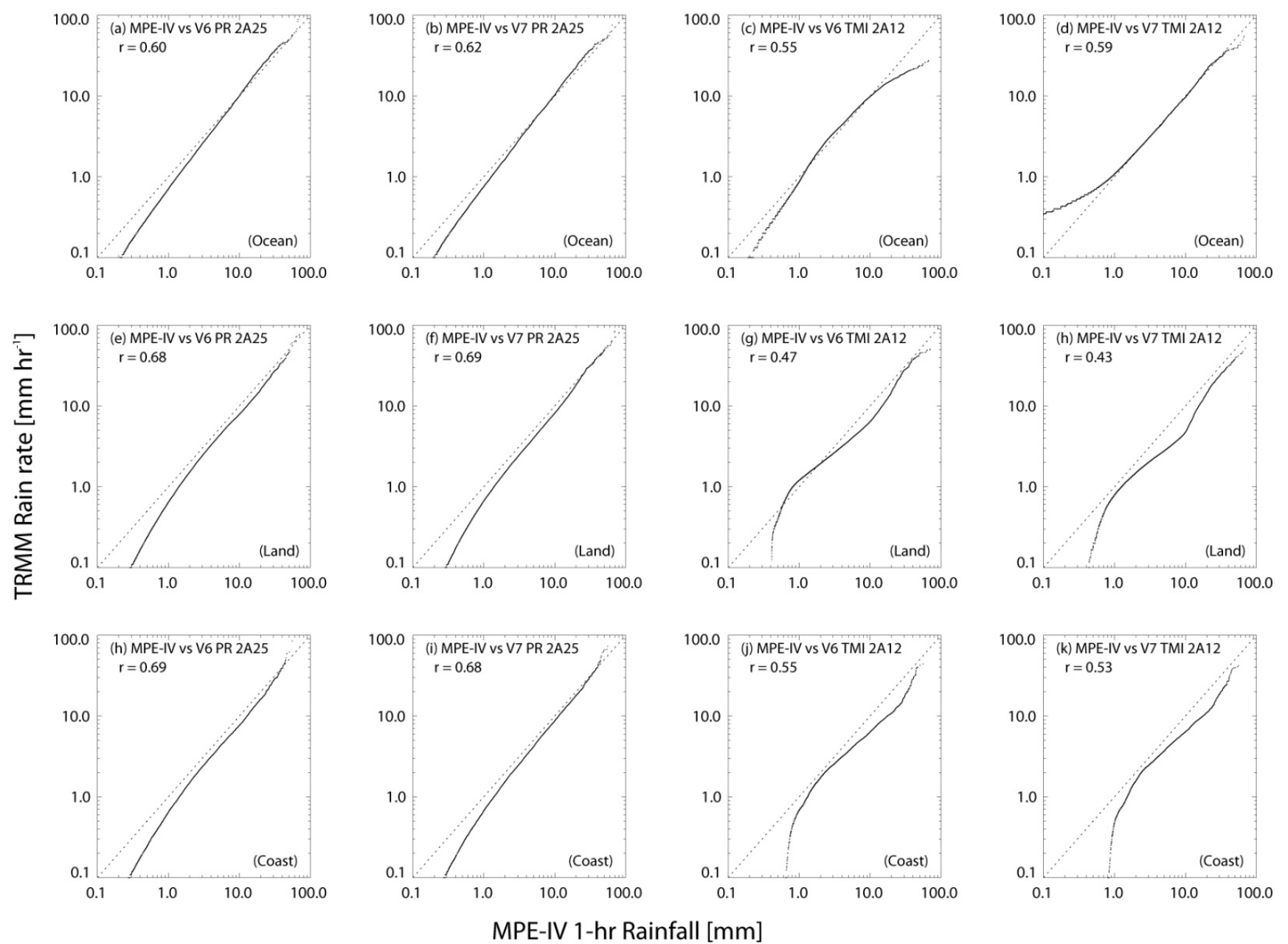

Figure 3.8: Quantile-Quantile plots of MPE-IV 1-hour rainfall vs. TRMM rain rate, divided by TRMM algorithm. The plots are arranged by TRMM algorithm (columns) and land, ocean, and coast/mixed (rows). 
below 0.5 . The bias at higher rain rates is visibly less in V6 compared with V7. The TMI coastal algorithm follows the same bias pattern as the TMI land algorithm.

\subsubsection{Error decomposition}

With several sources of error in the grid averaging, it is important to quantify how much of the deviation between TRMM and MPE-IV can be attributed to random vs. systematic causes. The error decomposition method described in section 3.b is applied to the four TRMM algorithms and the results are displayed in Table 3.3. The PR always has much lower systematic error than the TMI. Given the spatial and temporal grid resizing in this study, a large amount of random error is expected. The TMI is expected to have more random error from the resizing than the PR because of the discrepancy between the 1/7 degree grid size and the TMI FOV. If more TMI pixels were added to get an apparent TMI resolution closer to the TMI FOV, the result would be more blending of light and moderate rain rates, which would reduce the rain rate of some of the highest TMI grid boxes. The light and moderate rain rates could change in either direction, since both heavier and lighter/zero pixels would be averaged in. In other words, the systematic error at moderate to high rain rates (Figure 3.8 panels $g$ and h) is likely not caused by the grid resizing. The high percentage of systematic errors in Table 3.3 is reasonable, although a cautious observer may choose to only consider the relative difference between the V6 and V7 systematic errors.

In any case, it is somewhat surprising that the PR ocean algorithms have a higher RMSE than the TMI algorithms, although some of the difference can probably be attributed to uncertainties in MPE-IV. The TMI V7 ocean algorithm has both a lower 


\begin{tabular}{|l|c|c|c|c|c|c|}
\hline & \multicolumn{2}{|c|}{ Ocean } & \multicolumn{2}{c|}{ Land } & \multicolumn{2}{c|}{ Coast } \\
\hline Algorithm & RMSE & $\begin{array}{c}\% \\
\text { Systematic }\end{array}$ & RMSE & $\begin{array}{c}\% \\
\text { Systematic }\end{array}$ & RMSE & $\begin{array}{c}\% \\
\text { Systematic }\end{array}$ \\
\hline PR V6 & 3.85 & $13.8 \%$ & 2.75 & 35.2 & 3.44 & $30.7 \%$ \\
\hline PR V7 & 3.85 & $10.6 \%$ & 2.80 & 27.0 & 3.40 & $22.2 \%$ \\
\hline TMI V6 & 3.60 & $38.8 \%$ & 3.39 & 49.5 & 3.90 & $62.2 \%$ \\
\hline TMI V7 & 3.31 & $23.2 \%$ & 3.53 & 61.4 & 3.83 & $61.0 \%$ \\
\hline
\end{tabular}

Table 3.3: Mean square error (MSE) and the percent of the MSE that can be attributed to systematic biases.

RMSE and 15\% less systematic error, representing a major improvement over V6. The improvement above $15 \mathrm{~mm} \mathrm{hr}^{-1}$ (Figures 3.6 and 3.8) is the source of the error reduction. About $12 \%$ more systematic error still remains compared with PR V7. The systematic error increases for all four algorithms over land relative to ocean. The most striking difference is in the TMI, as V7 has a higher RMSE than V6 and over 10\% more systematic error. There is relatively little difference between V6 and V7 over coasts, although the PR systematic error is reduced in V7. The TMI coastal algorithms have a high RMSE, but the large percentage of systematic error suggests that it a bias correction technique may be able to remove a sizable portion of the error.

\subsubsection{Bias}

The bias calculations relative to the MPE-IV reference are displayed graphically in Figure 3.9. The biases are calculated for each algorithm vs. MPE-IV individually (only grid boxes with either the individual TRMM algorithm or MPE-IV greater than zero) instead of using the combined dataset. The bias sample sizes are shown in Table 3.4. The hit bias, miss bias, and false bias add up to the mean bias. The biases for all algorithms 

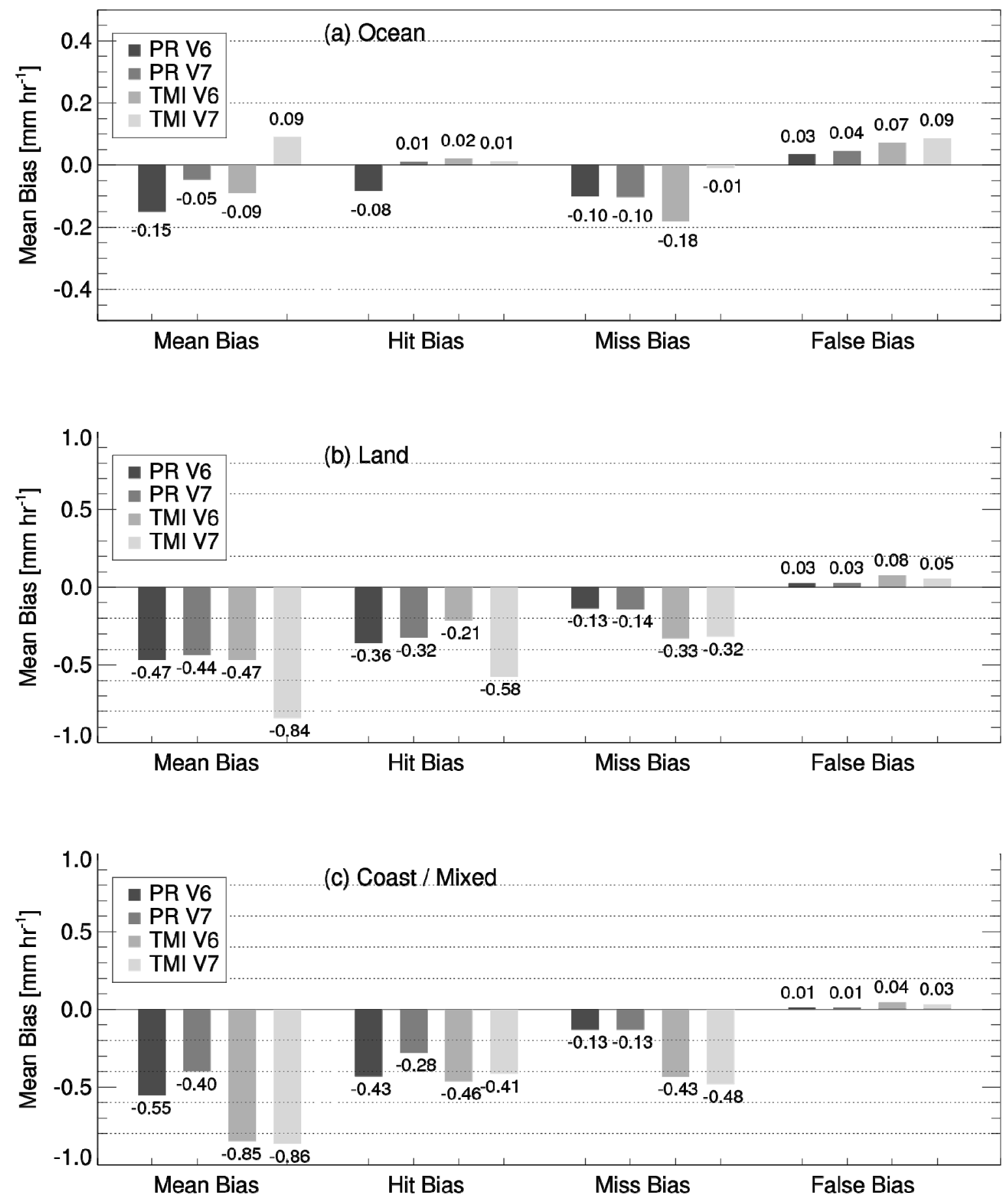

Figure 3.9: Bar plots of mean bias, hit bias, miss bias, and false bias, divided by (a) ocean, (b) land, and (c) coast/mixed surface. 


\begin{tabular}{|l|c|c|c|c|c|c|c|c|c|c|c|c|}
\hline & \multicolumn{3}{|c|}{ \# Grid Point } & \multicolumn{4}{c|}{ \% Hit } & \multicolumn{4}{c|}{ \% Miss } & \multicolumn{3}{c|}{ \%alse } \\
\hline Algorithm & Ocean & Land & Coast & Ocean & Land & Coast & Ocean & Land & Coast & Ocean & Land & Coast \\
\hline PR V6 & 26892 & 65787 & 19046 & $72.1 \%$ & $65.9 \%$ & $68.3 \%$ & $21.0 \%$ & $27.7 \%$ & $26.1 \%$ & $6.8 \%$ & $6.4 \%$ & $5.6 \%$ \\
\hline PR V7 & 19883 & 66192 & 24906 & $72.1 \%$ & $65.5 \%$ & $69.0 \%$ & $21.0 \%$ & $28.6 \%$ & $26.3 \%$ & $6.9 \%$ & $5.9 \%$ & $4.7 \%$ \\
\hline TMI V6 & 27793 & 65176 & 18878 & $65.4 \%$ & $53.5 \%$ & $48.5 \%$ & $24.8 \%$ & $41.0 \%$ & $46.8 \%$ & $9.9 \%$ & $5.5 \%$ & $4.8 \%$ \\
\hline TMI V7 & 26935 & 65419 & 24901 & $66.1 \%$ & $54.0 \%$ & $46.2 \%$ & $2.6 \%$ & $41.2 \%$ & $49.1 \%$ & $31.3 \%$ & $4.8 \%$ & $4.7 \%$ \\
\hline
\end{tabular}

Table 3.4: Sample size of grid boxes where each individual TRMM algorithm or the MPE-IV reference is nonzero and the percentage of those grid boxes that are designated as hits, misses, or false rain. 
are lowest over ocean, with miss bias contributing the most to the mean bias. The oceanic algorithms have a very low hit bias, as rain detection (raining vs. non-raining) remains the primary area of uncertainty. All of the land algorithms have a significant negative mean bias, with TMI V7 clearly showing the greatest underestimation. The negative bias in the PR and TMI land algorithms comes from both successful detection and missed detection. Recall that Figures 3.4, 3.5, and 3.6 show that the PR land underestimation is especially apparent at moderate to high rain rates. Version 7 of the PR does show some improvement over V6 in coastal regions, with less underestimation in raining areas. The systematic error over coasts derives from underestimation from both hits and misses. Finally, it is worth noting that false detection contributes very little to the mean biases as a whole.

The statistical percentages of hits, misses, and false rain are conveyed in Table 3.4. Both algorithms equaling zero does not count as a hit. The PR has a better hit percentage than the TMI over ocean, with the greatest difference over land and coast. Misses are clearly less frequent over ocean than land, which is expected because the emission-based channels can be added to the ocean algorithm. The TMI has more misses than the PR, especially over coasts. The geographic distribution of hits, misses, and false rain was also considered. Hits and misses did not show any noteworthy geographic biases. Maps of the false positives are displayed in Figure 3.10, normalized for sample size relative to the sample in Figure 3.3. Precipitation Radar false positives are relatively rare and just above evenly distributed everywhere. In the PR plots (Figure $3.10 \mathrm{a}$ and b), there is some evidence of false positives caused by the $230-\mathrm{km}$ radar range west of Tampa Bay, but overall the radar range problem does not appear to be significantly 
affecting the dataset. Version 6 of the TMI has a slightly elevated number of false positives over ocean relative to the PR. Most of the false positives are generated from the TMI V7 algorithm over ocean. The hit percentage is only marginally improved relative to V6, but the number of false positives more than triples to over $30 \%$. The next section examines these false positives in more detail.

\subsubsection{TMI V7 Probability of Rain Over Ocean}

The TMI V7 false positives over ocean must be considered in tandem with the TMI probability of rain parameter. Figure 3.11 examines the pixel-level TMI rain rates and rain probabilities for hits, misses, and false rain as inferred from the gridded data. The criteria are modified slightly from Figures 3.9-3.10 to reduce the risk of improper categorization. A hit is defined when all three V7 ocean algorithms are nonzero, a miss is when TMI V7 is zero and both MPE-IV and PR V7 are nonzero. False rain is when TMI V7 is greater than zero and both MPE-IV and PR V7 are zero. The fourth category, all zero, refers to when MPE-IV, PR, and TMI all agree that the rain rate is zero. This procedure retains $83 \%$ of the 34,590 ocean grid boxes including 7,136 false TMI V7 grid boxes. Panel (a) shows the CDF of rain rates for the hit and false cases. The leftmost bin contains the zero rain pixels that result from averaging to the larger grid size. The false TMI pixels are mostly $0.5 \mathrm{~mm} \mathrm{hr}^{-1}$ or less. The probability of rain CDF is displayed in panel (b). Only $5 \%$ of hits have less than a $100 \%$ probability of rain. Misses account for less than $0.5 \%$ of all grid boxes and likely result from being in the same grid box as PR and MPE raining pixels. Pixels that are zero in all three algorithms have the lowest probability of rain, generally less than $50 \%$. 
The false rain curve has several important characteristics. About one third of false rain pixels have a $100 \%$ probability of rain, while the remaining two thirds are nearly equally spread between $30-95 \%$ probability. Filtering the false TMI V7 pixels with a probability of rain below $50 \%$ does little to affect the dataset, especially since most of the $<50 \%$ false TMI V7 pixels are simply the zero rain pixels that are included from grid averaging. Setting the filter at $90 \%$ removes $64 \%$ of false pixels while only losing $4 \%$ of hits. However, it is difficult to determine which filtering criteria is closest to being physically correct. The PR minimum sensitivity is around $0.2-0.4 \mathrm{~mm} \mathrm{hr}^{-1}$ (Schumacher
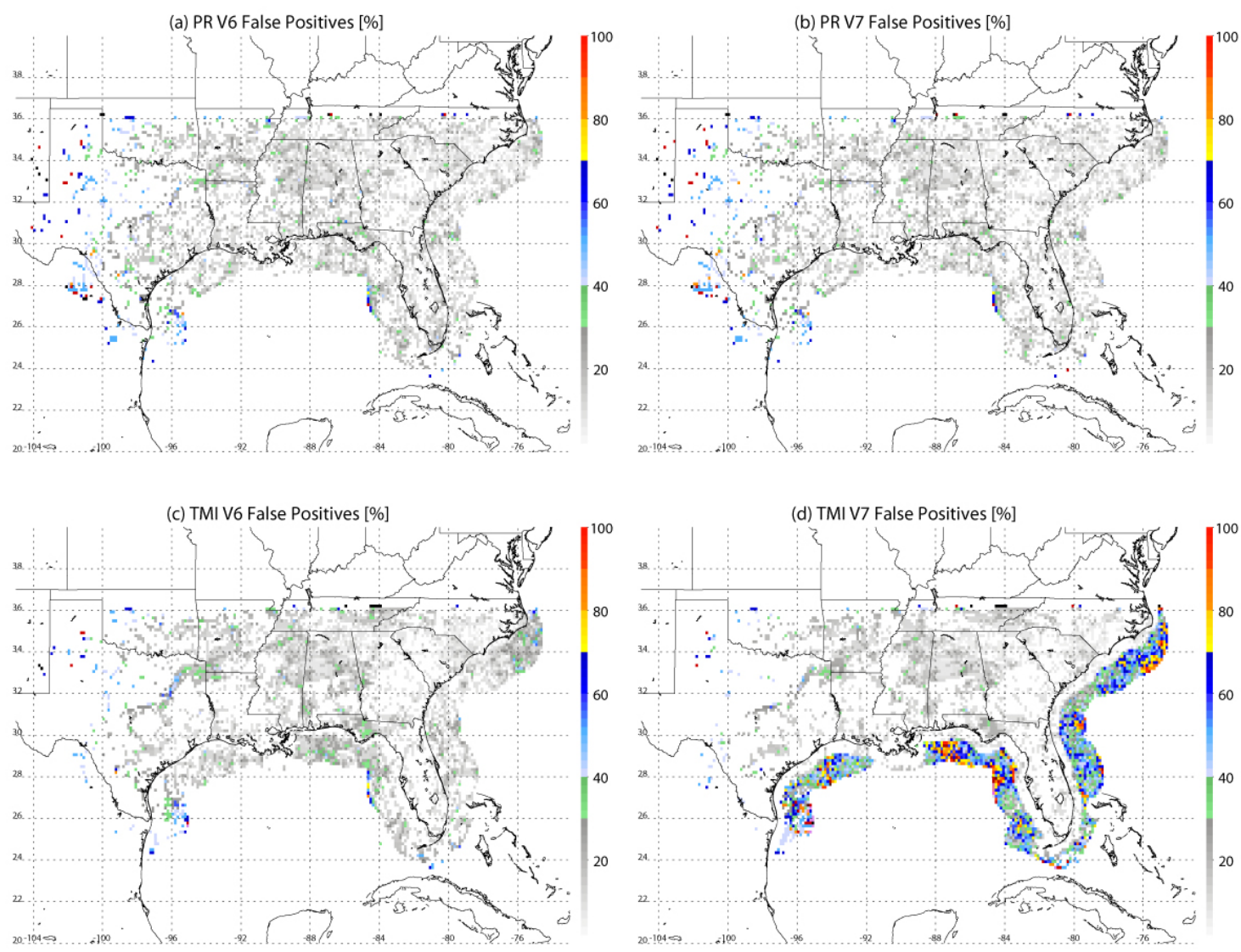

Figure 3.10: Geographic distribution of the percent of grid boxes by location with false positives (TRMM > 0, MPE-IV = 0), divided by (a) PR V6, (b) PR V7, (c) TMI V6, and (d) TMI V7. 

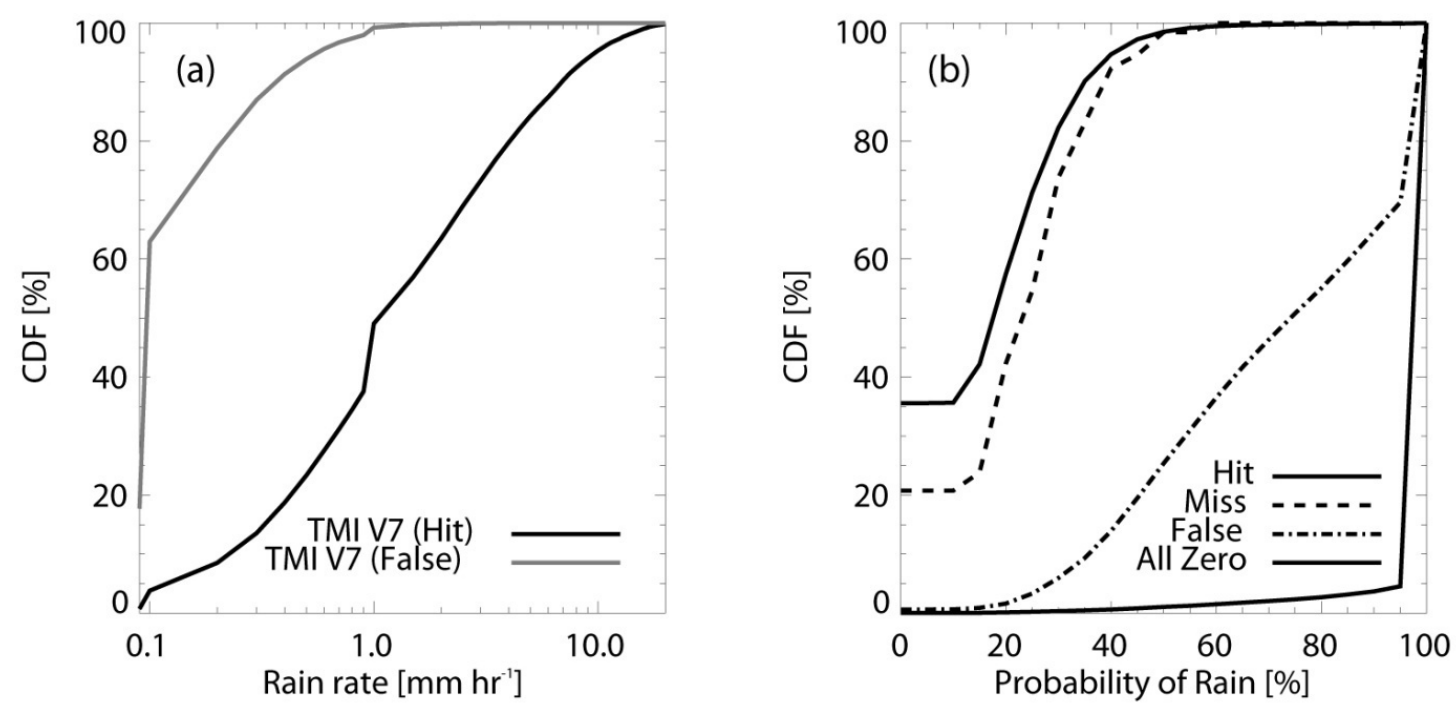

Figure 3.11: (a) Cumulative data functions (CDF) of pixel-level TMI V7 ocean rain rates from grid boxes defined as hits (black) and false positives (grey). (b) CDF of pixel-level TMI V7 ocean probabilities of rain from grid boxes defined as hits, misses, false rain, and all algorithms equal to zero.

and Houze, 2000) and beam overshoot likely limits MPE-IV sensitivity over ocean as well. The TMI pixels labeled as "false" with a $100 \%$ probability of rain have a mean rain rate of only $0.44 \mathrm{~mm} \mathrm{hr}^{-1}$ and a median of $0.30 \mathrm{~mm} \mathrm{hr}^{-1}$. Considering these limitations, it is difficult to determine the best criteria without additional validation data. There is no clear probability of rain cutoff and no way to distinguish whether TMI V7 ocean pixels with rain rates $<0.5 \mathrm{~mm} \mathrm{hr}-1$ are actually false or are just being missed by the PR.

\subsubsection{Bias relative to $85 \mathrm{GHz}$ ice scattering}

Wang et al. (2009) described several known anomalies in the TMI V6 land algorithm, including overestimation in strong, deep convective systems and an underestimation of warm rainfall. A simple way to evaluate these biases using the MPE- 
IV reference is to compare the rain rates relative to the minimum $85 \mathrm{GHz}$ PCT. The threshold for deep convection is generally defined as a system with a minimum $85 \mathrm{GHz}$ PCT $<225 \mathrm{~K}$ (Mohr and Zipser 1996). It is difficult to isolate areas of warm rain using only PCT, but generally warm rain will have an $85 \mathrm{GHz}$ PCT around or above $275 \mathrm{~K}$. By using a grid scale, this study also neglects characteristics of the precipitating systems as a whole that can be better understood using precipitation features (e.g., Mohr and Zipser 1996; Cecil and Zipser 1999; Cecil et al. 2002). Nevertheless, a brief comparison is undertaken to evaluate the TMI - PR relationship as it relates to the $85 \mathrm{GHz}$ ice scattering to rain rate relationship.

Figure 3.12 displays the mean grid box rain rate as a function of the minimum 85 GHz PCT and Figure 3.13 shows the mean bias. In panel (a), the ocean algorithms are in almost perfect agreement with MPE-IV for $85 \mathrm{GHz}$ PCTs above $250 \mathrm{~K}$. Below $250 \mathrm{~K}$, the algorithms have greater disagreements. In the $220-250 \mathrm{~K}$ realm, all of the algorithms overestimate MPE-IV. At lower $85 \mathrm{GHz}$ PCTs, TMI-IV underestimates rain rates and the other three algorithms overestimate. However, the biases are all within about $2 \mathrm{~mm} \mathrm{hr}^{-1}$, which is a reasonably acceptable range when considering the high rain rates. Of greater interest is the land algorithm in panel (b). The TMI overestimation is a strong function of minimum $85 \mathrm{GHz}$ PCT. Overestimation is significant at PCTs of $220 \mathrm{~K}$ and below, which confirms the result in Wang et al. (2009), at least for this regime over the southeast US. The issue persists in TMI V7, as little to no improvement is observed at low $85 \mathrm{GHz}$ PCTs compared to TMI V6. To improve on the deep convection issue, Gopalan et al. (2010) suggests that additional rain predictors are needed in order to improve the ice 
scattering signal and that the TMI - PR collocation method must consider viewing geometries more carefully in convective rainfall.

The relative contribution of this TMI land overestimation to the rain rate distributions in the rest of the study is addressed in Figure 3.14. Grid boxes with an 85 GHz PCT less than $220 \mathrm{~K}$ account for only about 4\% (5\%) of the land (ocean) dataset. As a result, less than $20 \%$ of the contribution to the mean rainfall comes from deep convection. The overestimation by the TMI land algorithms adds about a $10 \%$ contribution to the mean rain rate relative to the PR and MPE-IV datasets. The greatest contribution to the mean is about linearly distributed between the $220-280 \mathrm{~K}$ range, which represents average rain rates around $1-10 \mathrm{~mm} \mathrm{hr}^{-1}$ from Figure 3.11. The bias distribution in Figure 3.13 shows signs of the negative warm bias over land, but this bias does not appear to have a strong influence on the cumulative rainfall contributions.

\subsection{Discussion and conclusions}

The two most recent versions of the PR 2A25 and TMI 2A12 rainfall algorithms are compared relative to the reference MPE-IV radar/gauge precipitation estimate dataset in landfalling tropical cyclones. The statistical comparison reproduces the most common deficiencies in TRMM Version 6 that have been noted by several other studies. Matching the datasets spatially and temporally does add random errors, but the large sample of 252 storms is enough to remove biases related to any individual storm. Even in heavy precipitating systems like TCs, most of the rain rates are light and the heavy rain is concentrated over a relatively small area. Only around $2-3 \%$ of the sample area has a rain rate greater than $10 \mathrm{~mm} \mathrm{hr}^{-1}$, but that small area contributes around $40 \%$ of the total 

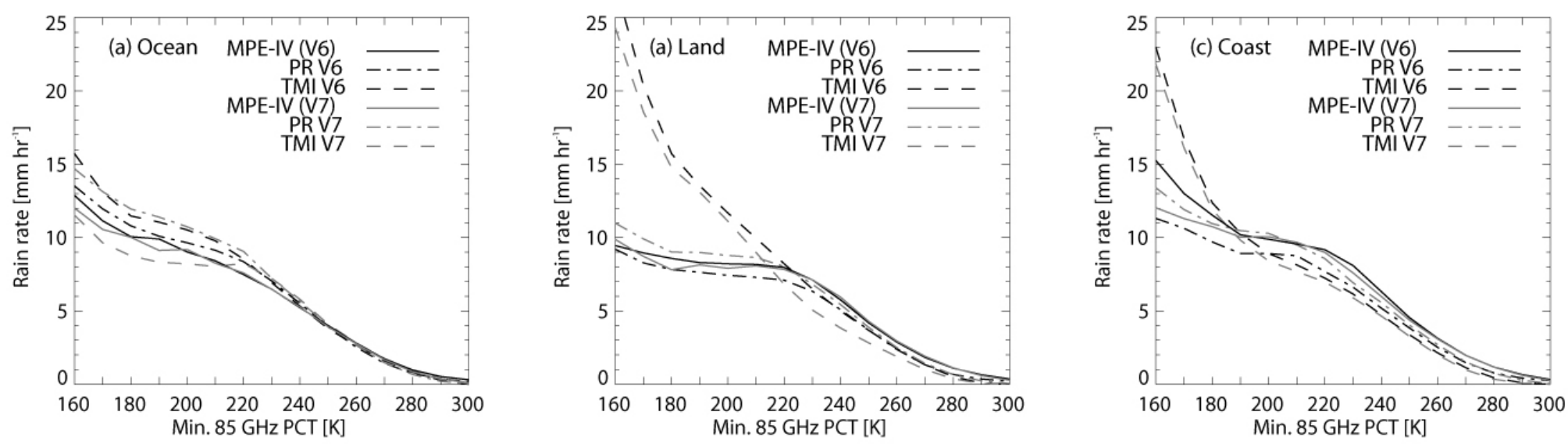

Figure 3.12: Distribution of mean rain rates as a function of the minimum $85 \mathrm{GHz}$ PCT (K) in each grid box.
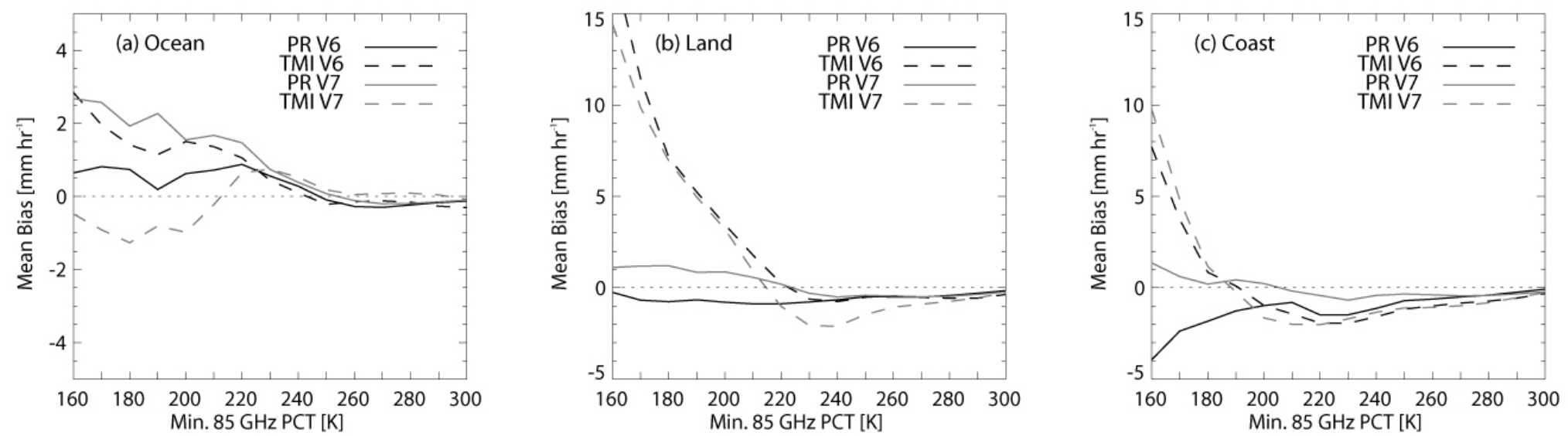

Figure 3.13: Distribution of mean bias relative to MPE-IV as a function of the minimum $85 \mathrm{GHz}$ PCT (K) in each grid box. 

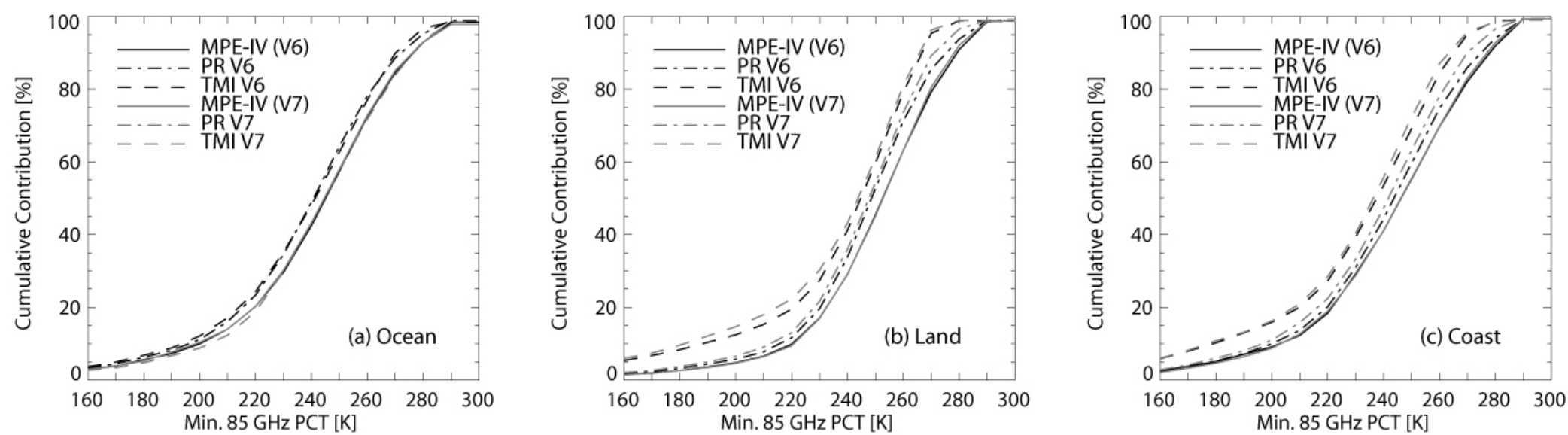

Figure 3.14: Cumulative contribution (\%) to mean rain rate for TRMM algorithms compared with the minimum $85 \mathrm{GHz}$ PCT. 
rainfall. Identifying the location and intensity of these areas of moderate to heavy rainfall is especially important when forecasting flood threads in landfalling TCs.

The PR V7 algorithm performs the best in all three surface classifications. Over ocean, PR V7 is slightly better than V6, as both algorithms have slightly more $>15 \mathrm{~mm}$ $\mathrm{hr}^{-1}$ grid boxes than MPE-IV and less $5-15 \mathrm{~mm} \mathrm{hr}^{-1}$ boxes. Over land, PR version 7 is again the best performing algorithm. The remaining PR V7 negative land bias can be mostly explained by underestimation in the $5-20 \mathrm{~mm} \mathrm{hr}^{-1}$ rain rate range. It appears that changes to the PR attenuation correction in V7 have removed most of the negative bias at rain rates above $20 \mathrm{~mm} \mathrm{hr}^{-1}$. The PR coastal algorithms both have negative biases of comparable magnitudes to land, with marginal improvement in V7. The PR also underestimates MPE-IV at light rain rates, an effect of the instrument's inherent minimum reflectivity criteria.

The TMI V7 ocean algorithm is significantly improved relative to V6 in the heavier rain rate range, $>15 \mathrm{~mm} \mathrm{hr}^{-1}$. The TMI V7 land algorithm is the only instance where V7 has a significantly greater negative bias than V6. Both TMI V6 and V7 land algorithms have much too great of a contribution from light rain rates $\left(<5 \mathrm{~mm} \mathrm{hr}^{-1}\right)$ and too small of a contribution from moderate rain rates $>5 \mathrm{~mm} \mathrm{hr}^{-1}$. Most of the additional negative bias in $\mathrm{V} 7$ comes from $5-10 \mathrm{~mm} \mathrm{hr}^{-1}$ rain rates. The main lingering issue with TMI V7 over ocean is the high number of false positives, which must be filtered using the probability of rain parameter. The false positives consist mostly of pixel-level rain rates of $0.1-0.5 \mathrm{~mm} \mathrm{hr}^{-1}$ and rain probabilities of $50-100 \%$. Setting a high probability of rain (90-95\%) removes about two-thirds of the false positives while losing less than 5\% of the hits. 
With respect to ice scattering, the main area where the TMI V7 land algorithm has significant overestimation relative to PR and MPE-IV is when the minimum $85 \mathrm{GHz}$ PCT is below $220 \mathrm{~K}$. These areas of deep convection are too rare to show up in most of the statistical analysis. One caveat is that the TRMM - MPE-IV grid matching scheme may result in larger errors for these isolated areas of deep convection than for dataset as a whole. The mean PR and MPE-IV rain rates of around $10 \mathrm{~mm} \mathrm{hr}^{-1}$ (in Figure 3.11) for land grid boxes with a minimum $85 \mathrm{GHz}$ PCT $<200 \mathrm{~K}$ seem too light. Gopalan et al. (2010) noticed the same issue over several regions including the Southern US. They suggested several possible causes including attenuation and viewing angle discrepancies. Another hypothesis is that upper level winds may displace the ice scattering downshear of the heaviest rain. Further investigation of the ice-scattering to rain rate relationship is required to better understand this discrepancy.

Several lingering questions are raised from this study. First, it is unclear whether the results can be translated to tropical cyclones away from the coastline and in other basins. Island areas may pose different challenges for the coastal algorithm and no high mountainous terrain was within this study's viewing range. The amount of error introduced by comparing instantaneous TRMM overpasses to 1-hr MPE-IV averages can only be estimated, which makes it hard to make definitive recommendations when the satellite algorithms are close to the reference data. In some instances, the PR appears to be more accurate than MPE-IV based on visual approximation. Future studies should emphasize detecting raining vs. non-raining areas and consider rain gauges as an additional reference dataset. 


\section{REFERENCES}

Berg, W., C. Kummerow, and C. A. Morales, 2002: Differences between East and West Pacific Rainfall Systems, J. Climate, 15, 3659-3672.

Berg, W, T. L'Ecuyer, C.Kummerow, 2006: Rainfall Climate Regimes: The Relationship of Regional TRMM Rainfall Biases to the Environment. J. Appl. Meteor. Climatol.,45, 434-454.

Bogner, P. B., G. M. Barnes, and J. L. Franklin, 2000: Conditional instability and shear for six hurricanes over the Atlantic. Ocean.Wea. Forecasting, 15, 192-207.

Breidenbach, J. P. and J. S. Bradberry, 2001: Multisensor precipitation estimates produced by National Weather Service River Forecast Centers for hydrologic applications, Proceedings of the 2001 Georgia Water Resources Conf., March 2627, 2001, Institute of Ecology, University of Georgia, Athens.

Burpee, R. W., and M. L. Black, 1989: Temporal and spatial variations of rainfall near the centers of two tropical cyclones. Mon. Wea. Rev.,117, 2204-2218.

Cecil, D.J., E.J. Zipser, and S.W.Nesbitt, 2002: Reflectivity, ice scattering, and lightning characteristics of hurricane eyewalls and rainbands. Part I: Quantitative description. Mon Wea. Rev., 130, 769-784.

Cecil, D. J., 2007: Satellite-derived rain rates in vertically sheared tropical cyclones, Geophys. Res. Lett., 34, L02811.

Cecil, D. J. and M. Wingo, 2009: Comparison of TRMM rain-rate retrievals in tropicalcyclones. J. Meteor. Soc. Japan, 87, 369-380.

Chen, S. S., J. A. Knaff, F. D. Marks, 2006: Effects of Vertical Wind Shear and Storm Motion on Tropical Cyclone Rainfall Asymmetries Deduced from TRMM. Mon. Wea. Rev., 134, 3190-3208.

Ebert, E. E., Janowiak, J. E., and C. Kidd, 2007: Comparison of near-real-time precipitation estimates from satellite observations and numerican models, Bull. Amer. Meteor. Soc., 88, 47-64. 
Emanuel, K., 1991: Current understanding of tropical cyclone structure and intensity changes - a review. Annual Rev. Fluid Mech.,87, 257-278.

Emanuel, K., 2005: Divine Wind: The History and Science of Hurricanes. Oxford University Press, 285pp.

Fulton, R. A., J. P. Breidenbach, D.-J.Seo, D. A. Miller, and T. O'Bannon, 1998: The WSR-88D Rainfall Algorithm. Wea. Forecasting, 13, 377-395.

Gopalan, K., N.-Y. Wang, R. Ferraro, C. Liu, 2010: Status of the TRMM 2A12 Land Precipitation Algorithm. J. Atmos. Oceanic Technol., 27, 1343-1354.

Habib, E., A. Henschke, and R. F. Adler, 2009a: Evaluation of TMPA satellite-based research and real-time rainfall estimates during six tropical-related heavy rainfall events over Louisiana, USA, J. Atmos. Research, 94, 373-388.

Habib, E., B. F. Larson, and J. Graschel, 2009b: Validation of NEXRAD multisensory precipitation estimates using an experimental dense rain gauge network in south Louisiana, J. Hydrology, 373, 463-478.

Hence, D. A., and R. A. Houze, Jr., 2012: Vertical structure of tropical cyclone rainbands as seen by the TRMM Precipitation Radar. J. Atmos. Sci., in press.

Houze, R. A., Jr., 2010: Clouds in tropical cyclones. Mon. Wea. Rev., 138, 293-344.

Huffman, G., R. Adler, D. Bolvin, G. Gu, E. Nelkin, K. Bowman, E. Stocker, and D. Wolff, 2007: The TRMM Multi-satellite precipitation analysis: quasi-global multi-year, combined-senson precipitation estimates at fine scale. $J$. Hydrometeorology, 8, 38-55.

Iguchi, T., T. Kozu, R. Meneghini, J. Awaka, and K. Okamoto, 2000: Rain-Profiling Algorithm for the TRMM Precipitation Radar, J. Appl. Meteor., 39, 2038-2052.

Jiang, H., E. M. Ramirez, and D. J. Cecil, 2012: Convective and Rainfall Properties of Tropical Cyclone Inner Cores and Rainbands from 11 Years of TRMM Data, Mon. Wea. Rev., in press.

Jiang, H., C. Liu, and E. J. Zipser, 2011: A TRMM-Based Tropical Cyclone Cloud and Precipitation Feature Database, J. Appl. Meteor. Climatol.,50, 1255-1274. 
Kummerow, C., W. S. Olson, and L. Giglio, 1996: A simplified scheme for obtaining precipitation and vertical hydometeor profiles from passive microwave sensors. IEEE Trans. Geosci. Remote Sens., 34, 1213-1232.

Kummerow, C., W. Barnes, T. Kozu, J. Shiue, and J. Simpson, 1998: The Tropical Rainfall Measuring Mission (TRMM) sensor package. J. Atmos. Oceanic Technol., 15, 809-817.

Kummerow, C., and co-authors, 2000: The status of the Tropical Rainfall Measuring Mission (TRMM) after two years in orbit. J. Appl. Meteor., 39, 1965-1982.

Kummerow, C., and co-authors, 2001: The evolution of the Goddard profiling algorithm (GPROF) for rainfall estimation from passive microwave sensors. J. Appl. Meteor., 40, 1801-1820.

Liu, C., E. J. Zipser, D. J. Cecil, S. W. Nesbitt, and S. Sherwood, 2008: A Cloud and Precipitation Feature Database from Nine Years of TRMM Observations, J. Appl. Meteor. Climatol.,47, 2712-2728.

Liu, C., and E. J. Zipser, 2009: "Warm rain" in the tropics: Seasonal and regional distribution based on 9 years of TRMM data. J. Climate, 22, 767-779.

Lonfat, M., F. D. Marks, and S. S. Chen, 2004: Precipitation Distribution in Tropical Cyclones Using the Tropical Rainfall Measuring Mission (TRMM) Microwave Imager: A Global Perspective, Mon. Wea. Rev., 132, 1645-1660.

Marks, F. D., Jr., 1985: Evolution of the structure of precipitation in Hurricane Allen (1980). Mon. Wea. Rev., 113, 909-930.

McCollum, J. R. and R. R. Ferraro, 2004: Microwave Rainfall Estimation over Coasts, $J$. Atmos. Oceanic Technol., 22, 497-512.

Mohr, K. I., and E. J. Zipser, 1996: Mesoscale Convective Systems Defined by Their 85$\mathrm{GHz}$ Ice Scattering Signature: Size and Intensity Comparison over Tropical Oceans and Continents, Mon. Wea. Rev., 124, 2417-2437.

Molinari, J., P. Moore, Vin.Idone, 1999: Convective Structure of Hurricanes as Revealed by Lightning Locations. Mon. Wea. Rev., 127, 520-534.

Nelson, B. R., D.-J. Seo, and D. Kim, 2010: Multisensor Precipitation Reanalysis, $J$. Hydrometeorology, 11, 666-682. 
Nesbitt, S. W., E. J. Zipser, and D. J. Cecil, 2000: A census of precipitation features in the tropics using TRMM: Radar, ice scattering, and lightning observations, $J$. Climate, 13, 4087-4106.

Nesbitt, S. W., E. J.Zipser, and C. D. Kummerow, 2004: An Examination of Version-5 Rainfall Estimates from the TRMM Microwave Imager, Precipitation Radar, and Rain Gauges on Global, Regional, and Storm Scales,J. Appl. Meteor., 43, 10161036.

Petty, G. W., 2004: A first course in atmospheric radiation. Sundog publishing, 444pp.

Rinehart, R.E., 2004: Radar for Meteorologists, Fourth Edition. Rinehart Publications, $482 \mathrm{pp}$.

Rodgers, E.B., and R. F. Adler, 1981: Tropical cyclone rainfall characteristics as determined from a satellite passive microwave radiometer. Mon. Wea. Rev., 109, 506-521.

Rodgers, E. B., S. Chang, and H. F. Pierce, 1994: A satellite observational and numerical study of precipitation characteristics in western North Atlantic tropical cyclones. J. Appl. Meteor., 33, 129-139.

Rodgers, R., S. S. Chen, J. Tenerelli, and H. Willoughby, 2003: A numerical study of the impact of vertical shear on the distribution of rainfall in Hurricane Bonnie (1998). Mon. Wea. Rev., 131, 1577-1599.

Schumacher, C. and R. A. Houze, 2000: Comparison of Radar Data from the TRMM Satellite and Kwajalein Oceanic Validation Site, J. Appl. Meteor., 39, 2151-2164.

Seinfeld, J. H. and Pandis, S. N., 1998: Atmospheric Chemistry and Physics: From Air Pollution to Climate Change, Wiley, 1349pp.

Seto, S. and T. Iguchi, 2007: Rainfall-Induced Changes in Actual Surface Backscattering Cross Sections and Effects on Rain-Rate Estimates by Spacebourne Precipitation Radar, J. Atmos. Oceanic Technol., 24, 1693-1709.

Shapiro, L. J., 1983: The asymmetric boundary layer flow under a translating hurricane. J. Atmos. Sci., 40, 1984-1998. 
Shige, S., H. Sasaki, K. Okamoto, and T. Iguchi, 2006: Validation of rainfall estimates from the TRMM precipitation radar and microwave imager using a radiativetransfer model: 1 . Comparison of the version-5 and -6 products, Geophys. Res. Lett., 33, L13803.

Simpson, J., C. Kummerow, W.-K. Tao, and R. F. Adler, 1996: On the Tropical Rainfall Measuring Mission (TRMM). Meteorl. Atmos. Phys., 60, 19-36.

Simpson, J., R. F. Adler, and G. R. North, 1988: A proposed Tropical Rainfall Measuring Mission (TRMM) satellite. Bull. Amer. Meteor. Soc., 69, 278-295.

Smith, J. A., D. J. Seo, M. L. Baeck, and M. D. Hudlow, 1996: An Intercomparison study of NEXRAD precipitation estimates, Water Resources Research, 32, No. 7, 2035 2045.

Spencer, R. W., H. M. Goodman, and R. E. Hood, 1989: Precipitation Retrieval over Land and Ocean with the SSM/I: Identification and Characteristics of the Scattering Signal, J. Atmos. Oceanic Technol., 6, 254-273.

Wallace, J. M. and P. V. Hobbs, 2006: Atmospheric Science an Introductory Survey, Second Edition. Academic Press, 124 pp.

Wang, N.-Y., C. Liu, R. Ferraro, D. Wolff, E. Zipser, and C. Kummerow, 2009: TRMM 2A12 land precipitation product-Status and future plans. J. Meteor. Soc. Japan, 87A, 237-253.

Wilheit, T., C. Kummerow, and R. Ferraro, 2003: Rainfall algorithms for the AMSR-E. IEEE Trans. Geosci. Remote Sens.,41, 204-214.

Wilheit, T. T., A. T. C. Chang, M. S. V.Rao, E. B. Rodgers, and J. S. Theon, 1977: A satellite technique for quantitatively mapping rainfall rates over the oceans. $J$. Appl. Meteor., 16, 551-560.

Willoughby, H.E., F. D. Marks, and R. J. Feinberg, 1984: Stationary and propagating convective bands in asymmetric hurricanes. J. Atmos. Sci., 41, 3189-3211.

Willmott, C. J., 1982: Some Comments on the Evaluation of Model Performance. Bull. Amer. Meteor. Soc., 63, 1309-1313. 
Wilmott, C. J., S. G. Ackleson, R. E. Davis, J. J. Feddema, K. M. Klink, D. R. Legates, J. O’Donnell, and C. M. Rowe, 1983: Statistics for the Evaluation and Comparison of Models, J. Geophys. Res., 90(C5), 8995-9005.

Wolff, D. B., D. A. Marks, E. Amitai, D. S. Silberstein, B. L. Fisher, A. Tokay, J. Wang, and J. L. Pippitt, 2005: Ground validation for the Tropical Rainfall Measuring Mission (TRMM). J. Atmos. Oceanic Technol., 22, 365-380.

Wolff, D. B. and B. L. Fisher, 2008: Comparisons of Instantaneous TRMM Ground Validation and Satellite Rain-Rate Estimates at Different Spatial Scales, J. Appl. Meteor. Climatol.,47, 2215-2237. 


\section{COPYRIGHT PERMISSION}

November 2, 2012

I, Grant W. Petty, owner(s) of the copyright to the work: A first course in atmospheric radiation by G.W. Petty hereby authorize Joseph P. Zagrodnik to use the following material as part of his dissertation to be submitted to Florida International University

Page

65: Figure 3.3

346: Figure 12.1

I (w) further extend this authorization to University Microfilms International, Ann Arbor, Michigan, for the purpose of reproducing and distributing copies of the work.

This authorization is conditioned on appropriate citation of the source in the figure legend.

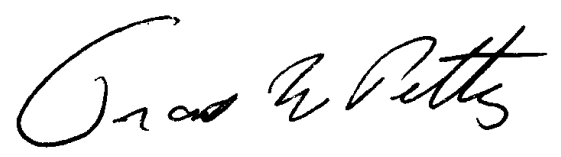

Signature 